MACIEL MANOEL DE QUEIROZ

MÉTODOS HEURÍSTICOS APLICADOS AO PROBLEMA DE PROGRAMAÇÃO DA FROTA DE NAVIOS PLVS

São Paulo

2011 
MACIEL MANOEL DE QUEIROZ

MÉTODOS HEURÍSTICOS APLICADOS AO PROBLEMA DE PROGRAMAÇÃO DA FROTA DE NAVIOS PLVS

Dissertação apresentada ao Programa de Pós-Graduação em Engenharia Naval para a obtenção do Título de Mestre em Engenharia

São Paulo

2011 


\section{MÉTODOS HEURÍSTICOS APLICADOS AO PROBLEMA DE PROGRAMAÇÃO DA FROTA DE NAVIOS PLVs}

Dissertação apresentada ao Programa de Pós-Graduação em Engenharia Naval para a obtenção do Título de Mestre em Engenharia

Área de Concentração:

Engenharia Naval e Oceânica

Orientador:

Prof. Dr. André Bergsten Mendes

São Paulo

2011 
Este exemplar foi revisado e alterado em relação à versão original, sob responsabilidade única do autor e com a anuência de seu orientador.

São Paulo, 29 de novembro de 2011.

Assinatura do autor

Assinatura do orientador

FICHA CATALOGRÁFICA

Queiroz, Maciel Manoel de

Métodos heurísticos aplicados ao problema de programação da frota de navios PLVs / M.M. de Queiroz. - ed.rev. -- São Paulo, 2011.

$101 \mathrm{p}$.

Dissertação (Mestrado) - Escola Politécnica da Universidade de São Paulo. Departamento de Engenharia Naval e Oceânica.

1. Embarcações de apoio 2. Matemática (Modelagem) 3. Programação heurística I. Universidade de São Paulo. Escola Politécnica. Departamento de Engenharia Naval e Oceânica II. t. 


\section{AGRADECIMENTOS}

Ao orientador, conselheiro e amigo Prof. Dr. André Bergsten Mendes, pela oportunidade, incentivo e por ter acreditado e me apoiado na concretização deste trabalho.

Aos funcionários da secretaria do PNV, a todos os professores que contribuíram, principalmente ao Prof. Dr. Marco Antonio Brinati e Miguel Cezar Santoro pelas valiosas contribuições no exame de qualificação.

À Agencia Nacional do Petróleo - ANP, por meio do programa PRH-19 e Financiadora de Estudos e Projetos - FINEP através do convênio \# 01.09.0458.00.

A todos que de forma direta ou indireta contribuíram para o desenvolvimento deste trabalho. 


\section{RESUMO}

O presente trabalho abordou um problema de programação de embarcações que realizam o lançamento de dutos ou linhas de produção e a interligação destes à infraestrutura submarina, em uma operação de exploração de petróleo offshore. As tarefas são realizadas por embarcações PLVs (pipe layer vessels), e possuem como atributos: duração, em dias; lista de embarcações compatíveis; instante de liberação; penalidade relacionada ao atraso na execução da tarefa. Este problema é uma variação da classe de problemas de programação de máquinas paralelas não-relacionadas, em que o objetivo é minimizar o atraso ponderado total. Este trabalho empregou como métodos de solução a meta-heurística GRASP com path relinking. Esta técnica foi implementada utilizando os recursos de processamento multi-threading, de forma a explorar múltiplas trajetórias simultaneamente. Testes foram feitos para comprovar o desempenho das heurísticas propostas, comparando-as com limitantes fornecidos pelo método geração de colunas.

Palavras-chave: Programação de frota; modelagem matemática; métodos heurísticos; GRASP; apoio marítimo offshore. 


\begin{abstract}
This work addressed a fleet scheduling problem present in the offshore oil industry. Among the special purpose services one will find the pipe layer activities and its connection to the subsea infrastructure, accomplished by the Pipe Layer Vessels (PLV). The jobs are characterized by a release date, which reflects the expected arrival date of the necessary material at the port. There are compatibility constraints between job and vessel, so that some vessels may not be able to perform a certain job; the duration of the jobs can be differentiated by vessel and if a job is finished after its due date, a penalty is incurred. This is a variation of the unrelated parallel machine problem with total weighted tardiness objective function. This research employed a metaheuristic GRASP with Path Relinking, which have proved to be competitive and an effective solution strategy. This method was implemented in a multi-threading scheme allowing multiple paths to be explored simultaneously. Computational experiments were conducted, comparing solutions with bounds provided by linear column generation.
\end{abstract}

Keywords: Fleet scheduling; mathematical modeling; heuristics; GRASP; offshore support vessels. 


\section{SUMÁRIO}

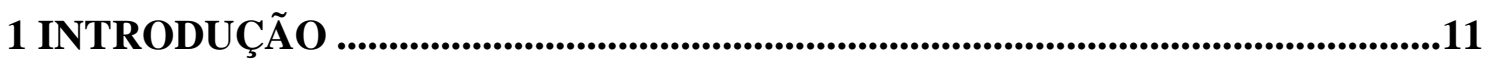

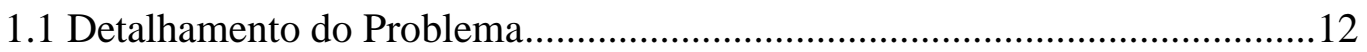

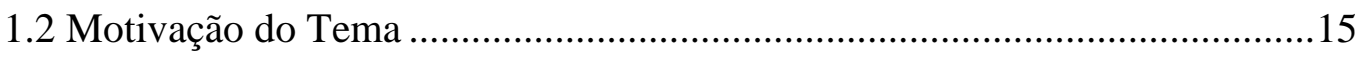

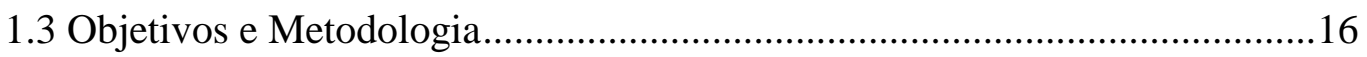

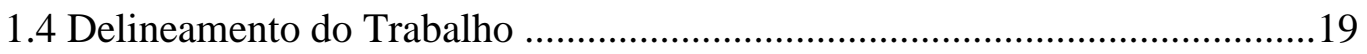

2 REVISÃO BIBLIOGRÁFICA ..............................................................................20

2.1 Introdução ao Problema de Programação de Máquinas Paralelas .................20

2.2 Métodos de Solução Empregados em Problemas de Programação de

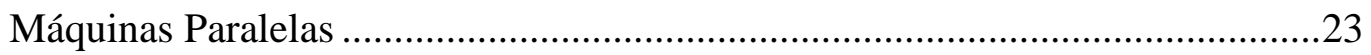

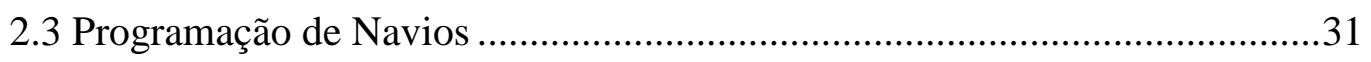

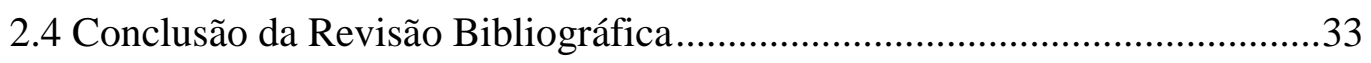

3 MODELAGEM MATEMÁTICA E MÉTODOS DE SOLUÇÃ̃ .........................36

3.1 Descrição Resumida do Problema …………….............................................36

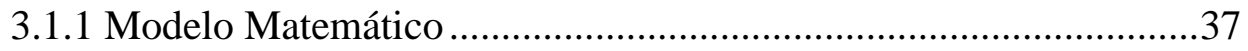

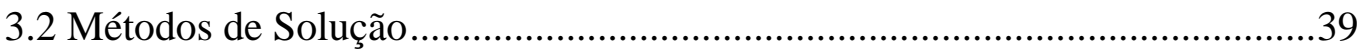

3.2.1 Heurísticas e Meta-heurísticas .........................................................39

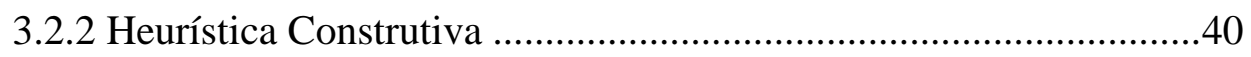

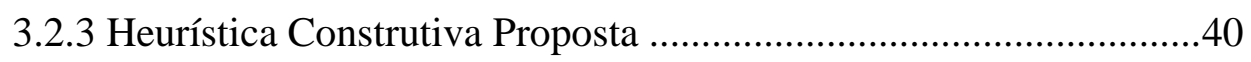

3.2.4 Heurísticas de Busca .................................................................41

3.2.5 Busca Local Inserção ...................................................................42

3.2.6 Busca Local Troca ...................................................................44

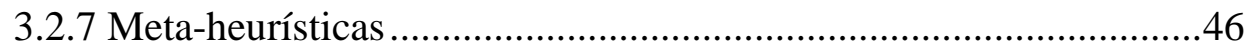

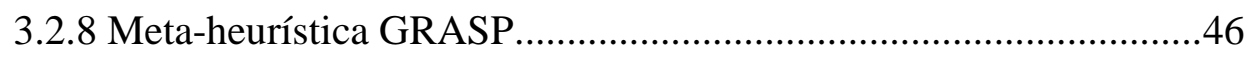

3.2.8.1 Descrição do GRASP Proposto.......................................48

3.2.9 Heurística Path Relinking .........................................................50

4 TESTES COMPUTACIONAIS E RESULTADOS ..................................................56

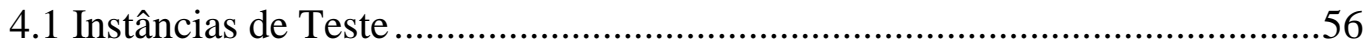

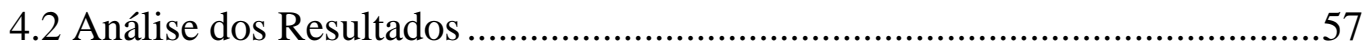

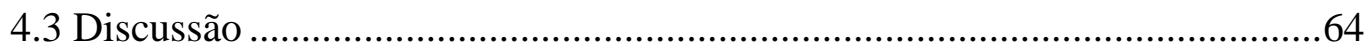

5 CONCLUSÕES E RECOMENDAÇÕES ................................................68

REFERÊNCIAS BIBLIOGRÁFICAS ........................................................................70

APÊNDICE A - Gap médio 30x4, 40x5 e 50x6 …................................................... 76

APÊNDICE B - Tempo médio de processamento 30x4, 40x5 e 50x6 ...........................77 


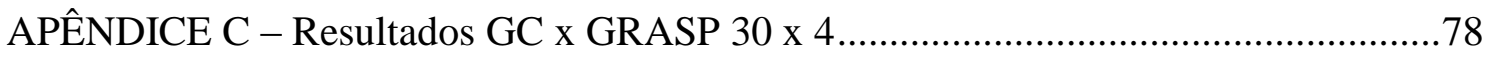

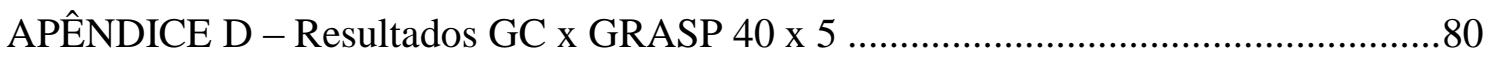

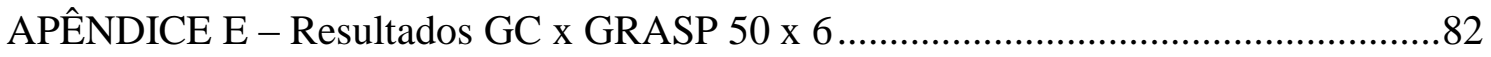

APÊNDICE F - Resultados GC x HEU_C + BL 30 x 4 ............................................ 84

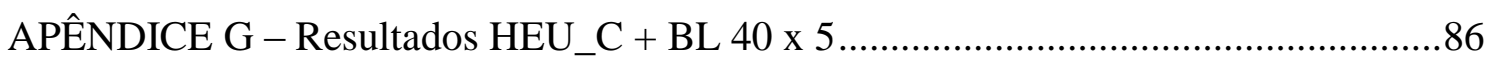

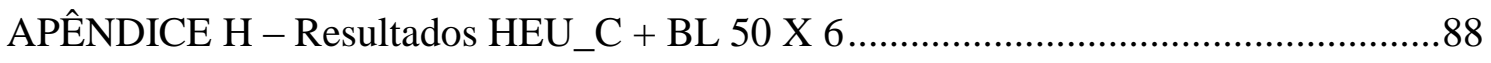

APÊNDICE I - Resultados HEU_C 30 x 4.............................................................. 90

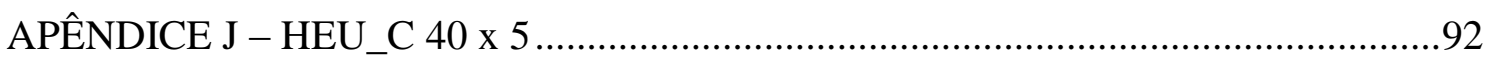

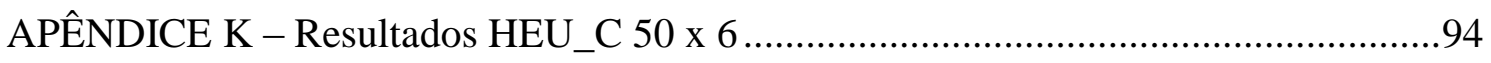

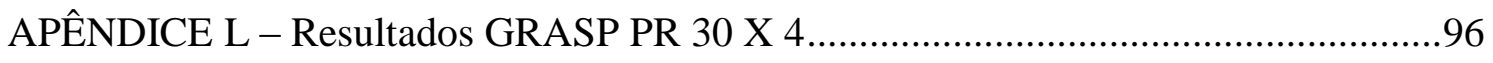

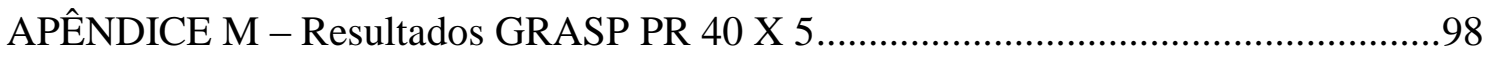

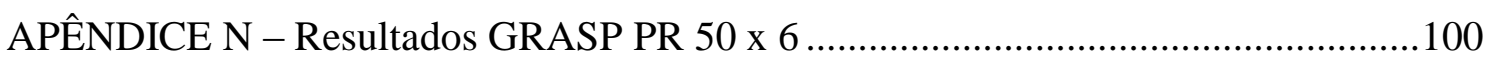




\section{LISTA DE ILUSTRAÇÕES}

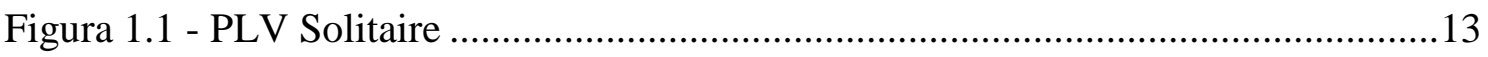

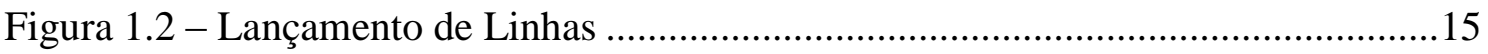

Figura 1.3 - Metodologia para resolução de problemas em Pesquisa Operacional (adaptado de Bertrand; Fransoo, 2002)

Figura 2.1 - Generalização do problema de programação de máquinas paralelas (adaptado de Morton; Pentico, 1993) ................................................................21

Figura 3.1 - Pseudocódigo da Heurística Construtiva HEU_C .....................................40

Figura 3.2 - Movimento que remove e testa a inserção da tarefa ...................................43

Figura 3.3 - Inserção da tarefa na melhor posição da melhor sequência ........................43

Figura 3.4 - Pseudocódigo Busca Local Inserção...........................................................44

Figura 3.5 - Remove e testa a inserção de duas tarefas entre um par de sequências ......45

Figura 3.6 - Inserção das tarefas na melhor posição do par de sequências......................45

Figura 3.7 - Pseudocódigo da busca local Troca ........................................................46

Figura 3.8 - Pseudocódigo GRASP Básico .............................................................47

Figura 3.9 - Exemplo de Lista Restrita de Candidatos ...............................................48

Figura 3.10 - Pseudocódigo GRASP Proposto ........................................................... 48

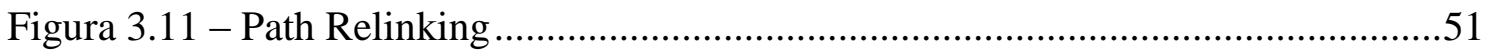

Figura 3.12 - Estrutura básica do GRASP com Path Relinking …................................53

Figura 4.1 - Distribuição dos gaps para HEU_C 30 x 4 ..............................................58

Figura 4.2 - Distribuição dos gaps para HEU_C 40 x 5 ..............................................59

Figura 4.3 - Distribuição dos gaps para HEU_C 50 x 6 .............................................59

Figura 4.4 - Distribuição dos gaps para HEU_C + BL 30 x 4 .......................................60

Figura 4.5 - Distribuição dos gaps para HEU_C + BL 40 x 5 ......................................60

Figura 4.6 - Distribuição dos gaps para HEU_C + BL 50 x 6 .......................................61

Figura 4.7 - Distribuição dos gaps para GRASP 30 x 4 ...........................................61

Figura 4.8 - Distribuição dos gaps para GRASP 40 x 5 ...........................................62

Figura 4.9- Distribuição dos gaps para GRASP 50 x 6 ..............................................62

Figura 4.10 - Distribuição dos gaps para GRASP PR 30 x 4 ......................................63

Figura 4.11 - Distribuição dos gaps para GRASP PR 40 x 5 .......................................63

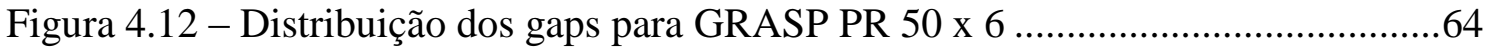

Figura 4.13 - Tempo para alcançar uma dada solução (GRASP PR x GRASP) ............65 


\section{LISTA DE TABELAS}

Tabela 2.1 - Principais referências de programação de tarefas da pesquisa ....................35

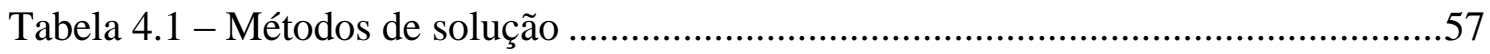

Tabela 4.2 - Método x gap médio, mínimo e máximo..................................................57

Tabela 4.3 - Método x tempo médio de processamento .................................................58

Tabela 4.4 - Abordagem multi- threading x processamento individual.........................64

Tabela 4.5 - Processamento multi-threading x Branch and Bound ...............................66 


\section{INTRODUÇÃO}

Este capítulo visa introduzir o problema de estudo desta pesquisa definido como MÉTODOS HEURÍSTICOS APLICADOS AO PROBLEMA DE PROGRAMAÇÃO DA FROTA DE NAVIOS PLVs (pipe layer vessel), bem como definir os objetivos, a metodologia aplicada e o direcionamento seguido.

O tema programação ou escalonamento de atividades, conhecida na literatura técnica como scheduling, está presente em diversos sistemas produtivos, e sempre envolve um número de atividades que estão atreladas à utilização de recursos por um determinado período de tempo (Morton; Pentico, 1993). A programação de atividades é um processo de decisão que possui um importante papel na maioria dos sistemas de manufatura, produção e ambientes de processamento de informação, como também nas áreas de transportes, distribuição e em outros diversos tipos de indústrias (Pinedo, 2002).

Geralmente a programação de tarefas envolve um conjunto de tarefas que necessitam ser executadas, por um conjunto de recursos previamente especificado, tendo em vista as datas de início e término das tarefas (Baker, 1974). A complexidade do processo de programação de tarefas e recursos é grande tendo em vista a natureza combinatória destes problemas, associada às diversas restrições que devem ser observadas, além da escala dos problemas reais.

Esta pesquisa tem seu foco no problema de programação de uma frota de navios especializados no processo de lançamento de risers e interligação submarina, presente no desenvolvimento de campos de petróleo offshore. Conforme será discutido, o problema em questão é uma variação do problema de programação de máquinas paralelas não-relacionadas, para o qual Liaw et al. (2003) demonstraram que a complexidade é NP-difícil.

Para resolver o problema, foi proposto um método heurístico, combinando-se o GRASP com path relinking; os limitantes inferiores foram estimados pela aplicação do método de geração de colunas, conforme proposto por van den Akker et al. (2000) e implementado por Mendes et al. (2010). 


\subsection{Detalhamento do Problema}

A exploração e produção de petróleo em alto mar, conhecida como exploração offshore, necessita de uma grande quantidade de atividades de apoio marítimo, requerendo a utilização dos mais variados tipos de embarcações especializadas. Uma etapa importante do desenvolvimento de um campo petrolífero é a de lançamento de risers ou linhas de produção.

As linhas ou dutos submarinos podem ser flexíveis ou rígidas, e são de fundamental importância para o transporte da produção de petróleo das plataformas marítimas (offshore) para refinarias ou tanques de armazenagem situados em terra (onshore). Cabe destacar também as linhas que coletam a produção dos poços e abastecem diretamente uma unidade estacionária de produção, ou o fazem por meio de um manifold submarino, o qual está instalado no leito marinho e recebe várias linhas dos poços em sua adjacência - desta caixa de conexão sai uma linha única para a plataforma.

As embarcações responsáveis pelo lançamento dos dutos e sua interligação são as PLVs - pipe layer vessels, que são recursos críticos que uma empresa petrolífera tem que administrar. As embarcações realizam estas operações basicamente de duas maneiras distintas: i) os dutos são soldados enquanto a embarcação está operando no próprio local de lançamento; ii) os dutos, previamente soldados em terra, são armazenados em grandes estruturas tipo carretéis, e são dispostos no leito marinho a uma determinada velocidade. A segunda opção é mais vantajosa do ponto de vista de desempenho (velocidade), e por não comprometer as operações de soldagem em condições climáticas adversas. A figura 1.1 mostra um certo navio, capaz de lançar entre 4 a $7 \mathrm{~km}$ de dutos por dia. Entre outros recursos, esta embarcação dispõe de um eficiente sistema de posicionamento dinâmico, permitindo a realização de serviços em áreas congestionadas.

Para a instalação de uma linha, seja ela flexível ou rígida, existem diversas atividades necessárias para que isto se concretize. No início da operação a embarcação necessita carregar as linhas e os equipamentos que serão utilizados na operação de lançamento. O próximo passo consiste em deslocar-se até ao local de instalação, dando 
início ao lançamento. Dependendo da profundidade e da extensão do lançamento, pode ser necessário retornar novamente ao porto para carregar material adicional. Existem casos de maior complexidade, como ilustrado na figura 1.2, em que é necessária a requisição de embarcações de apoio como, por exemplo, um rebocador (AHTS) ou uma embarcação dotada de sonda de observação (ROV).

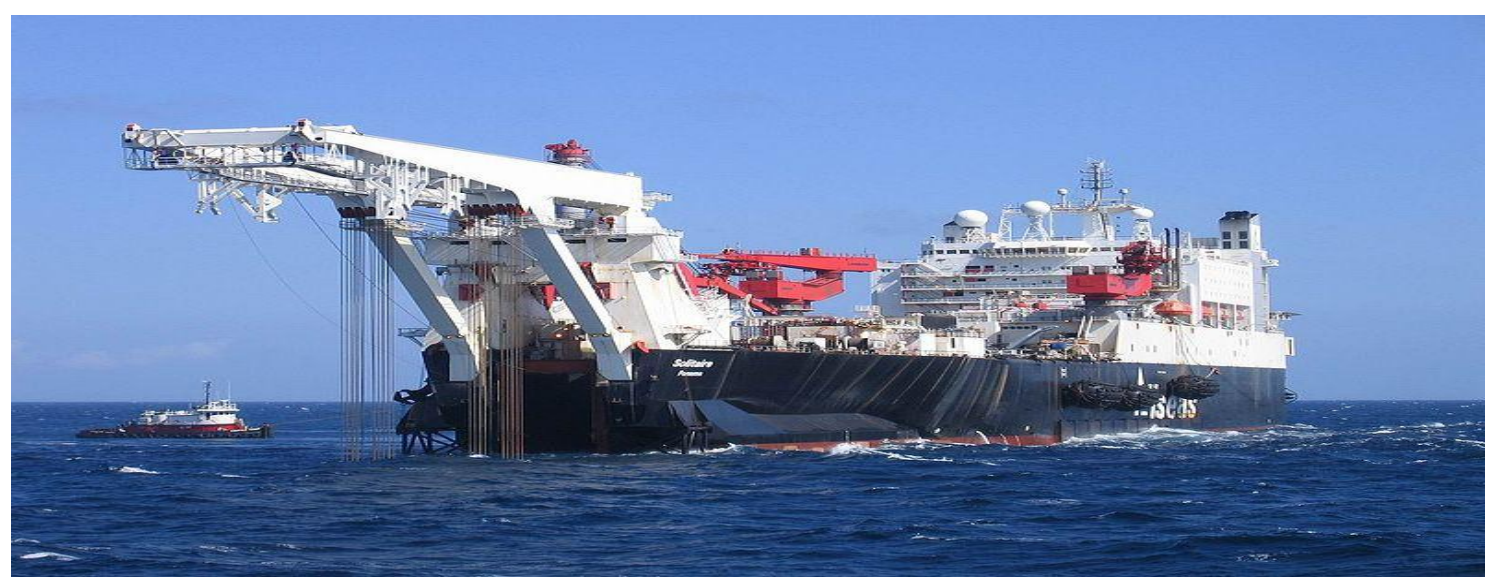

Figura 1.1 PLV Solitaire (Fonte: http://www.allseas.com/uk/20/equipment/solitaire.html)

Quando uma empresa petrolífera realiza o planejamento operacional da sua frota de PLVs, considera como uma macro-tarefa todas as atividades acima mencionadas. Em geral, o setor responsável pelo planejamento e execução desta operação avalia quais embarcações da frota estão aptas para realizar cada macro-tarefa (doravante, denominado simplesmente de tarefa), e elaboram uma matriz de compatibilidade entre cada par embarcação-tarefa, estimando o tempo necessário para que a tarefa seja realizada.

As diversas tarefas de interligação e lançamentos de linhas que compõem a demanda que a empresa deverá atender são decorrentes dos projetos de desenvolvimento de novos campos. Cada tarefa a ser realizada tem um potencial de produção associado, o qual reflete o volume diário de produção esperado ao longo da vida útil do poço que será interligado. Postergar uma tarefa, para realizar outra, implica em adiar o retorno sobre o investimento realizado.

Para programar a frota, algumas restrições operacionais devem ser observadas, como a compatibilidade embarcação-tarefa e a data mais cedo em que a tarefa pode ser iniciada. Esta data reflete o instante de disponibilização de material no porto para realizar aquela tarefa, além da obtenção de licença ambiental e da aprovação em 
instâncias internas à empresa. A extensão do horizonte de planejamento também deve ser considerada, já que a empresa trabalha com uma visão de médio prazo, que no caso da operação de lançamento de risers e interligação constitui um período de 3 a 6 meses. É importante ressaltar, contudo, que este horizonte, em princípio, não é conhecido com precisão. Os técnicos responsáveis pelo setor estimam um prazo capaz de atender a demanda e fixam este horizonte como meta.

É importante destacar que, quando uma tarefa é planejada, os tempos de navegação já são incluídos no tempo total de execução. Uma vez que uma operação inicia e termina em uma base operacional da empresa (um porto), o tempo de deslocamento entre duas tarefas consecutivas é zero.

Objetiva-se achar a sequência de execução das tarefas, de forma a minimizar as perdas financeiras pelo atraso no início da execução das mesmas em relação aos respectivos instantes de liberação.

Quanto à caracterização da demanda, adota-se como hipótese que a mesma é conhecida, bem como a duração da execução das tarefas. No caso da oferta, os recursos empregados são as embarcações, que se diferenciam uma das outras geralmente pela capacidade de armazenagem e tipo de lançamento das linhas. Admite-se conhecida a composição da frota, os instantes e os locais em que as embarcações estão disponíveis.

Este problema tem semelhanças com o problema de programação de máquinas paralelas não-relacionadas, com instante de liberação das tarefas, minimizando a soma dos atrasos ponderados das tarefas. Dado que algumas embarcações não estão habilitadas a realizar determinados serviços e, pelo fato das embarcações poderem realizar as tarefas em tempos diferentes, fica caracterizado o aspecto das máquinas serem não-relacionadas. Conforme dito anteriormente, o horizonte de planejamento não é conhecido com total precisão. Contudo, o valor imposto pelo corpo técnico da empresa, passa a ser uma restrição rígida, já que a empresa estabelece metas a serem atingidas dentro do período de planejamento de suas operações. 


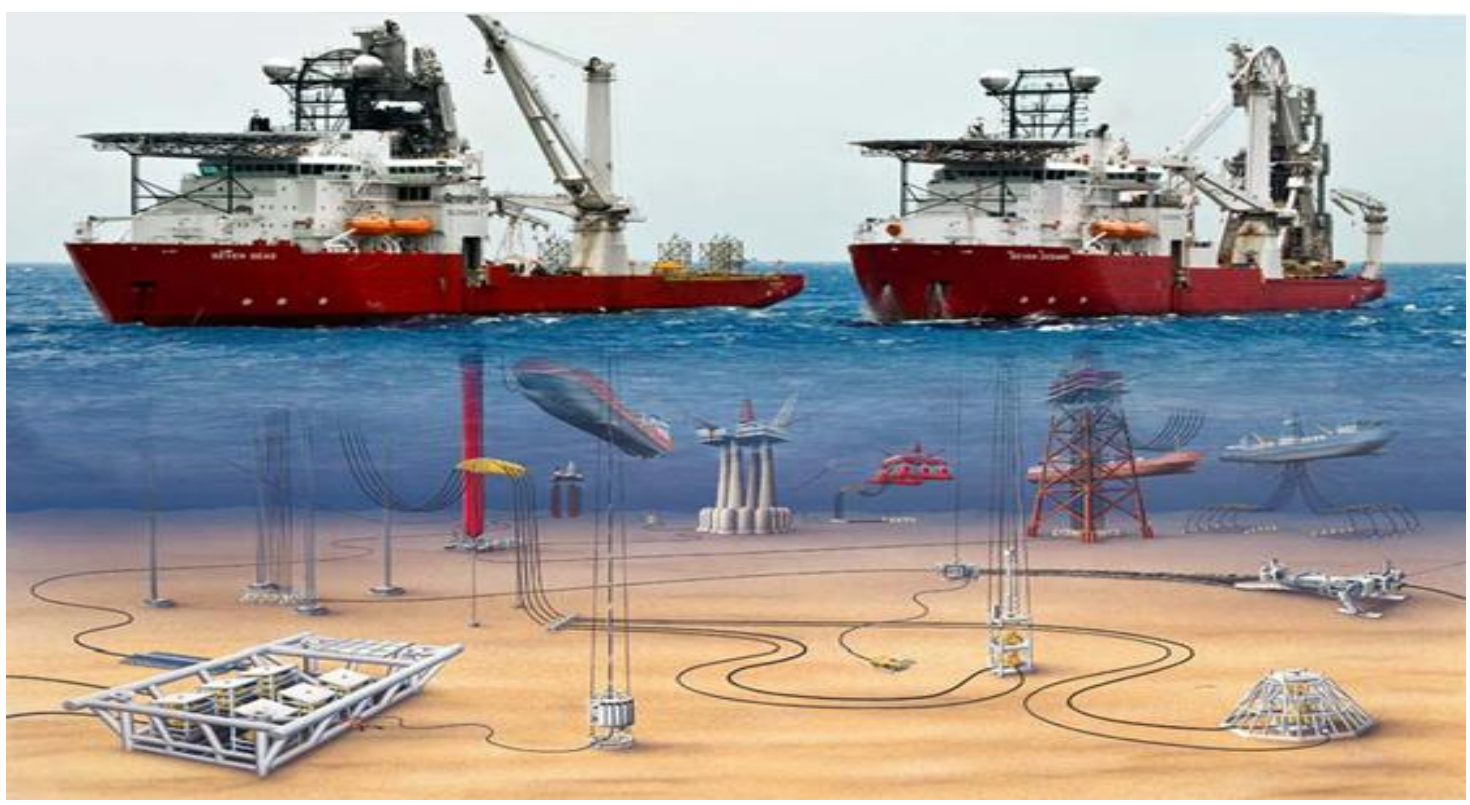

Figura 1.2 - Lançamento de linhas (fonte: http://www.abeam.org.br)

\subsection{Motivação do tema}

O Brasil tem se destacado no cenário mundial de exploração e produção de petróleo e gás natural em águas profundas e ultra-profundas. Nestes ambientes, são de fundamental importância o suporte e a operação coordenada dos serviços de apoio, tanto na fase prospectiva, quanto na fase da implantação de novos sistemas produtivos e, posteriormente, na manutenção e no escoamento da produção.

A busca pela eficiência operacional, ou seja, a utilização dos recursos produtivos da melhor forma possível é imprescindível, principalmente em se tratando do uso de recursos escassos, como são as sondas de perfuração e as embarcações de apoio (incluindo os PLVs). A nova política brasileira para o petróleo, ao permitir contratos com empresas estrangeiras para a exploração de novos campos na plataforma continental, incentiva não só a expansão da área de atuação da Petrobras, como a instalação de outras companhias no Brasil, aumentando sensivelmente a demanda de embarcações e equipamentos de apoio marítimo. Neste contexto, foram lançados pela Petrobras três planos de renovação (e expansão) da frota de apoio marítimo, oferecendo a armadores nacionais (isto é, embarcações com bandeira brasileira, de propriedade de empresas brasileiras) um prazo de mobilização suficiente para permitir a construção das embarcações no Brasil, e subsequentes contratos de afretamento por oito anos. 
A recente descoberta de petróleo na camada do pré-sal aponta para um cenário promissor e que deverá consolidar a liderança mundial do Brasil na produção de petróleo em águas profundas e ultra-profundas. Portanto, o desenvolvimento de abordagens baseadas em técnicas de otimização matemática, exatas e heurísticas, que possam conferir elevada produtividade e eficiência à gestão de recursos escassos, como é o caso da frota de PLVs, é de grande interesse prático. Além disso, considerando o fato de que o processo de interligação é a última etapa antes de um campo petrolífero entrar em produção, o setor que planeja e executa tais operações sofre uma pressão interna grande para que as metas de produção sejam alcançadas e, eventualmente, superadas.

\subsection{Objetivos e Metodologia}

A presente pesquisa possui o objetivo de resolver o problema de programação da frota de navios PLVs em operações de lançamento de linhas (dutos flexíveis e/ou rígidas) em cenários reais, contribuindo para que as empresas envolvidas no mercado de petróleo tenham uma melhor eficiência no planejamento operacional dos serviços de apoio offshore.

A solução de problemas complexos na área de planejamento de sistemas de operações é objeto central de estudo da área do conhecimento denominada de Pesquisa Operacional. É uma ciência que aplica o método científico para resolução dos mais diversos problemas operacionais, tendo como fundamento teórico os conhecimentos advindos das áreas da matemática aplicada, ciência da computação e estatística.

Por se tratar de um trabalho da área de Pesquisa Operacional, a metodologia aplicada será desenvolvida de acordo com o modelo de Bertrand; Fransoo (2002), onde os seguintes passos são desenvolvidos, de acordo com a figura 1.3. A partir de um problema real, passa-se por um processo de abstração, em que as variáveis importantes do problema e o que se espera obter como resposta é explicitado, gerando um modelo conceitual. A próxima fase é a modelagem matemática, cujo produto é um modelo matemático, no qual as inter-relações entre as variáveis são explicitadas. Em seguida, o modelo é resolvido por meio de métodos específicos, gerando uma solução, a qual poderá ser implementada. 


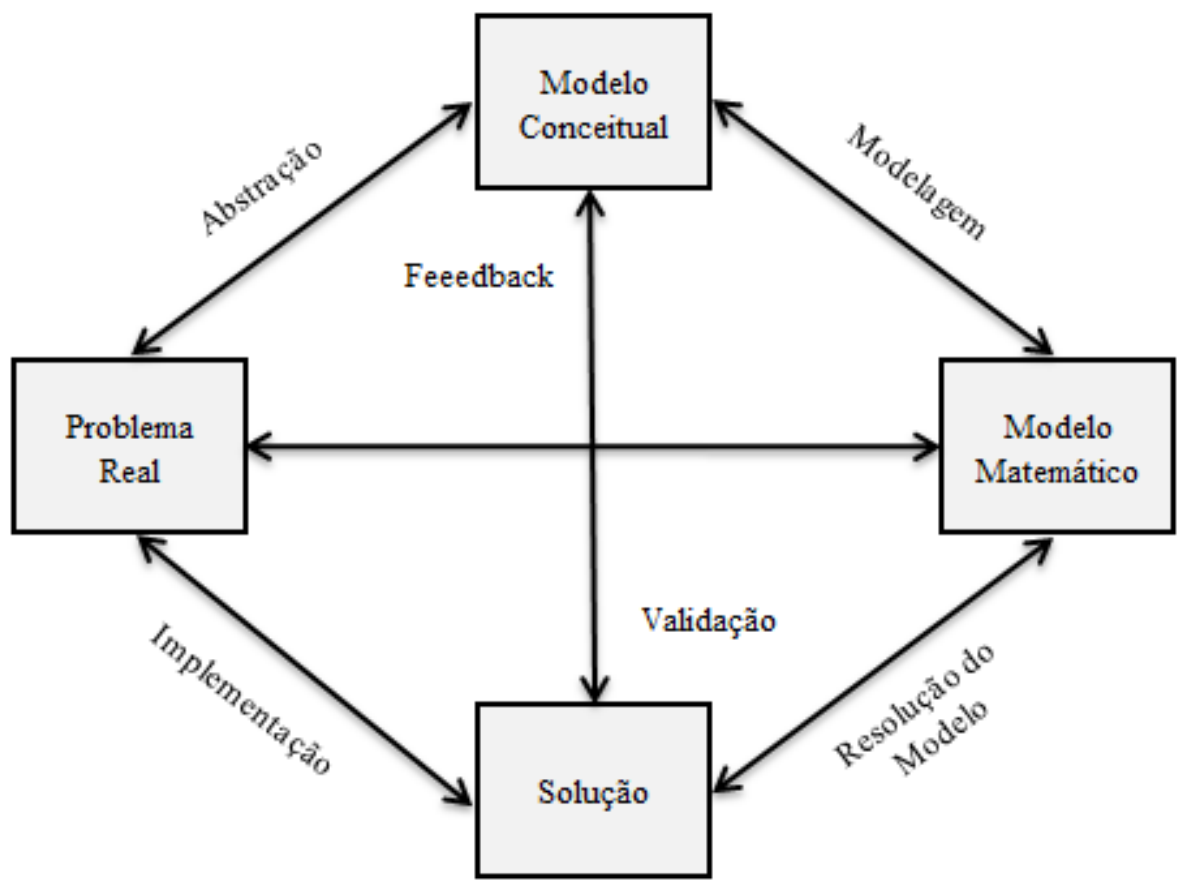

Figura 1.3 - Metodologia para Resolução de Problemas em Pesquisa Operacional (adaptado de Bertrand; Fransoo, 2002)

A presente pesquisa, além de envolver as etapas de abstração e modelagem matemática, irá se concentrar no desenvolvimento de métodos de resolução do modelo matemático, por meio de técnicas heurísticas.

O problema abordado nesta pesquisa pode ser enquadrado na classe de problemas de programação de tarefas em máquinas paralelas não-relacionadas, com instantes de liberação distintos por tarefa. Nestes problemas, as tarefas têm que ser alocadas às máquinas, de forma a otimizar uma função de mérito. São comuns os objetivos de minimizar o horizonte de planejamento (makespan), o atraso médio (mean tardiness), o atraso ponderado (weighted tardiness), o desvio médio (mean deviation), o desvio ponderado (weighted deviation) e o número de tarefas atrasadas (number of late jobs), entre outros (Cheng; Sin, 1990).

O presente trabalho tem por objetivo a determinação da melhor sequência de execução das tarefas para um problema real, designando cada tarefa para ser realizada por apenas uma embarcação, e respeitando as restrições operacionais. A função de mérito a ser utilizada é a minimização das perdas financeiras pelo adiamento da 
execução das tarefas, isto é, o atraso total ponderado (total weighted tardiness). Cabe ressaltar que a data de entrega (due date) é dada pela soma do instante de liberação mais a duração da tarefa. Desta maneira, qualquer atraso em relação ao instante mais cedo possível de término é penalizado.

Dada a natureza combinatória deste problema, será utilizada a abordagem heurística como método de solução. Estes são algoritmos especificamente construídos para resolver determinadas classes de problemas complexos, e são capazes de gerar soluções rápidas e de boa qualidade, explorando a estrutura do problema. Compõe esta categoria as heurísticas construtivas, as heurísticas de busca (local ou refinamento) e as meta-heurísticas, Demeulemeester; Herroelen (2002).

As heurísticas construtivas possuem uma característica básica que é a geração de uma solução, que pode ser de boa qualidade, com pouco esforço computacional. As heurísticas de busca clássica partem de uma solução inicial conhecida e procuram explorar a vizinhança desta solução por meio de movimentos, com o objetivo de melhorá-la, chegando a ótimos locais. Já as meta-heurísticas são métodos de busca capazes de escapar de ótimos locais, evitando uma parada prematura do algoritmo no primeiro ótimo local encontrado.

Nesta pesquisa, aplica-se a meta-heurística GRASP (Greedy Randomized Adaptive Search Procedure) de Feo; Resende (1989, 1995), e também algumas variações desta heurística como o path relinking, que produz novas soluções explorando a reconexão por caminhos entre uma solução inicial e uma dada solução de elite (Glover, 1996; Glover et al., 2000). Esta técnica é implementada utilizando os recursos de processamento multi-threading, de forma a explorar múltiplas trajetórias simultaneamente.

Para a fase de testes é utilizada uma base de dados construída a partir de um conjunto de regras disponível na OR-Library ${ }^{1}$ elaborada por Beasley (1990) e adaptada do trabalho de Crauwels et al. (1998). Estas regras foram propostas para um problema de máquina única (single machine), em que todas as tarefas são conhecidas e liberadas

\footnotetext{
${ }^{1}$ Coleção de conjunto de dados para teste para uma grande variedade de problemas de pesquisa operacional.
} 
no instante inicial. As modificações introduzidas permitiram gerar uma base com 375 instâncias teste do problema de pesquisa, com 30, 40 e 50 tarefas. A este conjunto de problemas aplicou-se a versão linear do método de geração de colunas (Mendes et al., 2010), para que se possa avaliar a qualidade da solução heurística em relação aos limitantes (lower bounds) fornecidos pelo método de geração de colunas.

\subsection{Delineamento do trabalho}

O restante deste trabalho está estruturado da seguinte forma:

Capítulo 2 - Revisão Bibliográfica: descreve a importância da programação de máquinas paralelas e sua aplicação em diversos setores, como por exemplo, em programação de navios; relata os principais métodos empregados para a solução de problemas de programação e, por fim, caracteriza as principais abordagens das heurísticas e meta-heurísticas aplicadas no trabalho.

Capítulo 3 - Modelagem Matemática e Métodos de Solução: apresenta de forma sucinta um modelo matemático que caracteriza o problema desta pesquisa, e também os métodos de solução empregados.

Capítulo 4 - Testes Computacionais e Resultados: aplicação de testes para os métodos empregados no trabalho, por meio de um conjunto de instâncias e avaliação dos resultados obtidos.

Capítulo 5 - Conclusões e Recomendações: possui as conclusões do trabalho e sugere futuras abordagens para aplicação dos métodos.

Referências Bibliográficas: descreve os trabalhos pesquisados. 


\section{REVISÃO BIBLIOGRÁFICA}

Este capítulo apresenta a revisão da literatura dos trabalhos pesquisados para a presente dissertação. Como o tema abordado nesta pesquisa faz parte de uma classe de problemas de programação em máquinas paralelas, faz-se necessário apresentar alguns dos principais trabalhos desta área nos últimos anos, assim como a literatura relativa às operações de transporte marítimo. Após a caracterização da programação em máquinas paralelas, são discutidas algumas heurísticas e meta-heurísticas aplicadas nestes tipos de problemas como método de solução.

\subsection{Introdução ao Problema de Programação de Máquinas Paralelas}

Os problemas de programação de máquinas paralelas são de grande interesse tanto do ponto de vista prático, quanto acadêmico, geralmente por envolver diversas possibilidades de combinar a utilização dos recursos, ou seja, por se tratar de problemas combinatórios em que podem haver diversas soluções com custos diferentes. Do ponto de vista teórico é uma generalização dos problemas de máquinas única e, do ponto de vista prático, é um ambiente muito encontrado na indústria (Liaw et al.; 2003).

Segundo Pinedo (2002), em todos os problemas de programação, o número de máquinas e tarefas é assumido como finito. Suponha que $m$ máquinas $M_{i}(i=1, \ldots, m)$ tenham que processar $n$ tarefas $J_{j}(j=1, \ldots, n)$. A programação é responsável pela alocação das tarefas nas máquinas para serem processadas em um determinado intervalo de tempo (Brucker, 2007). A figura 2.1 apresenta esta ideia para o problema de programação de frotas de embarcações, em que há $n$ tarefas para serem executadas por $m$ navios. Assim, cada tarefa $j$ deve ser designada para uma única embarcação $i$.

Os recursos e tarefas em uma organização podem ser caracterizados de várias formas. Por exemplo, os recursos podem ser as máquinas em uma fábrica, pistas em um aeroporto, as unidades de processamento em um ambiente de computação etc. As tarefas podem ser as operações em um processo de produção, as decolagens e aterrissagens em um aeroporto, execuções de programa de computador etc. (Pinedo, 2002). 


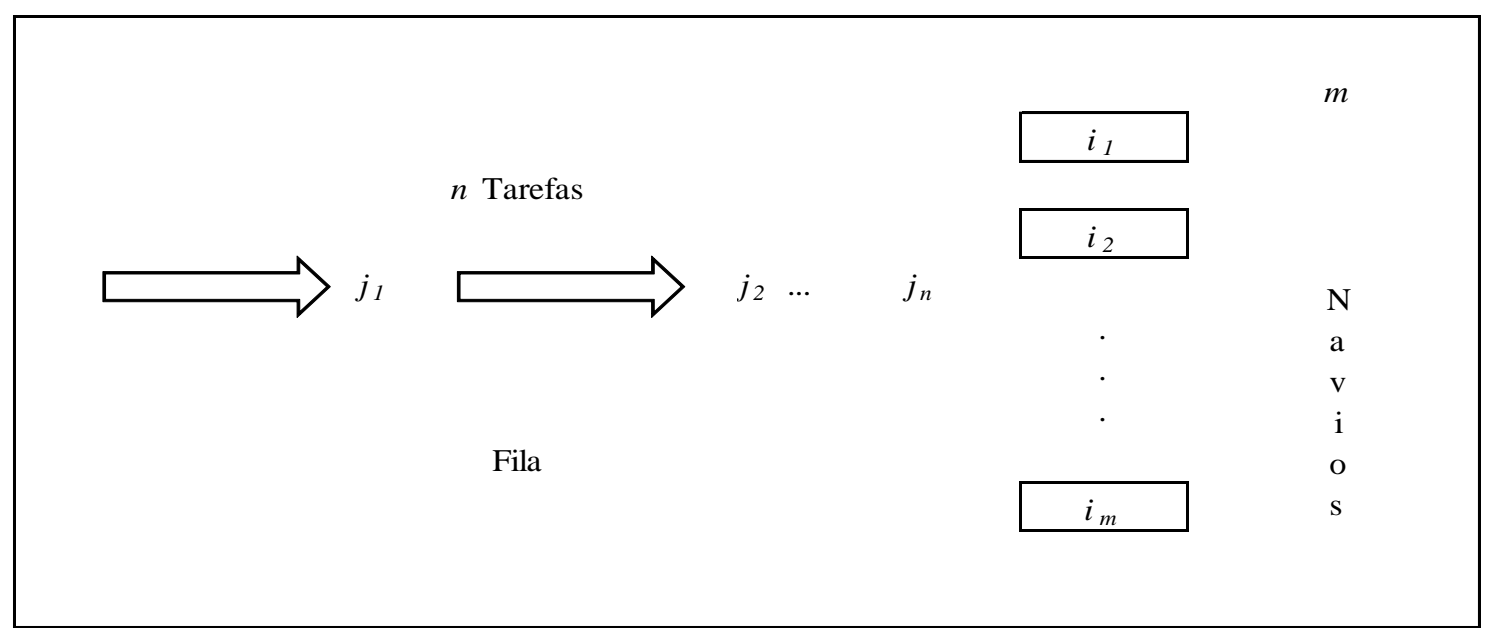

Figura 2.1 - Generalização do Problema de Programação de Máquinas Paralelas (adaptado de Morton; Pentico, 1993).

O número de tarefas é denotado por $n$, enquanto as máquinas por $m$. O subscrito $j$ caracteriza uma dada tarefa, e o índice $i$ uma determinada máquina. Com isto, o par $(i, j)$ refere-se ao processamento ou operação da tarefa $j$ na máquina $i$. A data de entrega (due date) é referenciada por $d_{j}$; o tempo de processamento da tarefa $j$ na máquina $i$ é dado por $p_{i j}$. O instante de liberação ou (release date) é escrito por $r_{j}$. Existe uma função de custo dada por $f_{j}(t)$, que mensura o custo de concluir certa tarefa $j$ no instante $t$. Assim, a data de entrega $d_{j}$ e a penalidade ou peso (weight) $w_{j}$, podem ser usadas para definir $f_{j}(t)$.

As classes de problemas de programação são especificados por uma classificação introduzida por Graham et al. (1979), a qual é expressa por três campos $\alpha|\beta| \gamma$, em que $\alpha$ especifica o ambiente de máquinas (machine environment), $\beta$ especifica as características da tarefa (job characteristics), e $\gamma$ denota o critério de otimalidade (optimality criterion).

O parâmetro $\alpha$ descreve o ambiente de máquina e pode assumir os valores, $P, Q$ e $R$, em que:

- $\quad P$ : denota máquinas idênticas em paralelo;

- $\quad Q$ : denota máquinas proporcionais em paralelo;

- $\quad R$ : denota máquinas não-relacionadas em paralelo;

Se $\alpha=P$, então existem máquinas idênticas em paralelo (identical parallel machines). Assim, para o tempo de processamento $p_{i j}$ da tarefa $J_{j}$ na máquina $M_{i}$ tem- 
se $p_{i j}=p_{j}$ para todas as máquinas $M_{i}$, ou seja, a tarefa pode ser processada em qualquer máquina utilizando o mesmo tempo de processamento. Um trabalho de destaque neste ambiente é o de Chen; Powell (1999), que utilizaram o método Branch and Bound com a abordagem de geração de colunas para resolução da relaxação linear como técnica de solução. Os autores formularam o problema por meio da abordagem de programação inteira que foi posteriormente reformulado utilizando a técnica de decomposição Dantzig-Wolfe. O objetivo foi minimizar a penalidade ponderada por adiantamento e atraso, e constataram que a abordagem proposta é eficiente para solucionar problemas difíceis.

Se $\alpha=Q$, então existem máquinas proporcionais em paralelo (uniform parallel machines), em que $p_{i j}=\frac{p_{j}}{v_{i}}$, onde $v_{i}$ é a velocidade da máquina $M_{i}$. Isto significa que uma tarefa $j$ qualquer poderá necessitar menos tempo de processamento em uma máquina mais rápida do que em uma mais lenta. Se todas as máquinas têm a mesma velocidade, então é igual ao ambiente de máquinas idênticas (Pinedo, 2002).

Finalmente, se $\alpha=R$, então existem máquinas não-relacionadas em paralelo (unrelated parallel machines). Trata-se de um caso mais geral do ambiente de máquinas proporcionais, dado por $m$ máquinas não-relacionadas em paralelo. A máquina $i$ pode processar a tarefa $j$ na velocidade $v_{i j}$. O tempo $p_{i j}$ que a tarefa $j$ gasta na máquina $i$ é igual a $\frac{p_{j}}{v_{i j}}$, assumindo que a tarefa recebe todos os processamentos na mesma máquina. Se a velocidade da máquina é independente das tarefas, por exemplo, $\left(v_{i j}=v_{i}\right.$ para todos $i$ e $j$ ), o ambiente é idêntico ao de máquinas proporcionais.

Azizoglu; Kirca (1999), abordaram um problema de máquinas paralelas nãorelacionadas, visava minimizar o tempo total de fluxo. Também apresentaram as propriedades de um programa ótimo, e propuseram um algoritmo branch and bound. Os autores puderam constatar que, com até 25 tarefas, o algoritmo consegue obter soluções em um tempo razoável. Jansen; Porkolab (2001) também abordaram o problema de programação de máquinas não-relacionadas em paralelo, mas com o objetivo de 
minimizar o makespan ${ }^{2}$. Mostraram casos em que as tarefas não podem ser interrompidas, e outros que podem haver interrupção. Como método de solução, foram propostos algoritmos de aproximação.

O parâmetro $\beta$ descreve as características da tarefa. As opções usualmente empregadas são: $\beta \in\left\{{ }^{\circ}\right.$, pmtn, prec $, r, p, d, S-$ batch $\}$, em que:

- $\quad$ : denota que a tarefa não pode ser interrompida;

- pmtn : o processamento pode ser interrompido e retornado mais tarde;

- $\quad$ prec : descreve relações de precedência entre as tarefas;

- $\quad r$ : indica que a data de liberação deve ser especificada para cada tarefa;

- $\quad p$ : especifica as restrições do tempo de processamento ou número de operações;

- $d$ : um prazo (deadline) é especificado para cada tarefa;

- $S-$ batch : caso as tarefas precisem ser processadas em lotes.

Finalmente, o parâmetro $\gamma$ diz respeito ao objetivo do problema. Por exemplo, se $\gamma=\sum w_{j} T_{j}$ tem-se uma função objetivo de atraso total ponderado. Dessa forma, um modelo pode ser identificado pela notação apresentada padrão de Graham et al. (1979). Para o problema desta dissertação, que tem por objetivo determinar um programa em que o atraso total ponderado seja minimizado, tem-se:

$R_{m} \| \sum_{j=1}^{n} w_{j} T_{j}$

\subsection{Métodos de Solução Empregados em Problemas de Programação de Máquinas Paralelas}

A literatura sobre os métodos de soluções empregados na classe de problemas de programação de máquinas paralelas é muito vasta. Vários métodos foram propostos desde a publicação do artigo de McNaughton (1959) sobre programação de máquinas idênticas em paralelo e também máquina única, o qual destaca o tratamento diferente que as tarefas podem receber de acordo com a sua urgência relativa. $\mathrm{O}$ autor apresenta

${ }^{2} \mathrm{O}$ makespan $=C_{\max }$ é o tempo de conclusão da última tarefa que sai do sistema, e definido como $\max \left(c_{1}, \ldots, c_{n}\right)$, em que $c_{j}$ é o tempo de conclusão da tarefa $j$. O mínimo makespan normalmente implica em uma alta utilização das máquinas. 
dois critérios para análise de desempenho: 1- abordagem baseada no tempo de finalizar a tarefa (completion time based); 2- abordagem baseada na data de entrega (due date based).

Cheng; Sin (1990) apresentam uma revisão das principais pesquisas e contribuições da época sobre programação de máquinas paralelas. São destacadas as principais características desses problemas, assim como os principais objetivos. Os métodos de solução em otimização combinatória podem ser classificados segundo o tipo de algoritmo empregado, e são divididos em quatro classes: enumeração completa, algoritmos com tempo polinomial, algoritmos com tempo não-polinomial, e algoritmos de aproximação. Uma contribuição importante também é dada por Blazewicz et al. (1991) que apresentam formulações matemáticas para problemas de programação de máquinas, tanto para ambientes de máquina única quanto para máquinas paralelas.

Na década de 60 começou-se a pensar sobre as alterações na quantidade de máquinas e o efeito gerado no processamento das tarefas, em que Graham (1969) analisou o problema de máquinas idênticas em paralelo por meio de técnicas de aproximação, para o caso em que certas anormalidades poderiam ocorrer, como por exemplo, alterações na quantidade das máquinas e a consequência provocada no tempo para completar determinado conjunto de tarefas.

Ao longo dos anos, muitas técnicas vêm sendo desenvolvidas e implementadas como, por exemplo, Bruno et al. (1974), que apresentam alguns métodos para reduzir o tempo médio de conclusão de tarefas independentes, onde aplicaram o critério (Weighted-Finishing-Time - tempo de finalização ponderado), ou tempo médio no sistema, em que o problema relacionado a máquinas idênticas é polinomial completo. 
Outras regras que também foram utilizadas são o $\mathrm{LPT}^{3}$ (longest processing time) e $\mathrm{SPT}^{4}$ (shortest processing time), sendo que, para programas de problemas pequenos, a regra LPT se mostrou melhor. Os autores apresentaram o algoritmo RPT (Reverse LPT) o qual procura incorporar as melhores propriedades das regras SPT e LPT.

Horowitz; Sahni (1976) mostraram algoritmos exatos e aproximados, aplicados no caso de máquinas paralelas proporcionias e não-relacionadas, com o objetivo de minimizar o tempo de conclusão das tarefas e o tempo de fluxo médio ponderado. Os algoritmos exatos apresentados na avaliação do desempenho no pior caso (worst-case) podem ser exponenciais. Já os algoritmos de aproximação apresentam complexidade polinomial em função do número de tarefas. Estes algoritmos são $\varepsilon$-aproximados, significando que eles garantem um erro fracionário de não mais que $\varepsilon$, entre o ótimo e o valor das soluções aproximadas.

Ainda em relação a máquinas paralelas não-relacionadas, Ibarra; Kim (1977) analisaram o desempenho de algumas heurísticas de aproximação (worst-case), propostas para o critério tempo de conclusão da programação. Para o caso de máquinas paralelas idênticas, os autores fazem uma analogia sobre a dificuldade computacional deste tipo de problema com problemas clássicos como o caixeiro viajante e o problema da mochila. É destacado que a regra LPT produz soluções próximas ao ótimo quando o número de tarefas é grande.

Devido à complexidade de alguns problemas, existe uma grande dificuldade de obter soluções ótimas, sendo que em diversos casos é melhor obter uma boa solução do que investir muito tempo, e onerar os custos tentando encontrar a otimalidade. Fuller (1978) faz uma comparação entre soluções ótimas e soluções boas, analisando as

\footnotetext{
${ }^{3}$ LPT - Longest Processing Time: programa as tarefas tendo como prioridade as que possuem o maior tempo de processamento, sendo que as tarefas são ordenadas de forma decrescente pelos tempos de processamento. Esta regra tende a balancear a carga de trabalho das máquinas. A justificativa para esta regra é que é mais vantajoso manter tarefas com tempos de processamento mais curtos para mais tarde, de modo que quando as tarefas forem designadas para suas respectivas máquinas, as tarefas em uma dada máquina podem ser resequenciadas sem afetar a carga de trabalho.

${ }^{4}$ SPT - Shortest Processing Time: programa as tarefas pelo menor tempo de processamento, geralmente utilizada para minimizar o tempo total de conclusão das tarefas e também reduzir a fila de tarefas em processo.
} 
heurísticas no processo de decisão. $\mathrm{O}$ autor destaca que as heurísticas simplificam o processo para o tomador de decisão, permitindo que as decisões sejam tomadas de forma rápida. A vantagem em utilizar heurísticas é que os métodos limitam a busca, reduzindo o número de alternativas.

Pelo fato de as heurísticas não garantirem soluções ótimas, Fuller (1978) sugere algumas abordagens para comparar os resultados, como por exemplo, utilizando programação linear, não-linear e verificando não apenas as soluções, mas também o tempo computacional. Existem várias abordagens de programação de máquinas paralelas utilizando a programação linear como método de solução. Lawler; Labetoulle (1978) empregaram a programação linear para resolver o problema de programação de máquinas paralelas não-relacionadas com o processamento podendo ser interrompido, o critério de desempenho utilizado foi minimizar o makespan.

Graham et al. (1979) analisaram a teoria de programação (scheduling) com ênfase em algoritmos de otimização e aproximação, e também na complexidade computacional. A pesquisa abrangeu diversos ambientes de programação de máquinas, inclusive o ambiente de máquinas paralelas. Problemas de programação em que não podem haver interrupção são mais difíceis de encontrar soluções. Davis; Jaffe (1981) também pesquisaram algoritmos para programação de tarefas em máquinas paralelas não-relacionadas, sendo que as tarefas não podiam ser interrompidas. Os autores destacam o caso quando há restrições de precedência entre as tarefas, em que as heurísticas tendem a ser pobres.

Zanakis et al. (1989) estudaram mais de 400 artigos sobre diferentes métodos heurísticos e suas aplicações, onde ficou evidenciado que a heurística construtiva, por ser simples de desenvolver e implementar, e por produzir resultados rápidos e muitas vezes boas soluções, já eram bastante utilizadas na época. Dependendo do porte e complexidade do problema, as heurísticas construtivas podem não conseguir atingir boas soluções, mas, pode ser útil ao fornecer uma solução inicial para um método mais robusto, como é caso das metaheurísticas.

As heurísticas construtivas geram soluções adicionando componentes individuais, como por exemplo: arcos, nós, variáveis, etc., até que uma solução viável 
seja obtida. Na maioria das heurísticas construtivas a solução viável é encontrada somente no final do procedimento. Um exemplo clássico é o caso do caixeiro viajante (Traveling Salesman Problem - TSP), onde pode ser utilizado o critério do vizinho mais próximo.

Alguns autores preferem trabalhar com regras de prioridade (ou de seqüenciamento) para programação de tarefas em máquinas paralelas, visto que são simples e rápidas para implementar Baker; Bertrand (1982) propuseram uma regra dinâmica de prioridade para programação com data de entrega (due-date) aplicado inicialmente no ambiente de máquina única. É apresentada uma regra modificada para due-date chamada de MDD (Modified Due Date). Esta heurística é uma combinação das regras SPT (Shortest Processing Time) e EDD $^{5}$ (Earliest Due Date). A heurística modificada $\left(\mathrm{MDD}^{6}\right)$ apresentou um desempenho melhor quando comparada com o SPT e EDD puros.

Potts (1985) analisa uma heurística para programação de máquinas paralelas não-relacionadas e sem interrupção no processamento, com o objetivo de minimizar o tempo de conclusão das tarefas. A heurística proposta utiliza duas fases; na primeira é empregada a técnica de programação linear, em que no máximo $m-1$ tarefas não são programadas, e na segunda fase, um método heurístico para as tarefas não programadas. O autor utiliza esta abordagem porque quando todas as tarefas são programadas nas suas respectivas máquinas, somente mudando a ordem das tarefas o tempo de conclusão não sofre alteração. Quando aplicada em situações que existem datas de liberação (release dates), e no ambiente de máquina única, a heurística se mostrou boa, mas, para problemas em que há restrições de precedência entre as tarefas, a heurística não consegue ser satisfatória.

Lenstra et al. (1990) estudaram algoritmos de aproximação para programação de máquinas paralelas diferentes com o objetivo de minimizar o makespan, os quais apresentam um esquema de aproximação polinomial. O algoritmo empregado é baseado

\footnotetext{
${ }^{5}$ EDD - Earliest Due Date: programa as tarefas tendo como prioridade as que possuem a data de entrega mais cedo, o objetivo é minimizar o atraso entre as tarefas.

${ }^{6}$ MDD - Modified Due Date: combina as características das regras EDD e SPT da seguinte forma: tarefas com folga são ordenadas segundo a regra EDD, e para as demais tarefas a regra SPT é utilizada.
} 
no relacionamento de programação inteira e suas relaxações lineares. Hariri; Potts (1991) utilizaram métodos heurísticos na programação de máquinas paralelas nãorelacionadas, o problema possui a característica de algumas máquinas não serem aptas para processar algumas tarefas. Empregaram o conceito de heurística duas fases LP/H (programação linear e heurística). Na primeira fase é aplicada a programação linear para gerar uma programação parcial e na segunda fase pode ser utilizado um método heurístico ou exato para programar as tarefas remanescentes.

Lee (1991) abordou um problema de programação de máquinas paralelas idênticas, em que as máquinas não estavam simultaneamente disponíveis. Assim, no instante de tempo zero, para iniciar o processamento, existiam apenas algumas máquinas disponíveis para processamento. Foi utilizada a regra de sequenciamento LPT e também uma versão modificada chamada de MLPT, sendo que esta versão apresentou um desempenho melhor do que a original.

Glass et al. (1994) estudaram o problema de programação de máquinas paralelas não-relaciondas utilizando métodos de busca. Os seguintes algoritmos foram propostos: Busca em Vizinhança (Neighbourhood Search); Método da Descida (Descent); (Simulated Annealing); Busca Tabu (Tabu Search); Algoritmo Genético (Genetic Algorithm) e (Genetic Descent Algorithm). Na análise da performance dos algoritmos acima, os autores perceberam que o algoritmo genético forneceu soluções pobres; a melhoria foi somente percebida após a incorporação do algoritmo descent, formando assim, o genetic descent algorithm-GD. Para ter uma visão melhor sobre os vários tipos de algoritmos utilizados, os autores compararam da seguinte forma: GD comparado com o simulated annealing e busca tabu, neste caso específico, a busca tabu mostrou melhor desempenho frente aos outros quando o tempo limite era (20 segundos). Com relação ao genetic descent e simulated annealing foi constatada com o aumento do tempo de processamento.

No caso de busca local empregada em problemas de programação de máquinas paralelas não-relacionadas, Piersma; Van Dijk (1996) mostram uma heurística com uma busca em vizinhança utilizando descida iterativa (iterative descent) na busca local. A estratégia utilizada na fase inicial foi uma heurística gulosa. 
Brucker et al. (1997) estudaram a complexidade dos problemas de programação com máquinas multi-propósito. A ênfase foi dada para os casos de máquinas paralelas idênticas e uniformes. O problema de programação de máquinas multi-propósito é uma generalização dos problemas clássicos de máquinas paralelas, nos quais uma tarefa só pode ser processada por uma máquina pertencente a um determinado conjunto especificado, ou seja, dado $m$ máquinas $M_{1}, \ldots, M_{m}$ e $n$ tarefas $i=1, \ldots, n$. A tarefa $i$ tem que ser processada por uma máquina do conjunto $\mu_{i} \subseteq\left\{M_{1}, \ldots, M_{m}\right\}$ de máquinas.

Koulamas (1997) estudou o problema de máquinas idênticas com o objetivo de minimizar o atraso médio, utilizando as ideias da heurística $\mathrm{PSK}^{7}$, dando origem à heurística $\mathrm{KPM}^{8}$ e também a uma versão da heurística simulated annealing. A heurística de decomposição proposta tem por objetivo decompor o problema em subproblemas de um tamanho tratável e assim, ser resolvido de uma maneira simples. Também foi proposto para este ambiente a heurística simulated annealing utilizando um processo de troca entre tarefas e máquinas, o qual apresentou um bom desempenho, com a desvantagem de demandar elevado esforço computacional.

As regras de prioridade, conforme comentado anteriormente são eficientes para determinados casos e também podem ser uma alternativa para iniciar um algoritmo mais robusto. Foi este o caso utilizado por Azizoglu; Kirca (1998), que estudou o problema de máquinas paralelas com o objetivo de minimizar o atraso total (total tardiness), aplicando um algoritmo SPT e EDD, para achar limitantes superiores para a árvore branch and bound, no início do processamento.

Alidaee; Rosa (1997) abordaram o problema de máquinas paralelas idênticas aplicados em casos para mimimizar o atraso total ponderado e também para atraso total não ponderado. Utilizaram uma heurística chamada de MDD (Modified Due Date), que é uma variação da regra de sequenciamento EDD. A regra MDD foi comparada com outras regras consagradas, como a regra COVERT (Cost Over Time) de Carroll (1965),

\footnotetext{
${ }^{7}$ PSK - Possui o objetivo de minimizar o atraso médio no caso de máquina única. Esta regra ordena as tarefas aplicando a regra SPT, em que as tarefas com menor tempo de processamento são priorizadas e, em caso de empate, é empregada a regra EDD.

${ }^{8} \mathrm{KPM}$ - utiliza as regras SPT e PSK para ordenar tarefas e designar para as máquinas com o objetivo de minimizar o atraso total.
} 
e AU (Apparent Urgency) de Morton, Rachamadugu e Vepsalainen (1984), e que por meio de testes comprovou ter conseguido melhores soluções.

Blazewicz et al. (2000) mostrou um problema de programação de tarefas em máquinas paralelas com o processamento podendo ser interrompido e as máquinas possuindo disponibilidade limitada, ou seja, existem intervalos de tempo em que as máquinas não estão disponíveis. Foram utilizadas técnicas de programação linear e de fluxo em rede com o objetivo de minimizar o makespan.

Cao et al. (2005) apresentaram um trabalho que tem por objetivo minimizar simultaneamente o custo do atraso do processamento das tarefas, e os custos que as máquinas "carregam". O problema é descrito como PMSSM (Parallel Machine Selection Scheduling Model). A função objetivo reflete o balanço entre o sistema de custo da máquina, e o custo relacionado com as penalidades de atraso das tarefas. Dessa forma, se uma máquina é selecionada para processar uma tarefa qualquer, um custo sobre a máquina é gerado. Assim, o custo de uma máquina com grande capacidade de processamento será muito maior do que o de uma com pouca capacidade. O método utilizado foi a busca tabu com memória de curto prazo, o qual apresentou bons resultados.

Liaw et al. (2003) abordaram um problema de máquinas paralelas não relacionadas com o objetivo de minimizar o atraso total ponderado, e mostraram as propriedades de um programa ótimo, e também propuseram um algoritmo branch and bound. Shim e Kim (2007) também exploraram as propriedades de um programa ótimo e sugeriram um algoritmo branch and bound aplicado ao caso de máquinas paralelas idênticas com o objetivo de minimizar o atraso total.

Panwalkar et al. (1993) propuseram a heurística PSK com o objetivo de minimizar o atraso médio no caso de máquina única. A heurística proposta mostrou-se eficaz para casos em que a data de entrega é mais apertada.

Biskup et al. (2008) relataram um problema de máquinas paralelas idênticas com função objetivo de minimizar o atraso total, onde propuseram algumas heurísticas 
baseadas em regras de sequenciamento como EDD, MDD, TPI $^{9}$ e Minimum Slack ${ }^{10}$ (folga mínima). Estas regras foram comparadas com as versões tradicionais MDD, KPM e TPI e comprovaram a boa performance do MDD proposto.

Ou; Leung (2008) mostram o problema de programação com máquinas paralelas idênticas com inclusão de conjuntos de restrições para serem processadas. Neste problema, o conjunto de tarefas são designadas para diferentes máquinas paralelas com a mesma velocidade de processamento e cada tarefa é compatível apenas com um conjunto de máquinas. Dessa forma, cada tarefa é compatível somente com um subconjunto destas máquinas. O objetivo é minimizar o makespan. Lin et al. (2011) abordaram o problema de máquinas não-relacionadas, avaliando os seguintes objetivos Makespan, Total Weighted Completion Time e Total Weighted Tardiness.

Minimizar o makespan siginifica não só concluir todas as tarefas tão rápido quanto possível, mas também maximizar a utilização das máquinas. Já o Total Weighted Completion Time $\left(\sum w_{j} c_{j}\right)$ fornece uma indicação do custo total de manter estoques, incorridos pelo programa. E por fim, a outra medida de desempenho $\left(\sum w_{j} T_{j}\right)$, é uma medida de satisfação do cliente em relação ao serviço ser executado no prazo. Os autores trabalham a questão de encontrar uma heurística que possua bom desempenho para as três funções objetivo mencionadas. A prática mostra que existem algumas heurísticas que possuem maior aderência em determinada medida de performance, sendo difícil encontrar uma que obtenha bom desempenho em mais de um critério.

\subsection{Programação de Navios}

Ronen (1993) abordou a questão de programação de navios, onde fez uma revisão dos principais trabalhos, abordagens e problemas deste campo até aquela época. A função objetivo mais encontrada nesta área é minimizar custos, dado o montante de capital envolvido nestas operações, e as principais decisões a serem tomadas são referentes a scheduling e fleet size (programação e composição da frota). A

\footnotetext{
${ }^{9}$ TPI - Traffic Priority Index: leva em consideração o congestionamento do sistema de produção, designando as tarefas para as máquinas com menor carga de trabalho.

${ }^{10}$ Minimum Slack - é uma variação da regra EDD, em que a folga remanescente de cada tarefa é calculada, e a tarefa com a mínima folga é a próxima a ser programada.
} 
programação de navios é o nível mais detalhado no planejamento operacional de uma empresa de navegação, e inclui decisões como: o que cada navio vai carregar e quando. Tratam-se de problemas combinatórios, os quais admitem diversas soluções.

Brown et al. (1987) abordaram o problema de programação de navios no transporte de óleo cru. Foi utilizado um modelo de partição de conjuntos para resolver o problema, no qual conseguiram determinar velocidades ótimas para as embarcações. Os problemas relacionados à programação de embarcações no transporte de óleo cru, geralmente tem como objetivo minimizar os seguintes custos:

- Custo de oportunidade (custo diário);

- Consumo de combustível;

- Consumo de combustível para sistemas auxiliares;

- Custos de entrada em portos e em canal;

- Custo do aluguel de uma embarcação para cargas eventuais (sem rota fixa).

Miller (1987) apresenta um modelo interativo para programação de navios. O problema abordado é relacionado com a programação de navios tanques empregados no reabastecimento de terminais (portos com tanques de armazenagem), o qual desenvolveu duas modelagens, uma utilizando o fluxo em rede e a outra utilizando programação inteira mista.

Fagerholt (2004) apresentou um sistema de apoio a decisão para programação de frota de navios. Brønmo et al. (2007a) apresentaram uma heurística de busca local com multi-início (multi-start) para o problema de programação de navios. As soluções iniciais são geradas de forma aleatória, por inserção. As melhores soluções iniciais são melhoradas por uma heurística de busca local.

Brønmo et al. (2007b) mostraram um modelo de programação mista e por partição de conjuntos aplicada no problema de programar e roteirizar uma frota de navios com cargas de tamanhos flexíveis. Mendes (2007) abordou o problema de programação de frota de apoio, onde para uma mesma tarefa, poderiam ser necessárias várias embarcações para atender ao serviço. Como métodos de solução foram usados: 
heurística construtiva, branch and cut, variable neighbourhood search (VNS), e combinação de heurística com os métodos descritos. Outra contribuição importante foi dada por Brønmo et al. (2010), na qual abordou a programação de navios utilizando o método de geração de colunas.

\subsection{Conclusão da Revisão Bibliográfica}

A revisão bibliográfica apresentou de uma forma geral, diversos problemas relacionados à programação de tarefas, com ênfase em máquinas paralelas e a generalização das características para o ambiente de programação de frota de embarcações. Dessa maneira, trata-se de uma situação que a empresa possui uma frota composta por uma determinada classe de embarcações, que no caso são os PLVs, e necessita programar a ordem de execução das tarefas dentro de um determinado horizonte de planejamento.

Graham et al. (1979) apresentam uma notação padrão para descrever as variações dos ambientes de programação de máquinas, incluindo as paralelas, que podem ser idênticas, proporcionais e não-relacionadas. O presente trabalho pode ser considerado uma generalização dos ambientes de máquinas paralelas não-relacionadas e possui o objetivo de minimizar o atraso total ponderado na execução das tarefas, que na literatura é conhecido como total weighted tardiness, que é uma medida de satisfação do cliente em relação ao serviço ser executado no prazo.

Outros critérios de medir o desempenho nos problemas de máquinas paralelas também foram apresentados como o makespan, que siginifica não só concluir todas as tarefas tão rápido quanto possível, mas também maximizar a utilização das máquinas. $\mathrm{O}$ Total Weighted Completion fornece uma indicação do custo total de manter estoques, incorridos pelo programa. O critério total weighted tardiness constitui um dos casos mais difíceis.

Quanto aos métodos de solução propostos, podem-se destacar duas grandes abordagens: métodos exatos e não-exatos. Devido à resposta cada vez mais rápida que o mercado necessita das empresas, nem sempre é possível utilizar uma abordagem por 
algum método exato. Assim, as heurísticas desempenham um papel fundamental no tocante a prover uma solução de boa qualidade em um intervalo de tempo razoável.

Também é importante destacar as regras de sequenciamento como a SPT, LPT, EDD, PSK, KPM, e suas modificações, que podem fornecer soluções de qualidade, ou ainda ser utilizada como um início para um algoritmo mais robusto.

A tabela 2.1 destaca as principais referências do trabalho, em que é evidenciado o tipo de problema e os métodos de solução propostos. 
Tabela 2.1 - Principais referências de programação de tarefas da pesquisa

\begin{tabular}{|c|c|c|}
\hline Referência & Problema & Abordagem \\
\hline McNaughton (1959) & Máquinas paralelas idênticas & Data de entrega / Tempo de fluxo \\
\hline Graham (1969) & Máquinas paralelas idênticas & Algoritmos de aproximação \\
\hline Bruno et al. (1974) & Máquinas paralelas idênticas & SPT/LPT \\
\hline $\begin{array}{l}\text { Horowitz; Sahni } \\
(1976)\end{array}$ & Máquinas paralelas não-relacionadas & $\begin{array}{llll}\begin{array}{l}\text { Algoritmos } \\
\text { aproximação }\end{array} & \text { exatos } & \text { e } & \text { de } \\
\end{array}$ \\
\hline Ibarra; Kim (1977) & $\begin{array}{l}\text { Máquinas paralelas não-relacionadas / } \\
\text { idênticas }\end{array}$ & Heurísticas, LPT, SPT \\
\hline $\begin{array}{l}\text { Lawler; Labetoulle } \\
\text { (1978) }\end{array}$ & Máquinas paralelas não-relacionadas & Programação linear \\
\hline Fuller (1978) & Programação de produção & Heurísticas \\
\hline \multirow{2}{*}{ Graham et al. (1979) } & $\begin{array}{l}\text { Máquinas paralelas idênticas /proporcionais } \\
\text { / não-relacionadas }\end{array}$ & Algoritmos de aproximação \\
\hline & $\begin{array}{l}\text { Open shop / flow shop / job shop/ máquina } \\
\text { única }\end{array}$ & Algoritmos de otimização \\
\hline Davis; Jaffe (1981) & Máquinas paralelas não-relacionadas & Algoritmos de aproximação \\
\hline $\begin{array}{l}\text { Baker; Bertrand } \\
(1982)\end{array}$ & Sistema de produção & SPT/EDD \\
\hline Potts (1985) & Máquinas paralelas não-relacionadas & Heurística duas fases \\
\hline Brown et al. (1987) & Programação de embarcação & Partição de conjuntos \\
\hline Miller (1987) & Programação de embarcação & $\begin{array}{l}\text { Fluxo em rede / programação inteira } \\
\text { mista }\end{array}$ \\
\hline Lenstra et al. (1990) & Máquinas paralelas não-relacionadas & Algoritmos de aproximação \\
\hline Hariri; Potts (1991) & Máquinas paralelas não-relacionadas & Heurísticas \\
\hline Lee (1991) & Máquinas paralelas idênticas & LPT/LPT (modificado) \\
\hline $\begin{array}{l}\text { Panwalkar et al. } \\
(1993)\end{array}$ & Máquina única & PSK \\
\hline \multirow{4}{*}{ Glass et al. (1994) } & \multirow{4}{*}{ Máquinas paralelas não-relacionadas } & Busca local / Busca tabu \\
\hline & & Algoritmo genético \\
\hline & & Simulated annealing \\
\hline & & Método da descida \\
\hline $\begin{array}{l}\text { Piersma; Van Dijk } \\
\text { (1996) }\end{array}$ & Máquinas paralelas não-relacionadas & Busca local \\
\hline Brucker (1997) & Máquinas paralelas idênticas / proporcionais & Complexidade computacional \\
\hline Alidaee e Rosa (1997) & Máquinas paralelas idênticas & MDD \\
\hline Koulamas (1997) & Máquinas paralelas idênticas & KPM e simulated annealing \\
\hline $\begin{array}{l}\text { Azizoglu; Kirca } \\
\text { (1998) }\end{array}$ & Máquinas paralelas idênticas/proporcionais & Branch and Bound \\
\hline $\begin{array}{l}\text { Blazewicz et al. } \\
(2000)\end{array}$ & $\begin{array}{l}\text { Máquinas paralelas idênticas / proporcionais } \\
\text { / não-relacionadas }\end{array}$ & Programação linear / fluxo em rede \\
\hline Fagerholt (2004) & Programação de embarcação & Sistema de suporte a decisão \\
\hline Brønmo et al. (2007a) & Programação de embarcação & Busca local \\
\hline Brønmo et al. (2007b) & Programação de embarcação & Partição de conjuntos \\
\hline Brønmo et al. (2010) & Programação de embarcação & Geração de colunas \\
\hline
\end{tabular}




\section{MODELAGEM MATEMÁTICA E MÉTODOS DE SOLUÇÃO}

Este capítulo aborda o modelo matemático e os métodos de solução do problema de programação da frota de navios PLVs. Antes da apresentação do modelo matemático serão revistos os principais aspectos do problema em questão.

\subsection{Descrição Resumida do Problema}

Este trabalho aborda o problema de uma operação de lançamento e instalação de linhas flexíveis e rígidas realizadas por embarcações denominadas pipe layer vessel. As atividades consideradas são expressas pelas tarefas de instalação de novas linhas e a interligação à malha existente, dentro de um horizonte de 3 a 6 meses (curto a médio prazo). As seguintes premissas são dadas:

1) Cada tarefa poderá ser realizada a partir de um determinado instante de liberação, refletindo a data prevista de chegada de material no porto, ou a data prevista da emissão da licença ambiental, ou alguma outra restrição do processo;

2) A data de entrega é dada pela data de liberação mais a duração da tarefa;

3) As diversas sub-atividades que compõem uma tarefa não serão objeto de análise ou de melhoria neste estudo, por demandarem conhecimento específico do processo;

4) $\mathrm{O}$ abastecimento e a troca de tripulação de um PLV ocorrerão concomitantemente com a estadia no porto, durante o processo de carregamento de material/equipamentos;

5) Há restrições de compatibilidade entre tarefa e embarcação, de forma que algumas embarcações poderão não ser aptas para executar uma certa tarefa;

6) As durações das tarefas podem ser diferenciadas por embarcação;

7) O tempo de reposicionamento de uma embarcação após a conclusão de uma tarefa é nulo, já que o término de uma tarefa ocorre no porto com a devolução de material;

8) A composição da frota é fixa, ou seja, os tipos de embarcação e a quantidade de cada uma delas na composição da frota não serão 
alteradas. Além disso, todas as características das embarcações que compõem a frota, necessárias à modelagem do problema, são conhecidas;

9) O critério de priorização das tarefas será exclusivamente baseado no potencial de produção e não levará em conta aspectos de meio-ambiente, de continuidade operacional e fatores políticos internos à empresa. Este potencial de produção reflete o quanto a interligação de uma linha em um determinado poço pode trazer de produção e retorno financeiro para a empresa petrolífera. Assim, existem tarefas que podem trazer um retorno maior do que as outras, fazendo necessário haver uma priorização;

10) As embarcações estarão disponíveis para o próximo horizonte de planejamento no instante em que finalizar a sua última tarefa, caracterizando a existência de uma data de liberação da embarcação;

11) Não existem restrições de precedência entre as tarefas;

12) Cada embarcação só poderá executar uma tarefa por vez e as tarefas só podem ser executadas por uma única embarcação; assim, não é admitido que uma determinada tarefa possa ser realizada parcialmente por duas embarcações.

As decisões do modelo são quanto à definição das datas de início de cada tarefa, e a respectiva embarcação responsável pela execução dessa tarefa. O modelo divide a escala de tempo em dias, impondo que o início de uma determinada tarefa ocorra em um determinado dia. Esta modelagem faz com que os parâmetros sejam tratados somente na unidade específica, que no caso são dias.

\subsubsection{Modelo Matemático}

Para o presente problema, foi formulado um modelo de programação linear inteira mista, usando as ideias apresentadas em van den Akker et al. (2000), para um problema de máquina simples com função objetivo regular. Esta formulação baseia-se em uma escala de tempo discretizada. É assumido que os parâmetros são conhecidos e inteiros, sendo utilizada a notação baseada em Blazewicz et al. (1991) e Unlu; Masson (2010). 


\section{Conjuntos}

$\begin{array}{lll}J & \text { Conjunto de tarefas } & j=1, \ldots, n \\ M & \text { Conjunto de embarcações } & i=1, \ldots, m\end{array}$

\section{Parâmetros}

$T \quad$ Horizonte de planejamento $=T($ índice $t)$

$r_{j} \quad$ Data de liberação da tarefa $j$

$v_{i} \quad$ Data de liberação da embarcação $i$

$p_{j}^{i} \quad$ Tempo de execução da tarefa $j$ pela embarcação $i$

$c_{j t} \quad$ Penalidade associada à tarefa $j$, quando é iniciada na data $t$

$a_{i j} \quad$ Parâmetro binário que será igual a 1 se a tarefa $j$ for compatível com a embarcação $i$; e 0 , em caso contrário.

\section{Variáveis de Decisão}

$x_{i j}^{t}=1$, se a embarcação $i$ inicia a tarefa $j \in J$ na data $t ; 0$, em caso contrário.

\section{Modelo}

$\min \sum_{i=1}^{m} \sum_{j=1}^{n} \sum_{t=\max \left(r_{j}+1, v_{i}+1\right)}^{T-p_{j}^{i}+1} c_{j t} x_{i j}^{t}$

Sujeito a:

$\sum_{i=1}^{m} \sum_{t=\max \left(r_{j}+1, v_{i}+1\right)}^{T-p_{j}^{i}+1} a_{i j} x_{i j}^{t}=1 \quad \forall j$

$\sum_{j=1:}^{n} \sum_{s=\max \left(r_{j}+1, t-p_{j}^{i}+1\right)}^{\min \left(t, T-p_{j}^{i}+1\right)} x_{i j}^{S} \leq 1 \quad \forall i, t: t>v_{i}$

$x_{i j}^{t} \in\{0,1\} \quad \forall j, t, i$

A equação (3.1) é a função objetivo do problema e contempla a soma dos atrasos ponderados de todas as tarefas. É importante destacar que a somatória em $t$ ocorrerá da maior data entre as datas de liberação da tarefa e da embarcação, até a última data possível de início da tarefa. A restrição (3.2) garante que toda a demanda seja atendida, por meio de embarcações compatíveis. A restrição (3.3) garante que, em cada data, não seja violada a capacidade da embarcação. A equação (3.4) impõe que as variáveis sejam binárias. 
Este modelo foi utilizado para gerar limitantes inferiores para os cenários de teste, por meio da técnica de geração de colunas. Utilizou-se a estrutura apresentada em van den Akker, et al. (2000), em que o problema foi reformulado utilizando-se a decomposição de Dantzig-Wolfe. O problema mestre restrito consistiu na seleção dos pseudo-schedules que cobrissem toda a demanda (conforme requerido pela restrição 2) a um mínimo custo. O subproblema consistiu em resolver um problema de caminho mínimo em uma rede acíclica para cada embarcação, o qual tinha como produto um pseudo-schedule, onde as tarefas poderiam, eventualmente, ocorrer mais de uma vez em uma mesma sequência, desde que não violassem a capacidade do recurso.

\subsection{Métodos de solução}

Esta subseção descreve os métodos de solução propostos para o problema de programação de frota de navios PLVs. Inicialmente, são apresentadas duas heurísticas construtivas e logo após dois métodos de busca (refinamento). Por fim, uma versão básica da meta-heurística GRASP e, após isto, o método GRASP com path relinking e algumas de suas estratégias de implementação.

\subsubsection{Heurísticas e Meta-heurísticas}

As heurísticas conseguem boas soluções empregando um esforço computacional relativamente baixo, mas sem garantir a otimalidade (Voß, 2001). De uma forma geral, as heurísticas são procedimentos que procuram solucionar problemas de uma forma racional, explorando a estrutura do problema, com o objetivo de encontrar uma solução boa, e quando possível, a ótima.

Demeulemeester; Herroelen (2002) apresentam as heurísticas em duas categorias: heurísticas construtivas e heurísticas de busca. As heurísticas construtivas iniciam a programação vazia e adicionam as tarefas uma a uma, até obter um programa viável. Já as heurísticas de busca iniciam a partir de um programa viável que foi obtido com a heurística construtiva, e são feitas operações para transformar a solução em uma melhor. Estas operações são repetidas até que um ótimo local seja obtido, ou se atinja uma critério de parada. 


\subsubsection{Heurística Construtiva}

As heurísticas construtivas são empregadas na geração de uma ou mais soluções viáveis, eventualmente, de boa qualidade, com baixo esforço computacional. Elas podem ser utilizadas de maneira isolada mas, de uma forma geral, são combinadas com outros métodos mais elaborados, como algoritmos de busca local, meta-heurísticas e métodos exatos.

\subsubsection{Heurística Construtiva Proposta}

A heurística construtiva proposta, denominada HEU_C é baseada em Lin et al. (2011). Esses autores apresentaram a heurística HEU-II para o caso de máquinas paralelas não-relacionadas, com o objetivo de minimizar o atraso ponderado total. A ideia principal está concentrada no cálculo do índice $\mathrm{M}_{\mathrm{ij}}$, que tem como função principal priorizar as tarefas de acordo com o rateio entre data de entrega e penalidade.

$\mathrm{O}$ índice $\mathrm{M}_{\mathrm{ij}}$ expressa a relação entre a data prevista de término da tarefa $j$ na máquina $i$, e a penalidade da tarefa $j$. A data prevista de término é calculada como sendo a maior data entre a data desejada de entrega (due date) e o possível instante de término da tarefa $j$ pela máquina $i$. Para tarefas que possuem mesma data de entrega, terão prioridade aquelas que tiverem maior penalidade. E, para tarefas com penalidades iguais, terão prioridade aquelas com menor data de entrega. A figura 3.1 mostra o algoritmo Heurística Construtiva HEU_C.

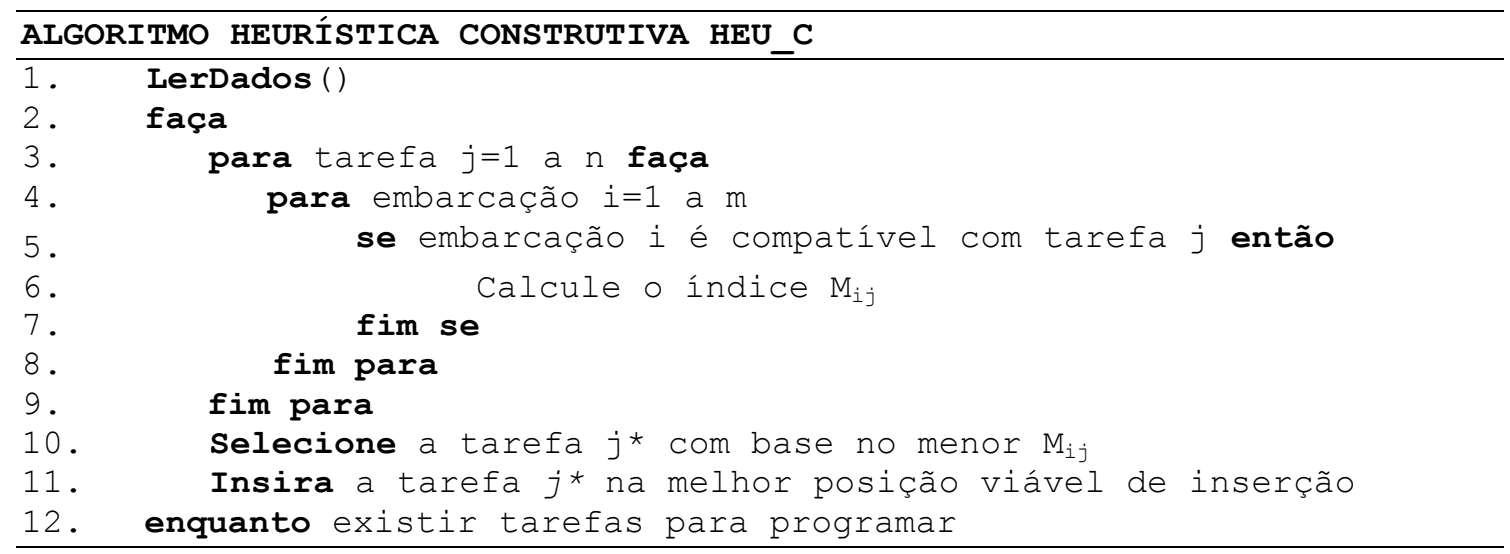

Figura 3.1 - Pseudocódigo da Heurística Construtiva HEU_C. 
A heurística construtiva HEU_C faz uma verificação de compatibilidade entre a embarcação e a tarefa para calcular o índice $\mathrm{M}_{\mathrm{i} j}$. Após este cálculo é selecionada a tarefa com o mínimo valor de $\mathrm{M}_{\mathrm{ij}}$, e a tarefa é inserida na sua melhor posição de inserção. $\mathrm{O}$ critério de parada é quando todas as tarefas forem programadas.

\subsubsection{Heurísticas de Busca}

As heurísticas de busca partem de uma solução inicial conhecida, e procuram explorar a vizinhança desta solução por meio de movimentos, com o objetivo de melhorá-la, chegando a ótimos locais.

Para a construção da vizinhança de uma dada solução é necessário definir as regras dos movimentos que alteram um ou mais atributos da solução. Dessa forma, é criada a vizinhança da solução inicial e é feita a escolha da solução nesta vizinhança com o menor valor de função objetivo (Demeulemeester, Herroelen; 2002). A solução escolhida torna-se, então, a nova solução de referência e o processo continua até ser encontrado um ótimo local.

Este fato faz com que o método chegue, muitas vezes, em ótimos locais distantes do ótimo global, visto que ele não é capaz de escapar da otimalidade local e explorar novas regiões do espaço de busca.

Existem algumas dificuldades com relação ao desenvolvimento das heurísticas de busca, como por exemplo, a sensibilidade à solução de partida, à definição do melhor tipo de vizinhança, à melhor estratégia para escolha da próxima solução, e a definição do número de iterações. Há algumas estratégias que podem ser seguidas como: Multivizinhança - neste caso, são consideradas mais de um método de escolha de vizinhança. Ao atingir o ótimo local em uma vizinhança, é iniciada uma nova busca local baseada em outra vizinhança. $\mathrm{O}$ algoritmo termina quando a solução atual é um ótimo local em relação a todas as vizinhanças empregadas, ou se alcance um critério de parada. Outra estratégia é redução da vizinhança na qual é investigado um subconjunto da vizinhança da solução atual. 
Aarts; Lenstra (2003) destacam a importância dos algoritmos de busca local, sendo que muitas variações e evolução surgiram por meio de analogias à natureza, e algumas por meio de outras áreas do conhecimento como física, biologia e neurofisiologia. Também discorrem que a utilização dos algoritmos de busca local tem sido intensificada nos dias atuais, em decorrência da evolução dos recursos computacionais.

Para a presente pesquisa são propostas duas buscas locais, intituladas de Busca Local Inserção e Busca Local Troca. A seguir é descrito o funcionamento de cada uma e também um esquema com os movimentos e pseudocódigo.

\subsubsection{Busca Local Inserção}

O movimento de inserção é caracterizado pela remoção de uma determinada tarefa de sua sequência, e pela inserção em outra. Com isto, quando uma tarefa da sequência é removida, é verificado o benefício que a remoção da mesma gera, uma vez que as demais tarefas poderão, eventualmente, ser antecipadas. Em seguida, é necessário verificar todas as possíveis posições de inserção em todas as sequências de embarcações compatíveis. Em cada posição de inserção, o custo da inserção é calculado, ou seja, mensura-se, financeiramente, o quanto que a inserção causa de atraso às demais tarefas da sequência. Após averiguar a melhor inserção para todas as embarcações e todas as tarefas, executa-se o movimento para aquela tarefa cujo resultado seja o melhor possível, isto é, a maior redução no valor da função objetivo. Quando não houver movimento capaz de reduzir o valor da função objetivo, um ótimo local terá sido atingido e o método é encerrado. Os esquemas das figuras 3.2 e 3.3 definem os principais movimentos da busca local inserção. A figura 3.4 contém o pseudocódigo desta heurística. 


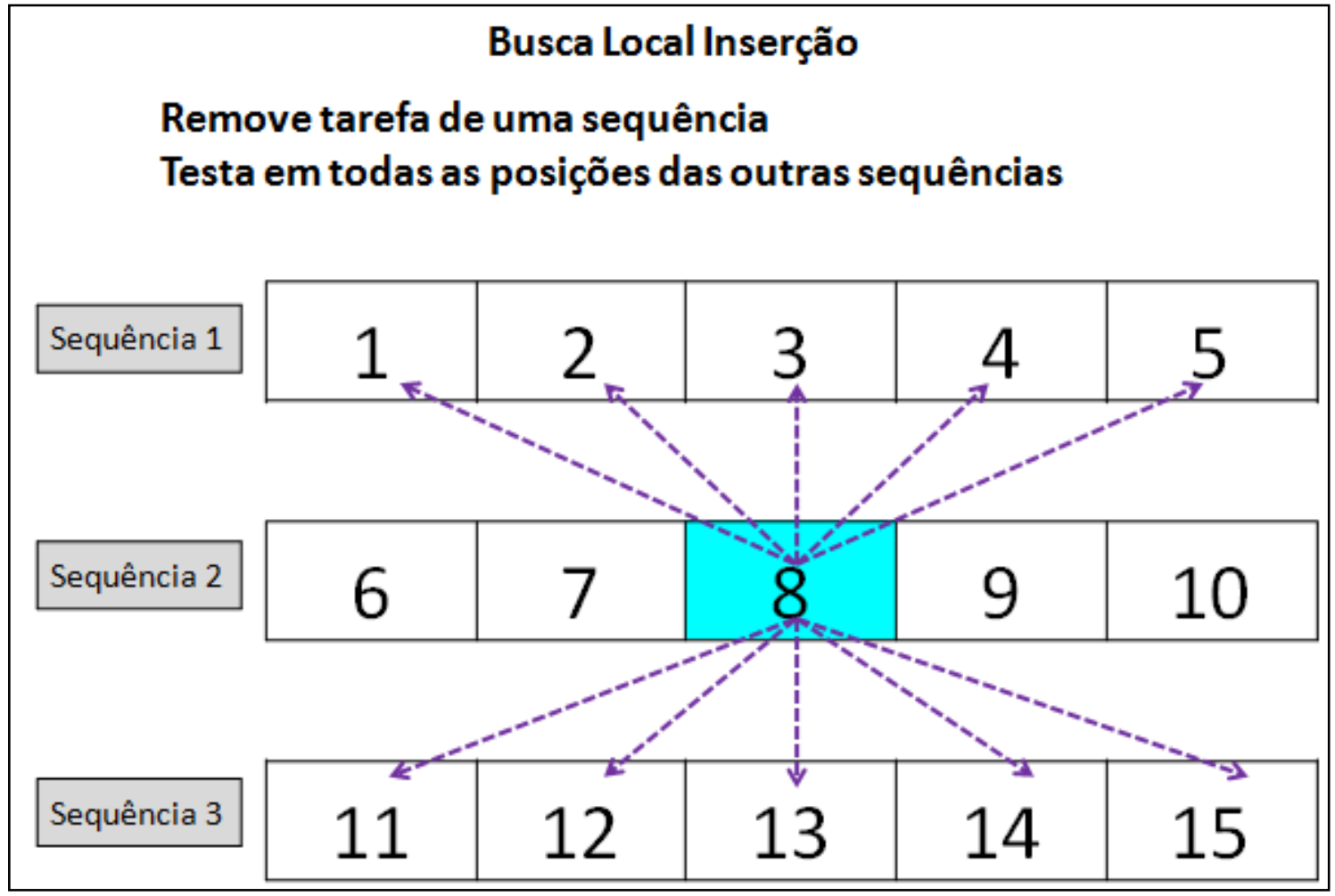

Figura 3.2 - Movimento que remove e testa inserção da tarefa.

\section{Busca Local Inserção}

Insere a tarefa na sequência e posiciona em um ponto de mínima penalidadeponderada

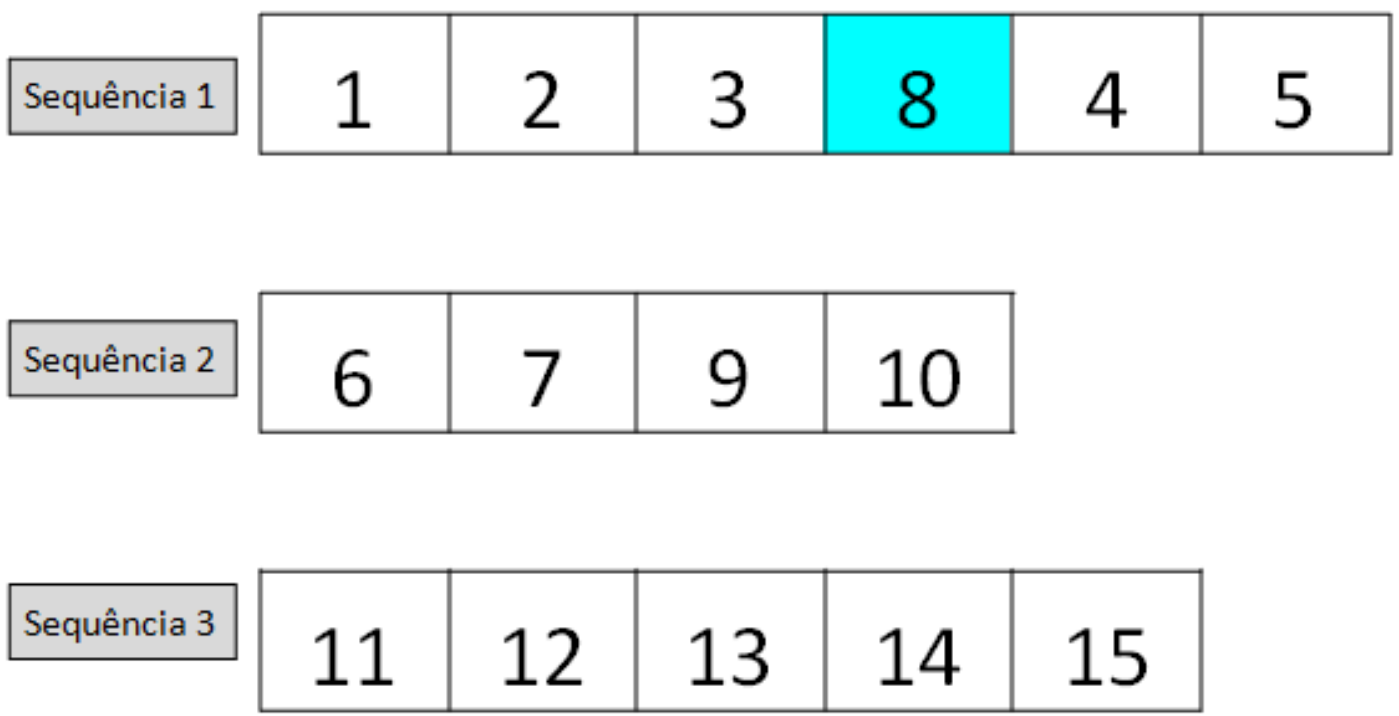

Figura 3.3 - Inserção da tarefa na melhor posição da melhor sequência. 


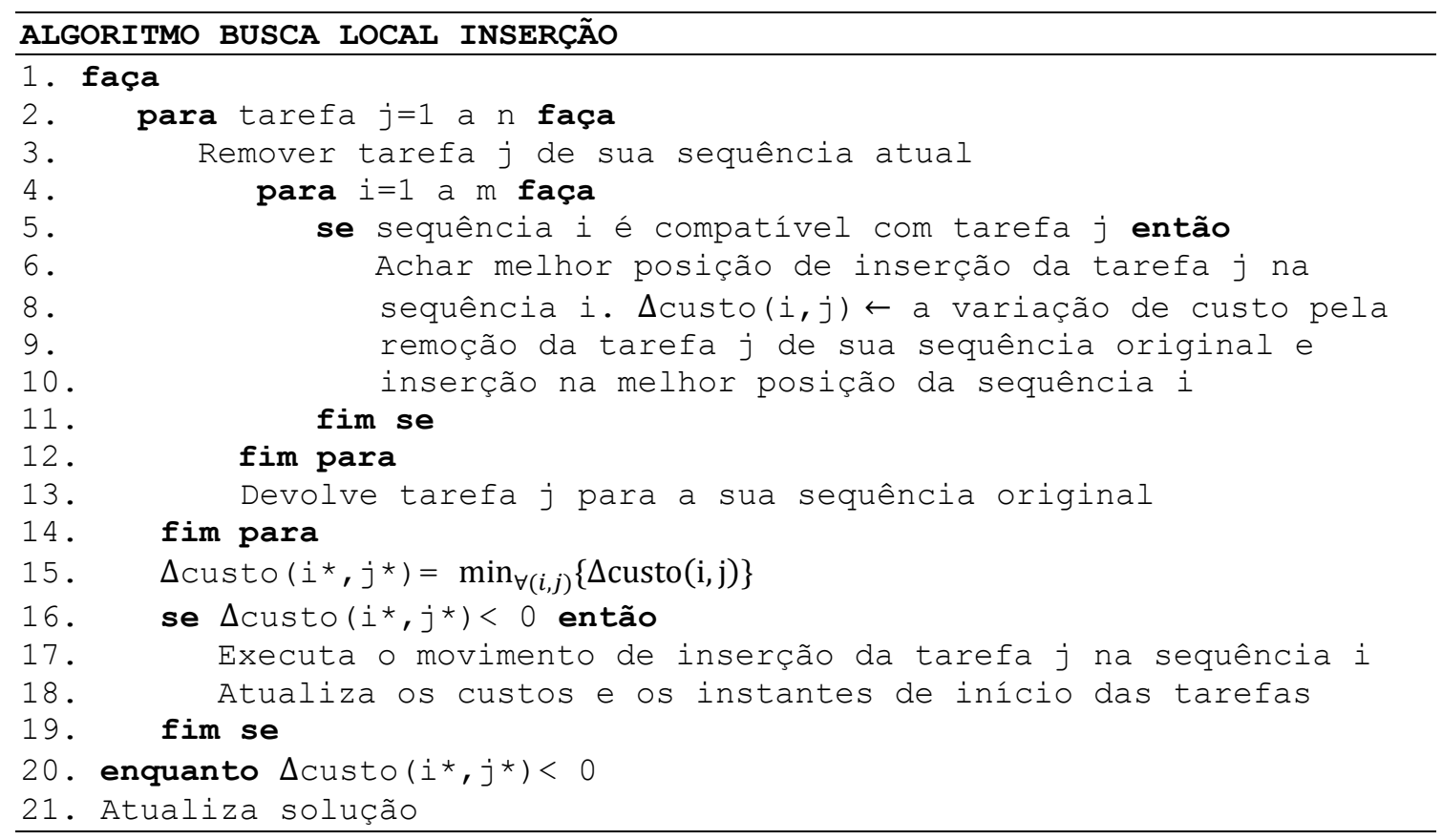

Figura 3.4 - Pseudocódigo Busca Local Inserção

\subsubsection{Busca Local Troca}

A busca local troca é semelhante a anterior, sendo que ela pode trabalhar junto com a busca local inserção. Ela necessariamente parte da solução inicial gerada pela heurística construtiva. A idéia básica é verificar o benefício causado pela remoção das duas tarefas de suas respectivas sequências, e identificar a melhor posição de inserção de cada tarefa na outra sequência, computando o ganho na função objetivo.

Este procedimento é realizado para todos os pares de tarefas desde que estejam em sequências distintas, e cujas embarcações sejam compatíveis entre si. Após testar todos os pares de troca viáveis, o movimento é realizado para o par que apresentar o maior ganho na função objetivo. Este processo é repetido enquanto houver melhoria na função objetivo. As ilustrações das figuras 3.5 e 3.6 destacam o procedimento básico desta heurística, enquanto a figura 3.7 contém o pseudocódigo. 


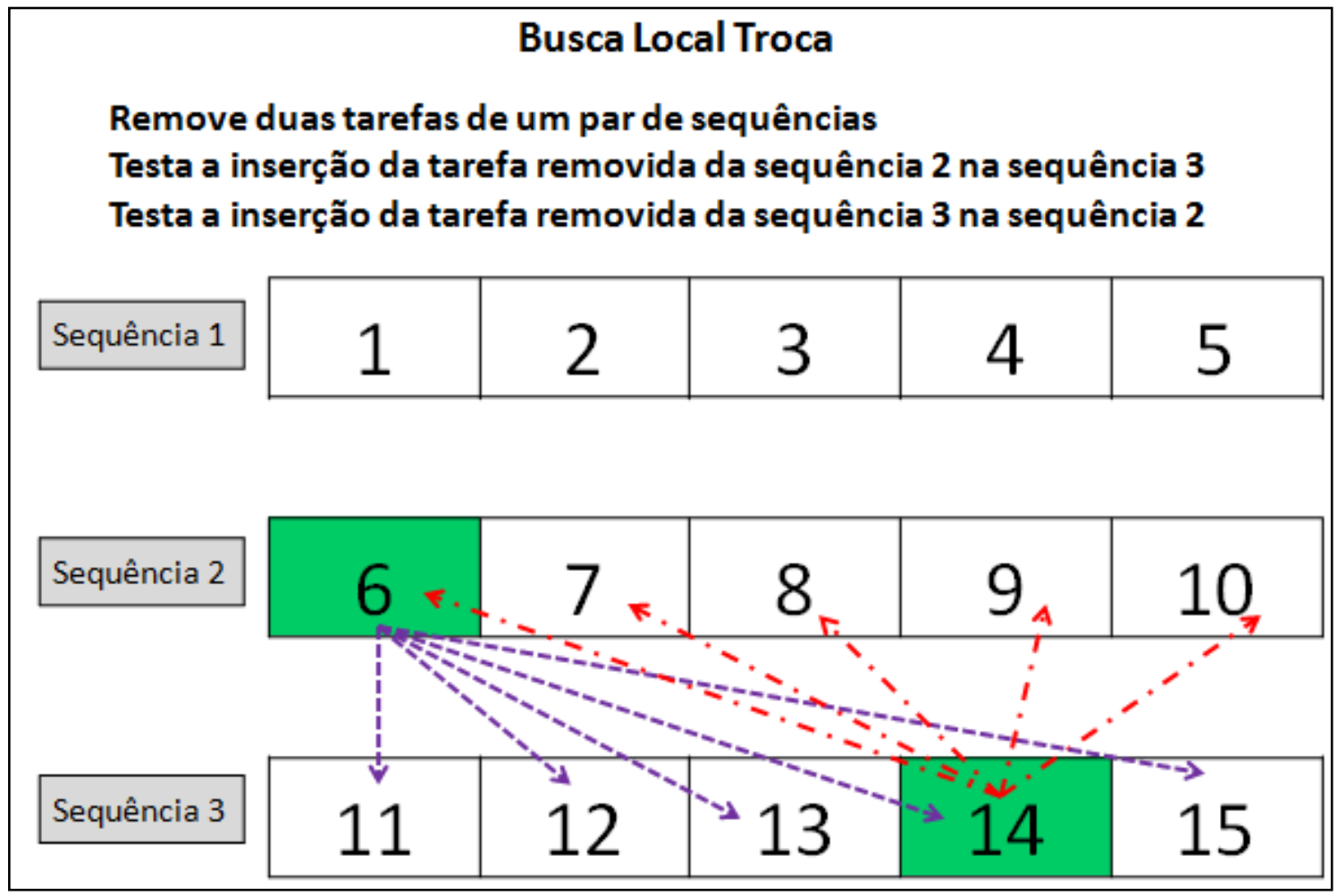

Figura 3.5 - Remove e testa a inserção de duas tarefas entre um par de sequências.

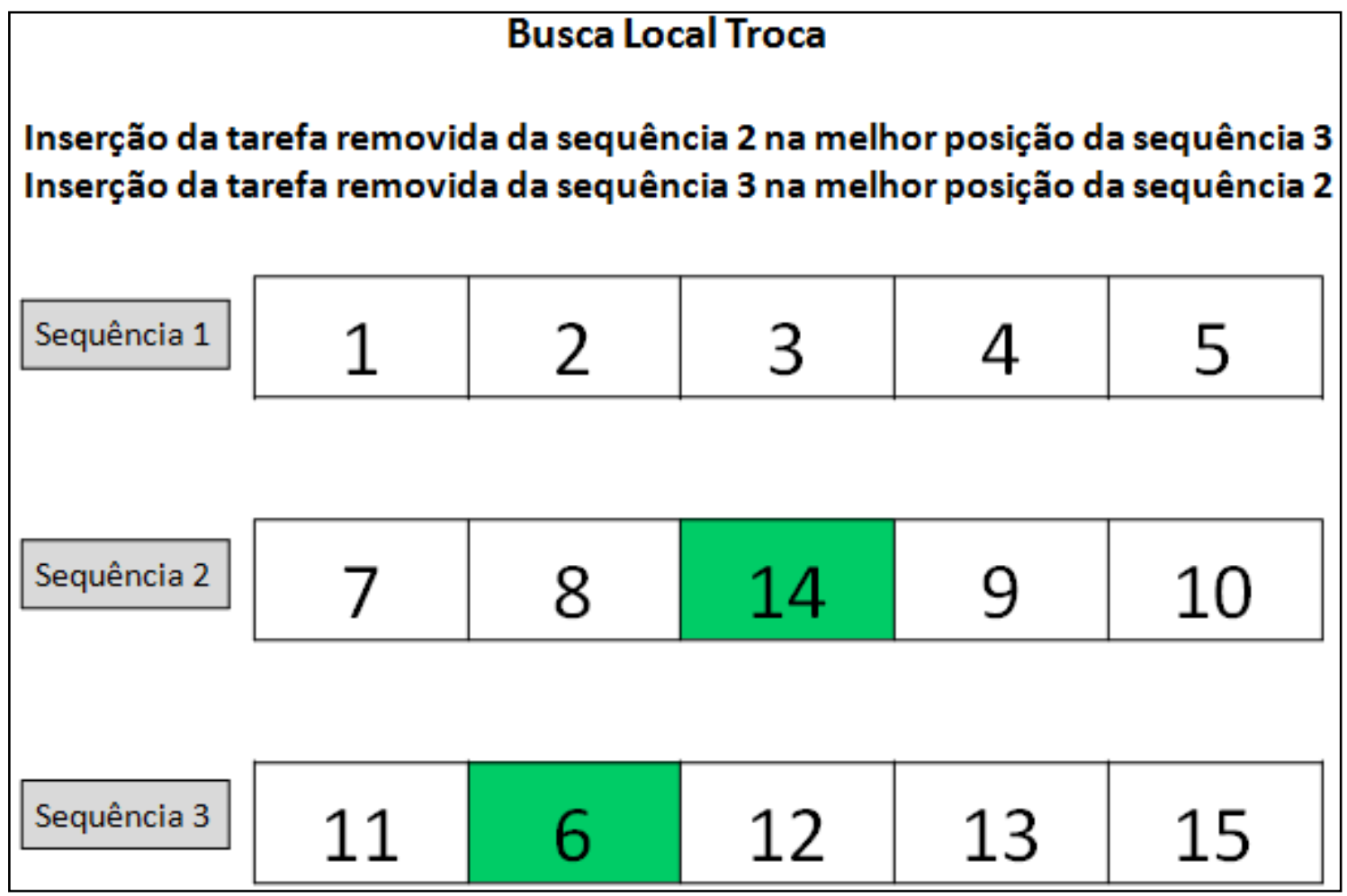

Figura 3.6 - Inserção das tarefas na melhor posição do par de sequências. 


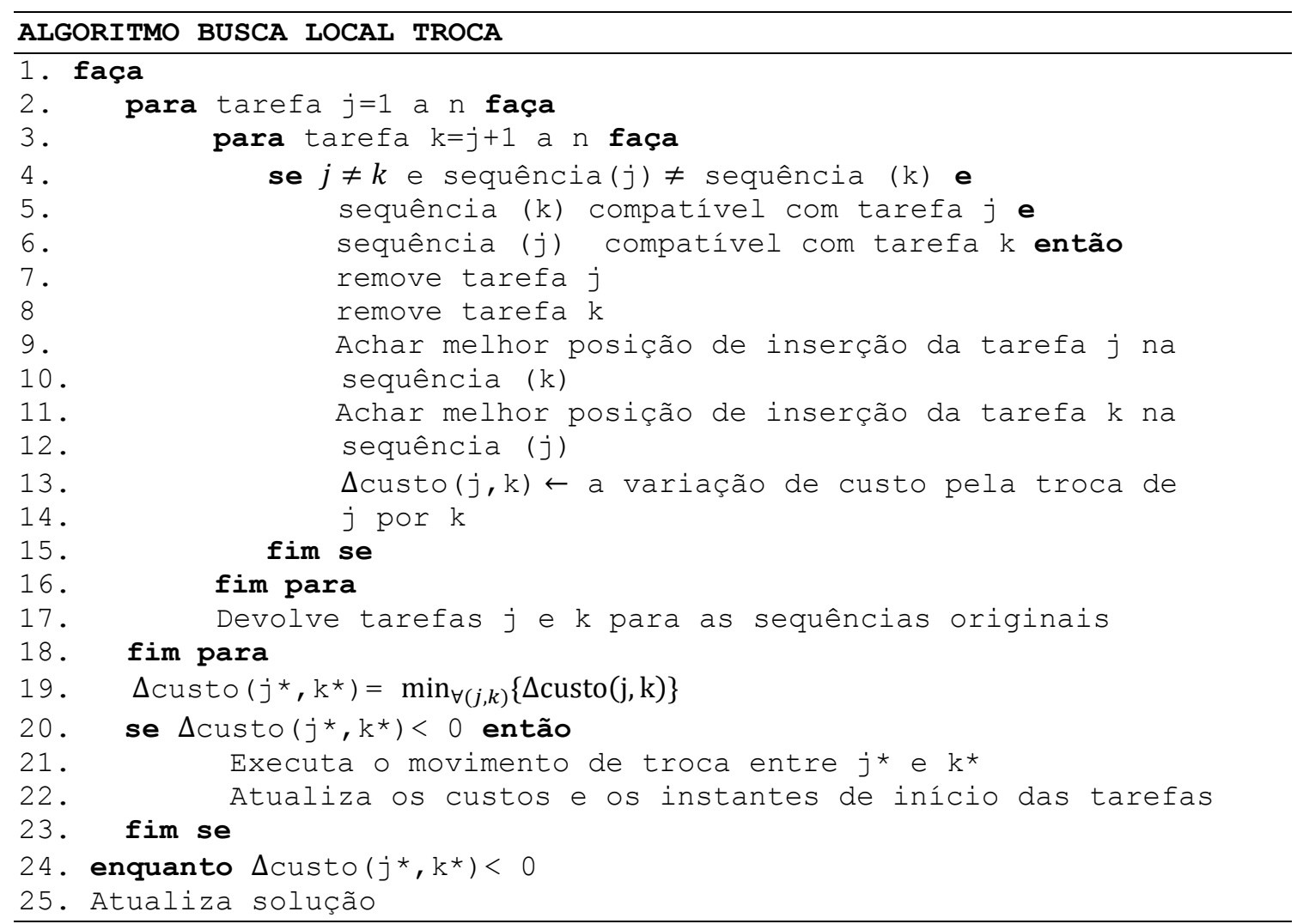

Figura 3.7 - Pseudocódigo da busca local troca

\subsubsection{Meta-heurísticas}

As meta-heurísticas são métodos de melhoria capazes de escapar de ótimos locais, evitando uma parada prematura do algoritmo de busca. Existem diversos tipos de meta-heurísticas, dentre as quais podemos destacar o GRASP - (Greedy Randomized Adaptive Search Procedure), Scatter Search, Busca Tabu dentre outros.

\subsubsection{Meta-heurística GRASP}

Segundo Feo e Resende (1989, 1995), a meta-heurística GRASP (Greedy Randomized Adaptive Search Procedure) trabalha com múltiplas soluções iniciais e, em cada iteração, duas fases devem ser realizadas: fase de construção e busca local. Na primeira fase é construída uma solução viável, por meio de um algoritmo guloso aleatório; na segunda fase, a vizinhança da solução gerada é explorada, até que um ótimo local seja atingido. 
Inicialmente, é requerida uma lista ordenada de tarefas de acordo com algum critério. Em seguida, constrói-se uma lista restrita de candidatos (RCL - Restricted Candidate List), que tem como objetivo armazenar os melhores elementos que possam fazer parte da solução parcialmente gerada, a qual será usada para sorteio da "próxima" tarefa que será incorporada à solução (parcial). Uma vez sorteado, a lista é refeita e o processo continua até que todas as tarefas tenham sido programadas.

Em relação à definição do melhor tamanho da RCL, alguns autores têm desenvolvido diferentes estratégias como, por exemplo, a de Prais; Ribeiro (2000), que elaboraram uma abordagem conhecida como GRASP Reativo, em que é utilizada uma estratégia para a escolha do melhor parâmetro alfa que define o tamanho da RCL. A vantagem desta abordagem é que a escolha de alfa é auto-adaptativa, ao passo que no GRASP tradicional o parâmetro alfa é fixo. Boudia et al. (2007) comprovaram a eficácia da abordagem reativa em relação à lista de tamanho fixa, em um problema acoplado de produção e distribuição.

A figura 3.8 descreve o pseudocódigo do algoritmo GRASP na sua versão básica.

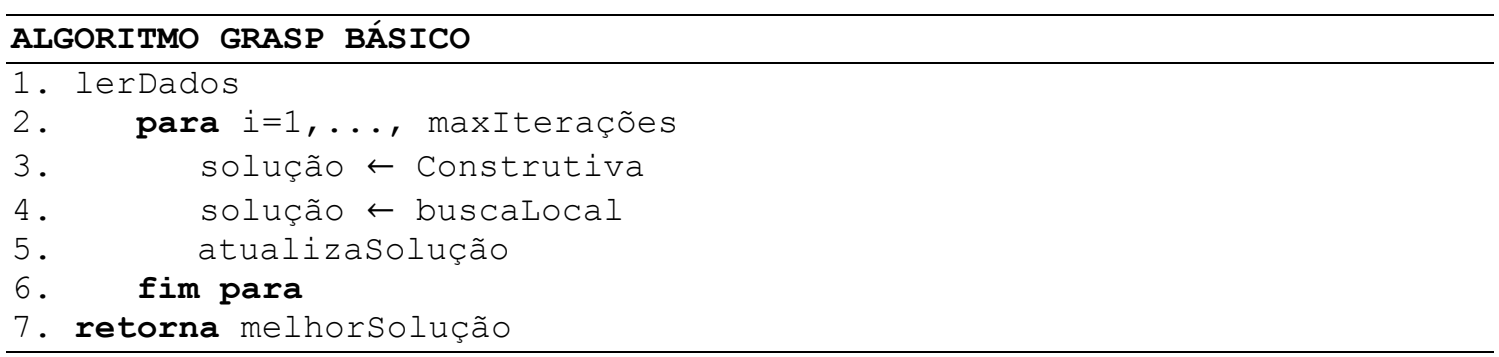

Figura 3.8 - Pseudocódigo GRASP Básico adaptado de Resende; Ribeiro (2003a).

O algoritmo da fase construtiva pode ser exemplificado da seguinte forma: suponha que a lista restrita de candidatos trabalha com três elementos, e que foi utilizado um critério de ordenação qualquer, e assim obtida a seguinte sequência gulosa: 
$\left\{j_{1}, j_{7}, j_{9}, j_{10}, j_{5}\right\}$

\begin{tabular}{|c|c|}
\hline $\begin{array}{l}\text { Iteração } 1 \\
R C L=\{j 1, j 7, j 9\} \\
\text { Tarefa sorteada }=j 7\end{array}$ & Solução Parcial $\{j 7\}$ \\
\hline $\begin{array}{l}\text { Iteração } 2 \\
R C L=\{j 1, j 9, j 10\} \\
\text { Tarefa sorteada }=j 10\end{array}$ & Solução Parcial \{j7, j10\} \\
\hline $\begin{array}{l}\text { Iteração } 3 \\
R C L=\{j 1, j 9, j 5\} \\
\text { Tarefa sorteada = j1 }\end{array}$ & Solução Parcial $\{j 1$, j7, j10\} \\
\hline $\begin{array}{l}\text { Iteração } 4 \\
R C L=\{j 9, j 5\} \\
\text { Tarefa sorteada }=j 9\end{array}$ & Solução Parcial \{j9, j1, j7, j10\} \\
\hline $\begin{array}{l}\text { Iteração } 5 \\
R C L=\{j 5\} \\
\text { Tarefa sorteada }=\mathrm{j} 5\end{array}$ & Solução Completa $\{j 9$, j1, j5, j7, j10\} \\
\hline
\end{tabular}

Figura 3.9 - Exemplo de Lista Restrita de Candidatos

$\mathrm{Na}$ busca local, é tentado melhorar a solução da fase construtiva, até que uma solução ótima local é atingida (linha 4 da figura 3.8).

\subsubsection{Descrição do GRASP Proposto}

Para o presente trabalho foi realizada uma implementação da heurística GRASP e, posteriormente, adicionou-se o mecanismo de path relinking. A versão inicial segue a estrutura apresentada na figura 3.10.

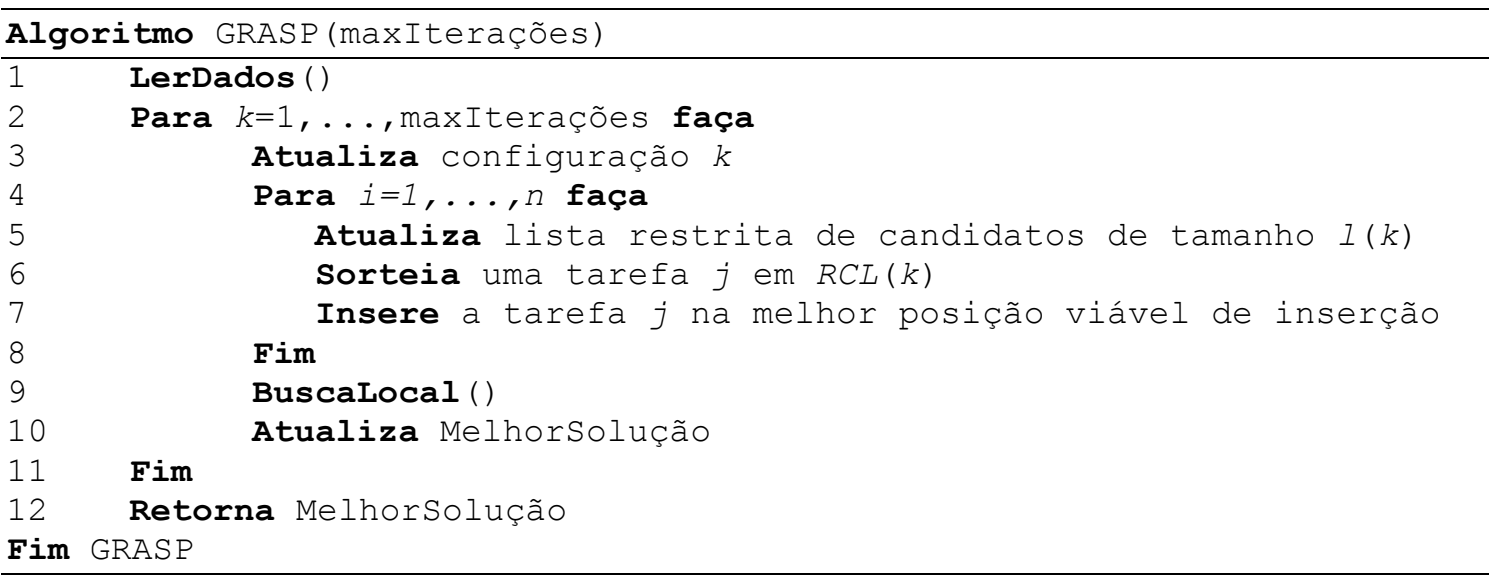

Figura 3.10 - Pseudocódigo GRASP Proposto. 
Em cada iteração será atualizada uma determinada "configuração" do algoritmo. Esta configuração consiste em três elementos: o tamanho da lista restrita de candidatos $(l)$, a regra de ordenação que será aplicada às tarefas, e a atualização da semente do gerador de número aleatório. Quanto ao tamanho da lista restrita, os seguintes valores serão adotados: 2, 3, 4, 5, 6 e $n$. Isto permitirá trabalhar com regras aproximadamente gulosas (quando $l=2$ ), ou com busca totalmente aleatória (quando $l=n)$.

Quanto à regra de ordenação, ao invés de usar uma regra dinâmica em que, após um determinado sorteio as tarefas remanescentes sejam reclassificadas, optou-se por utilizar uma regra fixa de ordenação. Desta forma, quando uma tarefa pertencente à lista restrita é escolhida, a próxima tarefa a compor a lista restrita já será conhecida. Seis regras de ordenação das tarefas foram testadas, sendo que cada regra possui dois critérios de ordenação. Em caso de empate após a aplicação do primeiro critério, o segundo critério servirá para desempatar. Se persistir o empate, então as tarefas serão ordenadas pelo seu índice. As regras desenvolvidas foram:

(1) Menor Compatibilidade e Menor Instante de Liberação;

(2) Menor Compatibilidade e Maior Penalidade;

(3) Menor Instante de Liberação e Menor Compatibilidade;

(4) Menor Instante de Liberação e Maior Penalidade;

(5) Maior Penalidade e Menor Instante de Liberação;

(6) Maior Penalidade e Menor Compatibilidade.

A ideia de utilizar "menor compatibilidade" é para que tarefas com poucos navios compatíveis, isto é, aptos para realizarem o serviço, sejam priorizadas, de forma a facilitar a geração de soluções viáveis. Quanto à semente, para cada combinação acima descrita (tamanho de lista restrita e regra de ordenação), serão testadas 100 diferentes sementes, perfazendo um total de 6 × 6 x $100=3.600$ iterações. 
Após a leitura dos dados na linha 1, a configuração da iteração é atualizada, e a fase construtiva é aplicada entre as linhas 4 e 8 , até que todas as tarefas tenham sido programadas. Cabe destacar que, após a atualização da lista restrita (linha 5) e o sorteio da próxima tarefa a ser programada (linha 6), realiza-se um procedimento, descrito na linha 7, de identificação da melhor posição de inserção. Isto consiste em testar, para cada embarcação compatível com a tarefa sorteada, todas as possíveis posições de inserção, verificando aquela que gera o menor acréscimo de custo à solução parcialmente gerada.

Após alocar todas as tarefas, uma rotina de busca local é chamada na linha 9. Esta rotina aplica os operadores de inserção (relocate) e troca (swap), descritas anteriormente neste capítulo. O primeiro operador remove a tarefa de sua posição atual e insere-a em todas as demais posições das embarcações compatíveis. O segundo operador realiza a troca entre cada par de tarefas, entre embarcações que sejam compatíveis. Em cada iteração da busca, realiza-se o movimento que proporciona a maior redução na função objetivo. Quando nenhuma melhoria for encontrada, uma solução ótima local com relação às vizinhanças de troca e inserção terá sido encontrada e o algoritmo encerra.

Por último, caso a solução gerada seja melhor que a "MelhorSolução", esta é atualizada. O GRASP continua até que o limite de iterações dado por "maxIterações" seja atingido.

\subsubsection{Heurística Path Relinking}

A heurística path relinking ou (reconexão por caminhos), descrita originalmente por Glover (1996), e também em Glover et al. (2000), consiste em explorar o caminho ou trajetória entre duas soluções, uma denominada de solução inicial e a outra de solução guia. Em cada iteração é realizado um movimento na solução inicial, com o objetivo de aproximá-la da solução guia. Isto implica em introduzir atributos encontrados na solução guia na solução inicial, até que ambas as soluções sejam iguais. Esta trajetória pode ser compreendida como um processo que faz um balanço entre intensificação e diversificação, que é importante por permitir explorar o espaço de solução no caminho de aproximação entre as duas soluções. É possível que, 
ao longo deste processo, um novo ótimo local seja alcançado, conforme ilustra a figura 3.11 , onde a solução inicial é dada por $x^{\prime}$ e a solução guia $x^{\prime \prime}$. Para chegar de $x^{\prime}$ a $x^{\prime \prime}$ são produzidas novas soluções: $x^{\prime}=x(1), x(2), \ldots, x(r)=x^{\prime \prime}$, indicada pela linha pontilhada.

Ho; Gendreau (2006) destacam alguns componentes considerados críticos para a implementação do path relinking, como a forma que será construída o conjunto de elite (referência), o critério de escolha da solução inicial e da solução guia. Todas estas escolhas afetam o caminho que o algoritmo irá explorar.

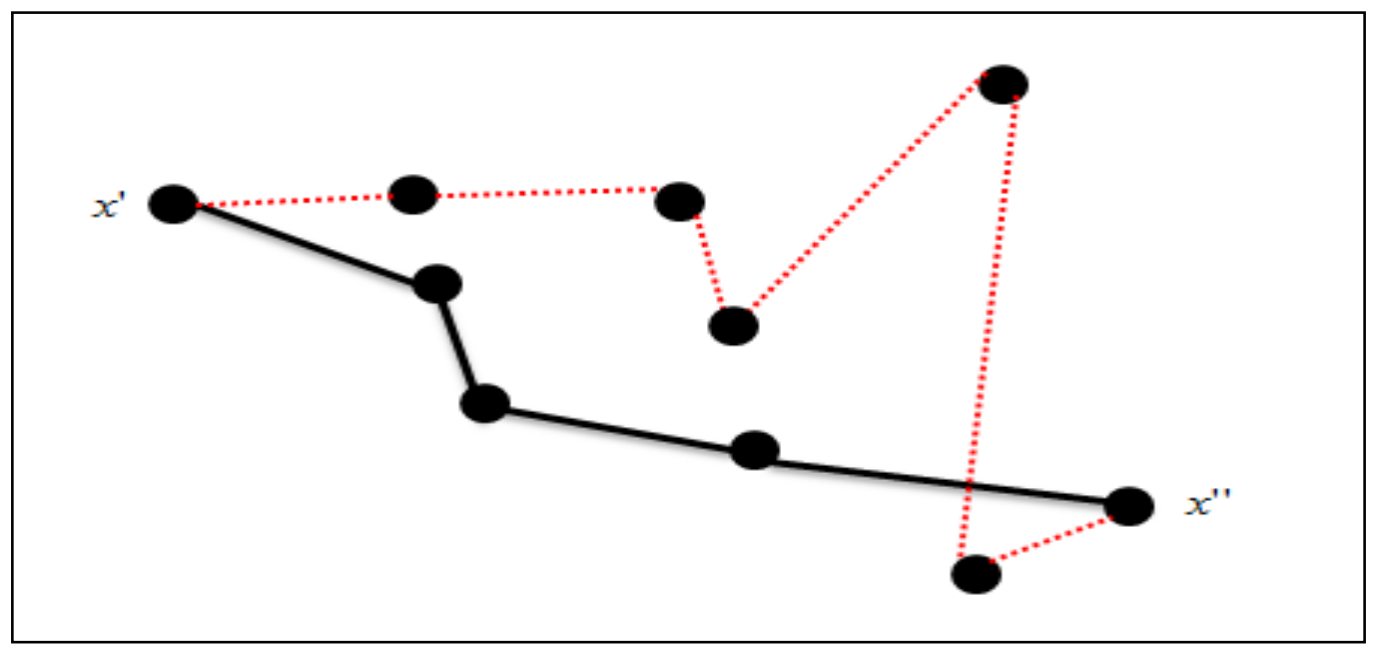

Figura 3.11 - Path Relinking: caminho original denotado pela linha contínua e uma possibilidade de reconexão pela linha pontilhada. Adaptado de Glover et al. (2000).

O path relinking possui atributos ou formas distintas de implementação. Resende et al. (2010a) discutem a "atualização estática", em que o conjunto de elite é preenchido e atualizado ao longo das iterações da aplicação do GRASP. Ao final, o path relinking é aplicado entre as soluções de elite, com o intuito de explorar o espaço que há entre cada par de soluções de elite. Na "atualização dinâmica”, para cada solução gerada pelo GRASP escolhe-se, aleatoriamente, uma solução dentre o conjunto de elite, e o path relinking é aplicado. Em ambas as estratégias (estática ou dinâmica), a solução resultante é sempre submetida a um processo de busca local.

Resende; Werneck (2004) mesclaram estas duas estratégias. Ao longo das iterações, toda solução gerada foi submetida ao path relinking. E, ao final, a trajetória 
entre cada par de soluções do conjunto de elite foi explorada, usando uma estratégia evolucionária, denominada de EvPR (Evolutionary Path Relinking): cada nova solução gerada pelo path relinking, após passar por determinados critérios de aceitação, era adicionada a uma nova população de soluções. As gerações são sucessivamente criadas com a aplicação do path relinking, até que nenhum indivíduo gerado seja capaz de melhorar a solução global.

Resende; Ribeiro (2003b) destacam outras variações importantes: Forward Relinking: a trajetória é construída partindo da solução inicial $x^{\prime}$, até alcançar a solução guia $x^{\prime \prime}$; Backward Relinking: esta estratégia é o inverso da anterior, ou seja, a solução inicial neste caso é $x^{\prime \prime}$ e a guia $x^{\prime}$; Mixed Relinking: duas trajetórias são simultaneamente exploradas, a primeira iniciando em $x^{\prime}$ e a segunda em $x^{\prime \prime}$, até que se encontrem.

Em Resende et al. (2010b) é discutido o Randomized Path Relinking (RPR). A versão usual do path relinking adota um critério guloso na escolha do melhor movimento em cada iteração, na construção da trajetória que ligará a solução inicial à guia. Isto faz com que, certamente, um único caminho seja gerado, o que poderá impedir a obtenção de soluções melhores. O RPR introduz uma lista restrita de candidatos, na qual os melhores movimentos são inseridos e um deles, aleatoriamente, é escolhido. Isto garante que trajetórias diferentes serão geradas, aumentando a possibilidade de atingir novas soluções, eventualmente, de boa qualidade.

Ribeiro; Rosseti (2007), Ribeiro et al. (2009) trabalharam a ideia conhecida como time-to-target solution, em que é determinada a probabilidade de o algoritmo encontrar uma solução igual ou superior a uma dada solução (target solution) dentro de um determinado tempo. Os autores também abordam estratégias de implementação paralela em metaheurísticas com o objetivo de acelerar a busca e resolver problemas grandes. Duas abordagens foram apresentadas: a paralelização independente, em que os threads não trocam nenhuma informação e a paralelização cooperativa onde a informação é compartilhada e usada pelos outros threads.

A versão implementada do path relinking, apresentada na figura 3.12, utiliza a estratégia de "atualização dinâmica", ou seja, cada solução gerada pelo GRASP é 
combinada com uma solução sorteada dentre o conjunto de soluções de elite e é submetida à rotina de path relinking. Este procedimento só será realizado após o conjunto de elite estar totalmente preenchido. Na presente implementação, adotou-se um conjunto de elite com tamanho igual a 10.

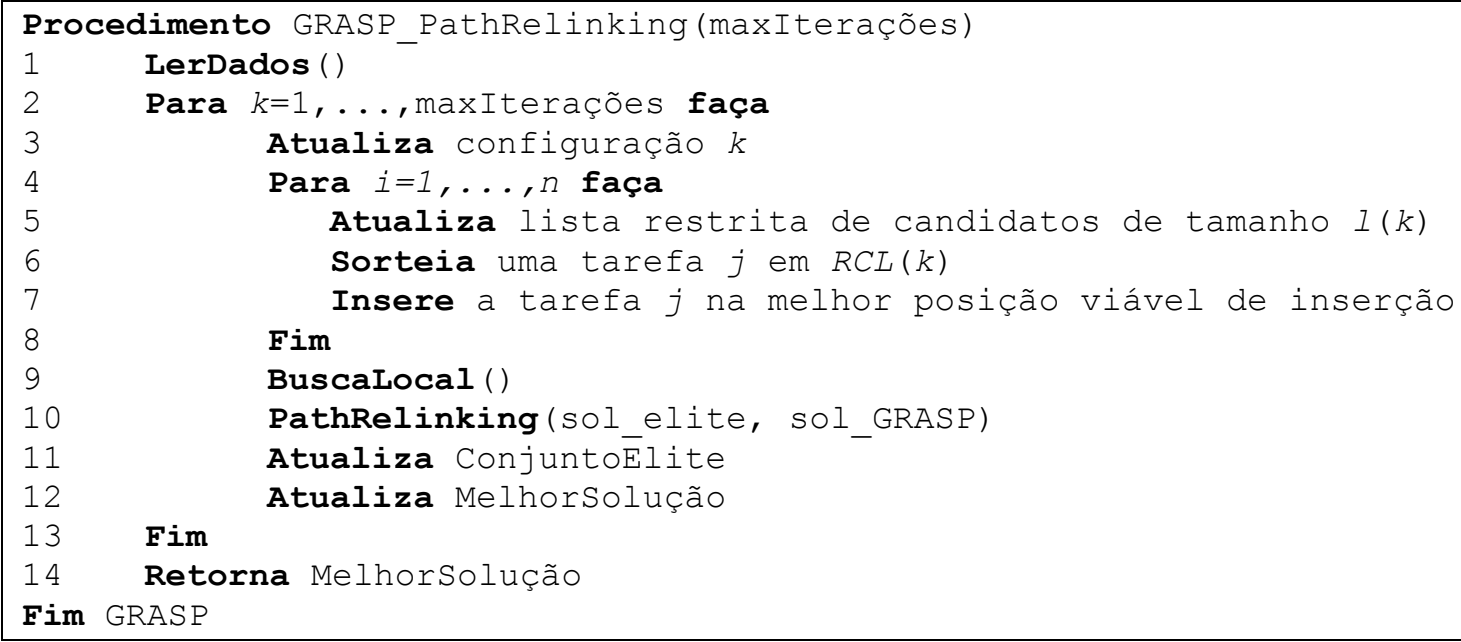

Figura 3.12 - Estrutura básica do GRASP com Path Relinking

A rotina do path relinking inicia ajustando as soluções de referências (inicial e guia), dependendo da estratégia escolhida (forward, backward, mixed). Se for a estratégia backward ou mixed, a solução guia será o ponto de partida, isto é, o algoritmo será iniciado pela melhor solução a qual é progressivamente modificado, até que a outra solução seja atingida. No caso da estratégia forward, a busca ocorre da pior solução para a melhor solução.

É importante destacar que o presente problema envolve diferentes embarcações. Esta característica torna imprescindível a resolução de um problema de pareamento (matching), semelhante do que foi proposto por Ho; Gendreau (2006). Isto consiste em identificar qual a sequência da solução guia que é mais próxima de uma dada sequência da solução inicial. Após todas as sequências da solução inicial ser avaliadas, aplica-se um critério guloso, estabelecendo o pareamento às sequências mais similares, até que todas as sequência recebam a indicação de uma sequência equivalente.

A aplicação do path relinking consistirá em realizar os movimentos que inserem as tarefas que estão fora de suas sequência correspondentes (na solução guia), 
na solução inicial. Isto pode ser feito tanto por meio de um movimento de inserção (relocate), quanto por meio de um movimento de troca (swap) entre duas tarefas. Após todos os possíveis movimentos serem avaliados, o melhor movimento será executado. É importante lembrar que o melhor movimento poderá piorar o valor da função objetivo.

Outro aspecto a ser comentado é que uma tarefa, ao ser transferida para uma nova sequência, é posicionada na melhor posição de inserção. Contudo, após todas as tarefas terem sido enviadas às sequências correspondentes da solução guia, pode acontecer que algumas tarefas não estejam nas mesmas posições que em suas sequência de referência. Então, um procedimento de inserção/remoção intrínseco à sequência é realizado, reposicionando as tarefas, uma a uma, até que as soluções inicial e guia sejam iguais.

Se a estratégia do path relinking for a mixed, então duas trajetórias serão exploradas, uma a partir de cada solução. Neste caso, uma forma eficiente de implementação é a inversão, a cada iteração, de quem é a solução inicial e quem é a guia, conforme sugerido por Resende et al. (2010b).

Por último, a versão Randomized Path Relinking (RPR) consiste em não necessariamente adotar o melhor movimento possível a partir de um dado estágio do path relinking. Antes, os custos associados aos movimentos são ordenados em ordem crescente do acréscimo causado na função objetivo. Seja $z_{\min }$ o custo do movimento que proporciona o menor acréscimo, e $z_{\max }$ o custo associado ao movimento que proporciona o maior acréscimo na função objetivo. Seja também $\alpha$ um número aleatório sorteado entre 0 e 1, o qual estará fixo durante uma iteração completa do path relinking. Os movimentos que estarão presentes na lista restrita serão todos aqueles cuja variação $z$ na função objetivo estejam na faixa dada por $\left[z_{\min }, z_{\min }+\alpha\left(z_{\max }-z_{\min }\right)\right]$.

Após a execução da rotina do path relinking na linha 10, o conjunto de elite é atualizado. Uma solução só será aceita no conjunto de elite se o valor da função objetivo for inferior à solução de pior qualidade pertencente ao conjunto. Quanto à determinação de qual solução que será excluída, optou-se por substituir a solução com valor da função objetivo superior à solução candidata, e que possua a menor distância a esta solução. Isto fará com que a solução mais próxima ou similar será excluída, contribuindo para 
aumento da diversidade entre as soluções de elite. A medida de distância entre duas soluções é dada pelo número de vezes que uma tarefa possui uma tarefa sucessora diferente do que acontece na outra solução.

Na presente implementação, foi testada a execução simultânea de múltiplas trajetórias com suporte de processamento multi-threading. Na linha 10 (figura 3.12) seis trajetórias serão exploradas, no caminho de aproximação entre a solução inicial e guia, a saber: path relinking forward, path relinking backward, path relinking mixed, path relinking randomized forward, path relinking randomized backward e path relinking randomized mixed. 


\section{TESTES COMPUTACIONAIS E RESULTADOS}

Este capítulo tem por objetivo apresentar os resultados dos métodos de solução propostos. Inicialmente será descrita a estrutura da base de dados utilizada para os testes e, em seguida, os resultados obtidos pela aplicação das heurísticas, comparando-as com os limitantes gerados pelo método de geração de colunas.

\subsection{Instâncias de Teste}

Foi desenvolvido um gerador de cenários baseado em Crauwels et al. (1998), disponível na OR-LIBRARY (2009), que fornece diferentes instâncias para o problema de máquina única, o qual foi devidamente adaptado para o problema em estudo. Em todos os testes realizados, foram verificados o gap das soluções obtidas, o qual foi definido como a distância relativa da função objetivo gerada pelo método geração de colunas em relação à função objetivo da melhor solução obtida, calculado da forma indicada pela expressão 4.1, onde QM= Função objetivo do método empregado; GC = Função objetivo do método geração de colunas.

$$
G A P=100(Q M-G C) / Q M
$$

Os problemas teste foram gerados da seguinte forma: para cada tarefa $j$ um tempo de processamento $p_{j}$ inteiro foi gerado empregando-se uma distribuição uniforme no intervalo $[1,100] \mathrm{e}$, para a penalidade, utilizou-se a faixa $[1,10]$. O horizonte de planejamento é denotado por $\frac{\sum_{j=1}^{n} p_{j}}{v}$ em que $v$ é o número de embarcações. A dificuldade do problema depende do fator RDD (Relative Range of Due Dates) e do TF (tardiness factor). Os valores de RDD e TF são $\{0,2 ; 0,4 ; 0,6 ; 0,8 ; 1,0\}$. O instante de liberação é calculado em duas etapas:

$$
\begin{aligned}
& d p_{j}=\left[\sum_{j=1}^{n} p_{j}(1-R D D / 2), \sum_{j=1}^{n} p_{j}(1+R D D / 2)\right] \\
& r_{j}=\max \left(0, d p_{j}-\left(\min _{k=1}^{n}\left\{d p_{k}\right\}\right)\right)
\end{aligned}
$$

$\mathrm{Na}$ expressão (4.2) tem-se o cálculo do fator $d p_{j}$ (instante de liberação preliminar) e, na equação (4.3) o instante de liberação efetivo. A data de finalização da tarefa (due date) é dada por $d_{j}=r_{j}+p_{j}$. Cada fator TF é combinado com todos os RDDs e feito 5 replicações, ou seja, 5 x $25=125$ instâncias teste. Foram geradas, 
portanto, 125 instâncias testes para 4 embarcações e 30 tarefas (4mx30n), 5 embarcações e 40 tarefas ( $5 m x 40 n)$ e 6 embarcações e 50 tarefas $(6 m \times 50 n)$.

\subsection{Análise dos Resultados}

Esta seção tem por objetivo apresentar os resultados dos métodos empregados para o problema de Programação da Frota de Navios PLVs. Os métodos identificados na tabela 4.1 foram implementados, usando as seguintes configurações de hardware: processador intel ${ }^{\circledR}$ Core $^{\mathrm{TM}}$ i7 $2.80 \mathrm{GHz}$ e $16374 \mathrm{MB}$ de memória RAM DDR3 SDRAM, codificado em linguagem $\mathrm{C}++$.

Tabela 4.1 - Métodos de solução

\begin{tabular}{ll}
\hline Método & Legenda Método \\
\hline Heurística Construtiva & HEU_C \\
Heurística Construtiva + Busca Local & HEU_C + BL \\
GRASP & GRASP \\
GRASP Path Relinking Multithreading & GRASP PR \\
\hline
\end{tabular}

Para analisar o desempenho dos métodos, são comparadas as soluções obtidas com a versão linear do método de geração de colunas (Mendes et al., 2010). A tabela a seguir, mostra o gap médio, mínimo e máximo em relação ao geração de colunas.

Tabela. 4.2 - Método x gap médio, mínimo e máximo

\begin{tabular}{|c|c|c|c|c|}
\hline nxm & Método & \% Gap Médio & \% Gap Mínimo & \% Gap Máximo \\
\hline \multirow{4}{*}{ 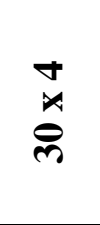 } & HEU_C & 13,22 & 1,33 & 51,55 \\
\hline & HEU_C + BL & 5,31 & 0,48 & 22,77 \\
\hline & GRASP & 1,86 & 0,03 & 12,59 \\
\hline & GRASP PR & 1,54 & $\mathbf{0 , 0 0}$ & 9,69 \\
\hline \multirow{4}{*}{$\begin{array}{l}\text { in } \\
\stackrel{x}{f}\end{array}$} & HEU_C & 15,68 & 1,65 & 60,62 \\
\hline & HEU_C + BL & 6,12 & 0,29 & 26,01 \\
\hline & GRASP & 1,96 & 0,00 & 9,96 \\
\hline & GRASP PR & $\mathbf{1 , 5 7}$ & $\mathbf{0 , 0 0}$ & 7,66 \\
\hline \multirow{4}{*}{ 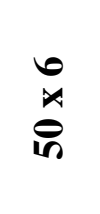 } & HEU_C & 18,93 & 1,36 & 97,61 \\
\hline & HEU_C + BL & 6,14 & 0,24 & 94,30 \\
\hline & GRASP & 1,59 & 0,01 & 8,43 \\
\hline & GRASP PR & 1,35 & $\mathbf{0 , 0 2}$ & 6,23 \\
\hline
\end{tabular}


Tabela. 4.3 - Método x tempo médio de processamento

\begin{tabular}{|l|c|c|c|}
\hline \multicolumn{4}{|c|}{ Tempo médio de processamento [Segundos] } \\
\hline \multirow{2}{*}{ Método } & \multicolumn{3}{|c|}{ n;m } \\
\cline { 2 - 4 } & $\mathbf{3 0} \times \mathbf{4}$ & $\mathbf{4 0} \times \mathbf{5}$ & $\mathbf{5 0} \times \mathbf{6}$ \\
\hline HEU_C & 0,013 & 0,017 & 0,02 \\
\hline HEU_C + BL & 0,039 & 0,096 & 0,196 \\
\hline GRASP & 52,385 & 150,737 & 332,142 \\
\hline GRASP PR & 84,745 & 211,255 & 447,815 \\
\hline
\end{tabular}

Inicialmente, as instâncias foram avaliadas por meio da heurística construtiva HEU_C. Os resultados obtidos estão resumidos na tabela 4.2, na qual fica evidente a baixa qualidade da solução, expressa pelos gaps médios iguais a 13,22\%, 15,68\% e $18,93 \%$, respectivamente para 30, 40 e 50 tarefas. As figuras 4.1, 4.2 e 4.3 mostram a dispersão do gap, ressaltando que em poucas ocorrências a heurística gerou bons resultados. O tempo médio de processamento foi de 0,013 segundos para as instâncias de 30 tarefas, 0,017 para as instâncias com 40 tarefas e 0,020 para as instâncias com 50 tarefas.

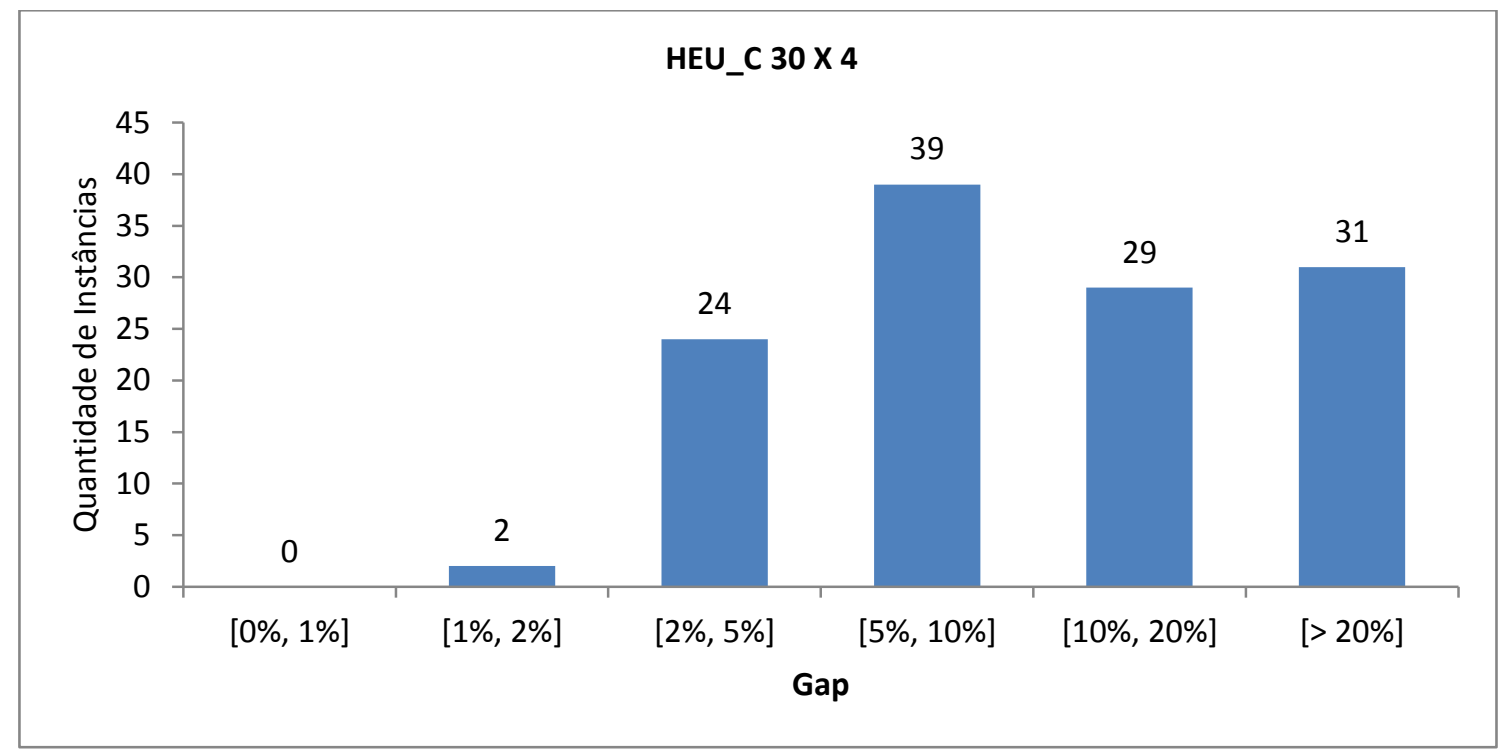

Figura 4.1 - Distribuição dos gaps para HEU_C 30 x 4 


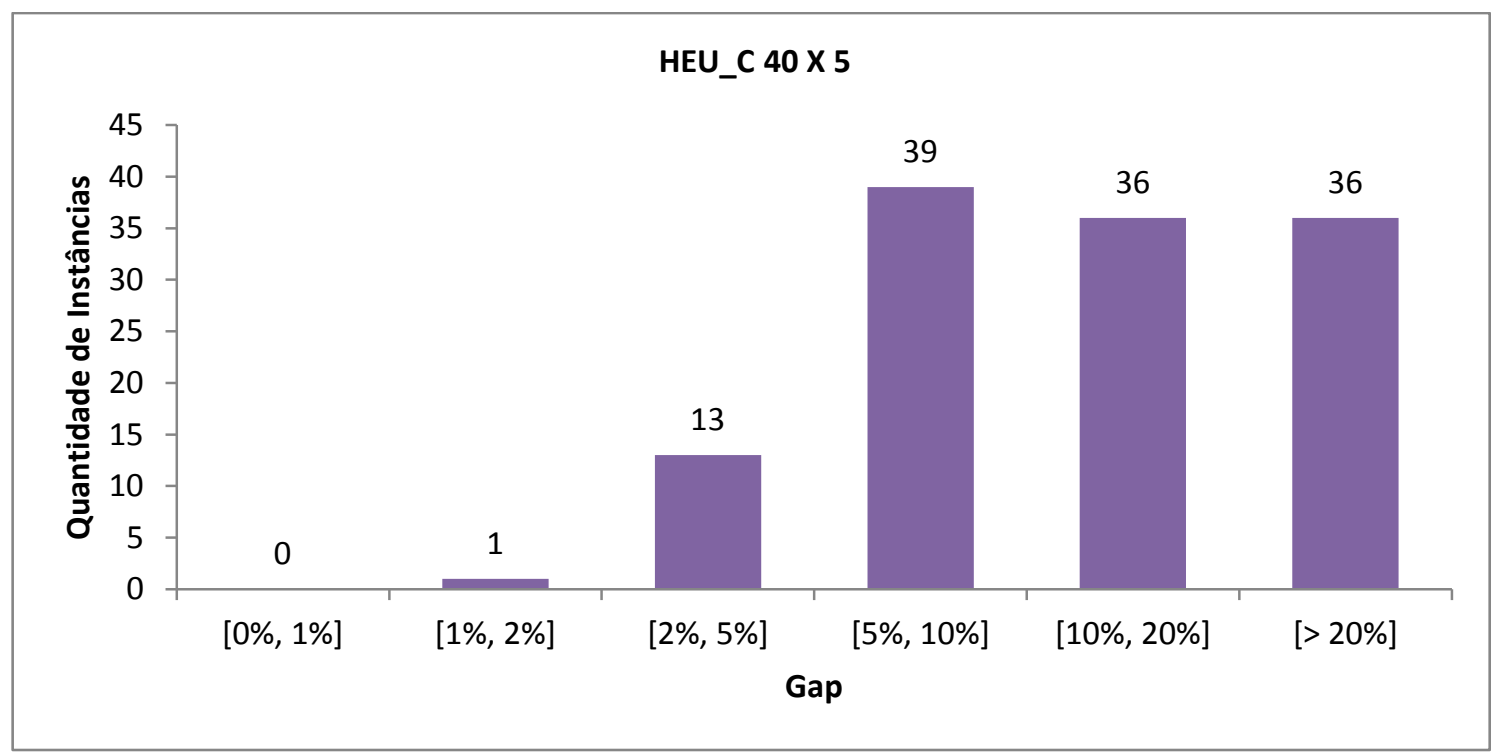

Figura 4.2 - Distribuição dos gaps para HEU_C 40 x 5

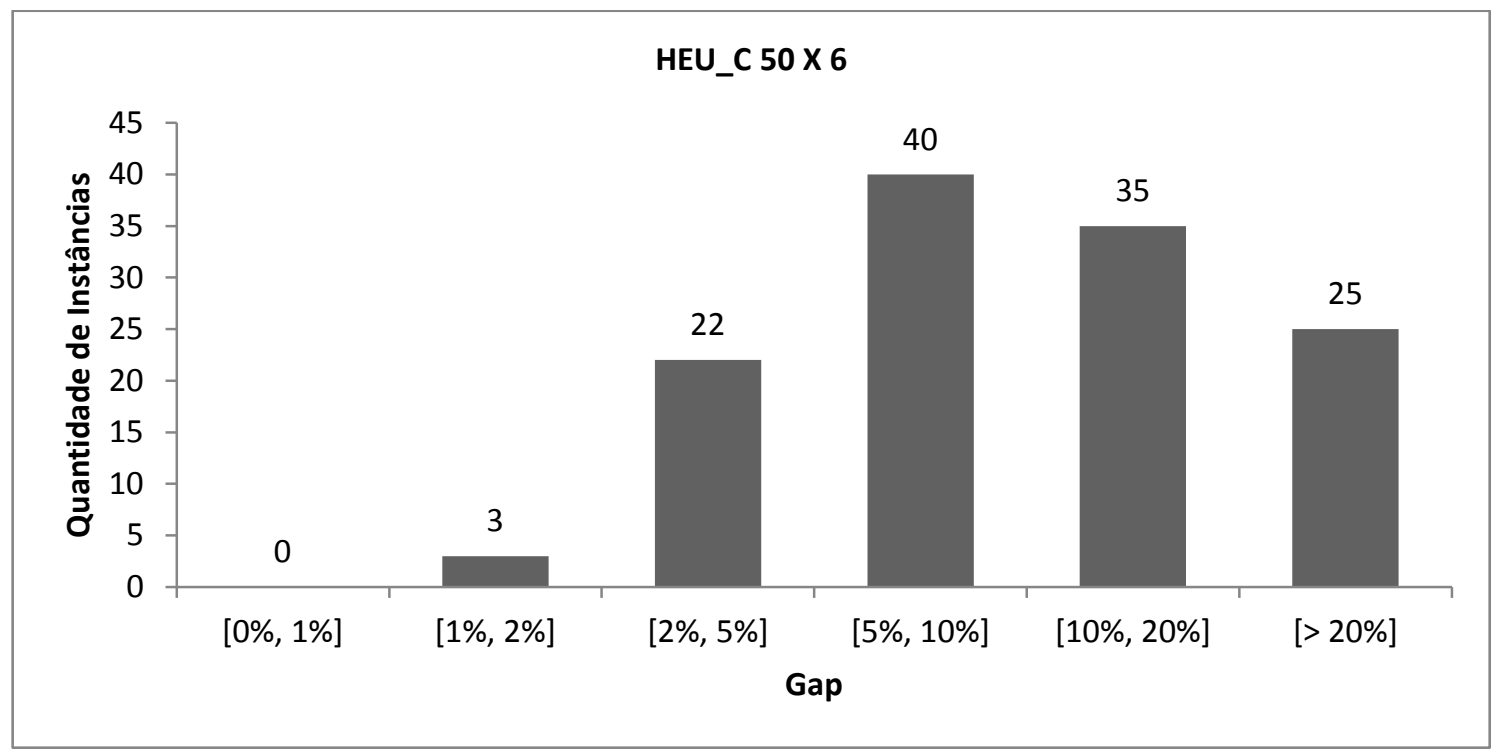

Figura 4.3 - Distribuição dos gaps para HEU_C 50 x 6

Em seguida, combinou-se a heurística construtiva com a heurística de busca, descritas nas seções 3.2.5 e 3.2.6. Os resultados estão resumidos na tabela 4.2 e mostraram uma melhoria importante, reduzindo o gap médio para 5,31\%, 6,12\% e 6,14\%, respectivamente, para instâncias de 30, 40 e 50 tarefas. As figuras 4.4, 4.5 e 4.6 mostram a dispersão do gap. No caso específico de 30 tarefas, apenas uma instância apresentou gap superior a 20\%. O tempo médio de processamento foi de 0,039 segundos para 30 tarefas, 0,096 para 40 tarefas e 0,196 segundos para 50 tarefas. 
Mesmo assim pode-se observar que 40\%, 44,80\% e 28,80\% das instâncias, respectivamente, de 30, 40 e 50 tarefas, ficaram com gaps acima de 5\%.

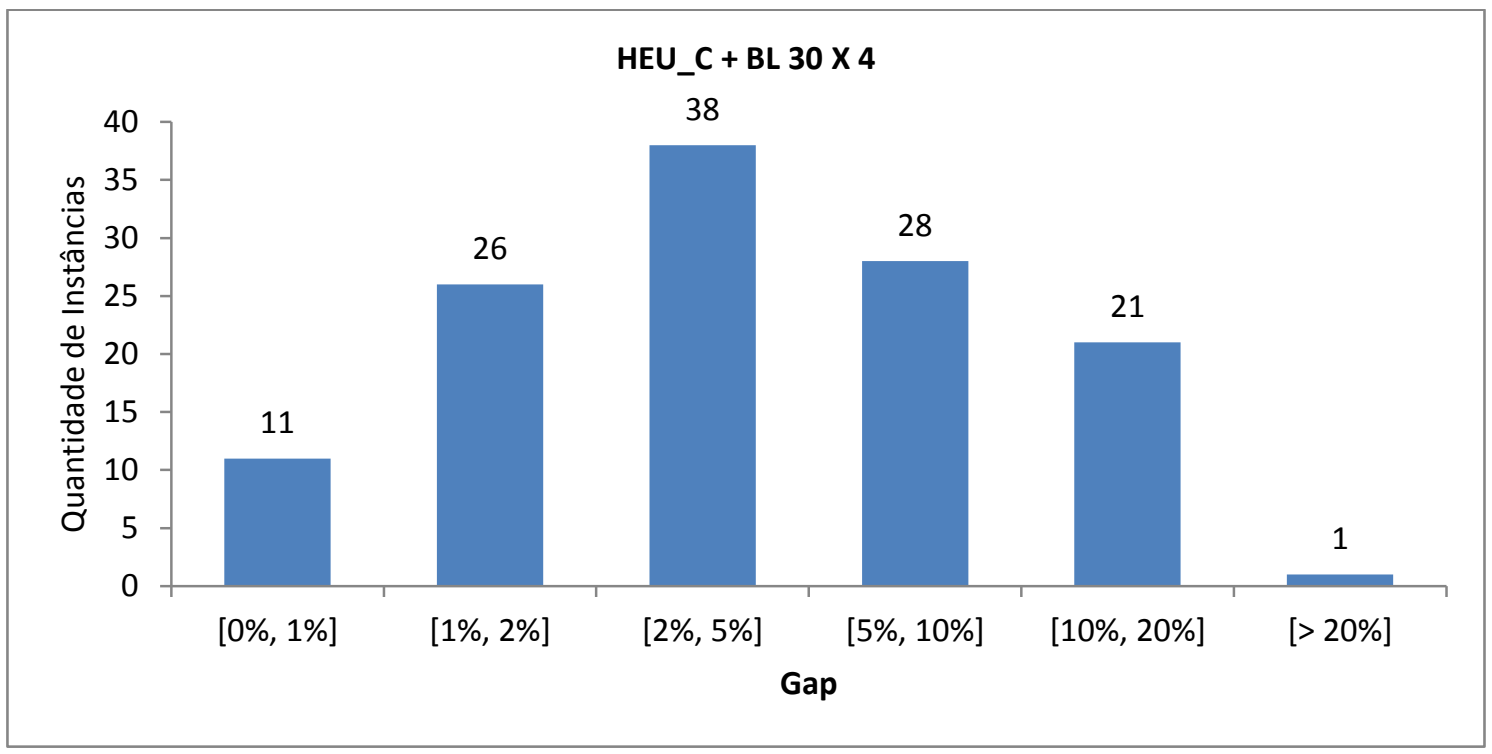

Figura 4.4 - Distribuição dos gaps para HEU_C + BL 30 x 4

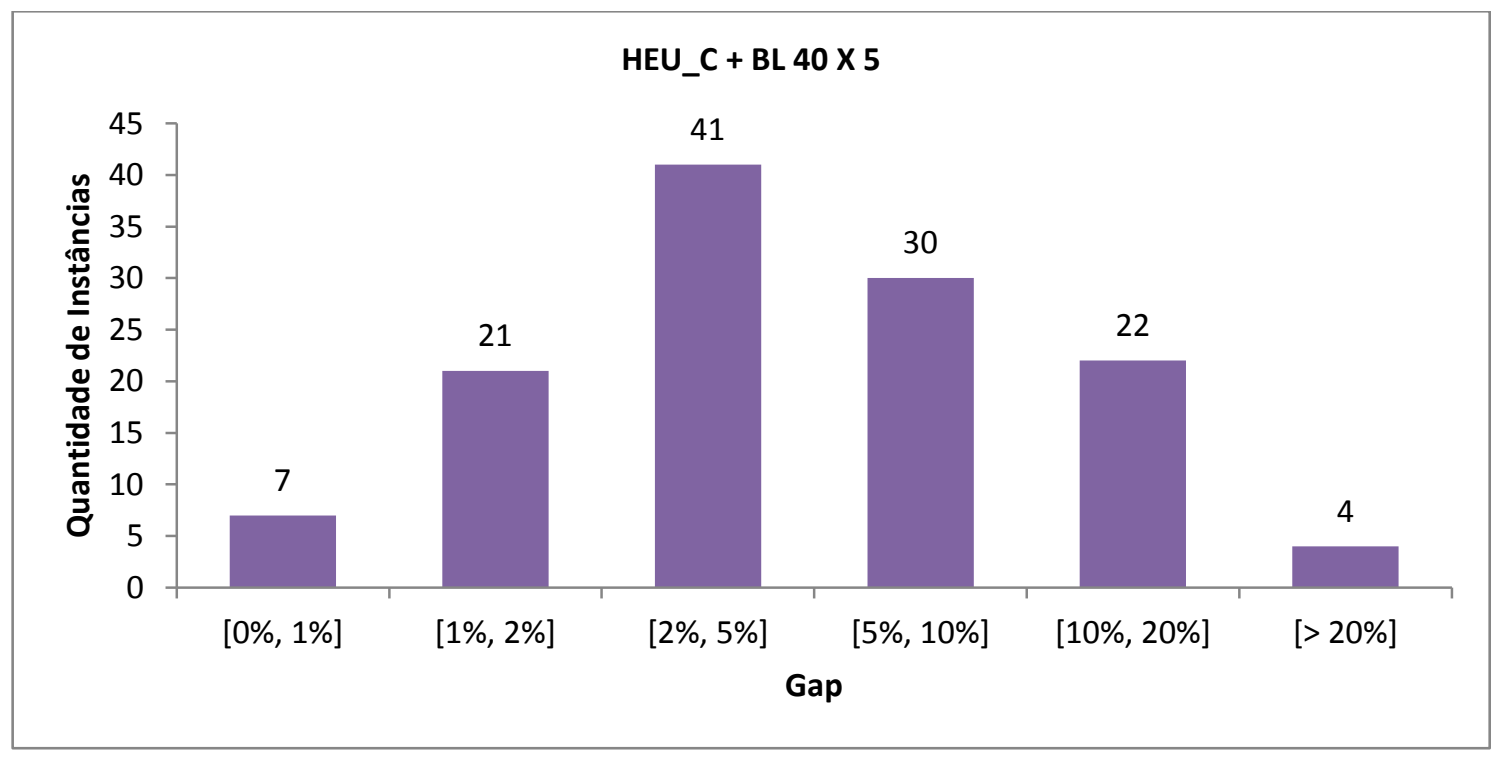

Figura 4.5 - Distribuição dos gaps para HEU_C + BL 40 x 5 


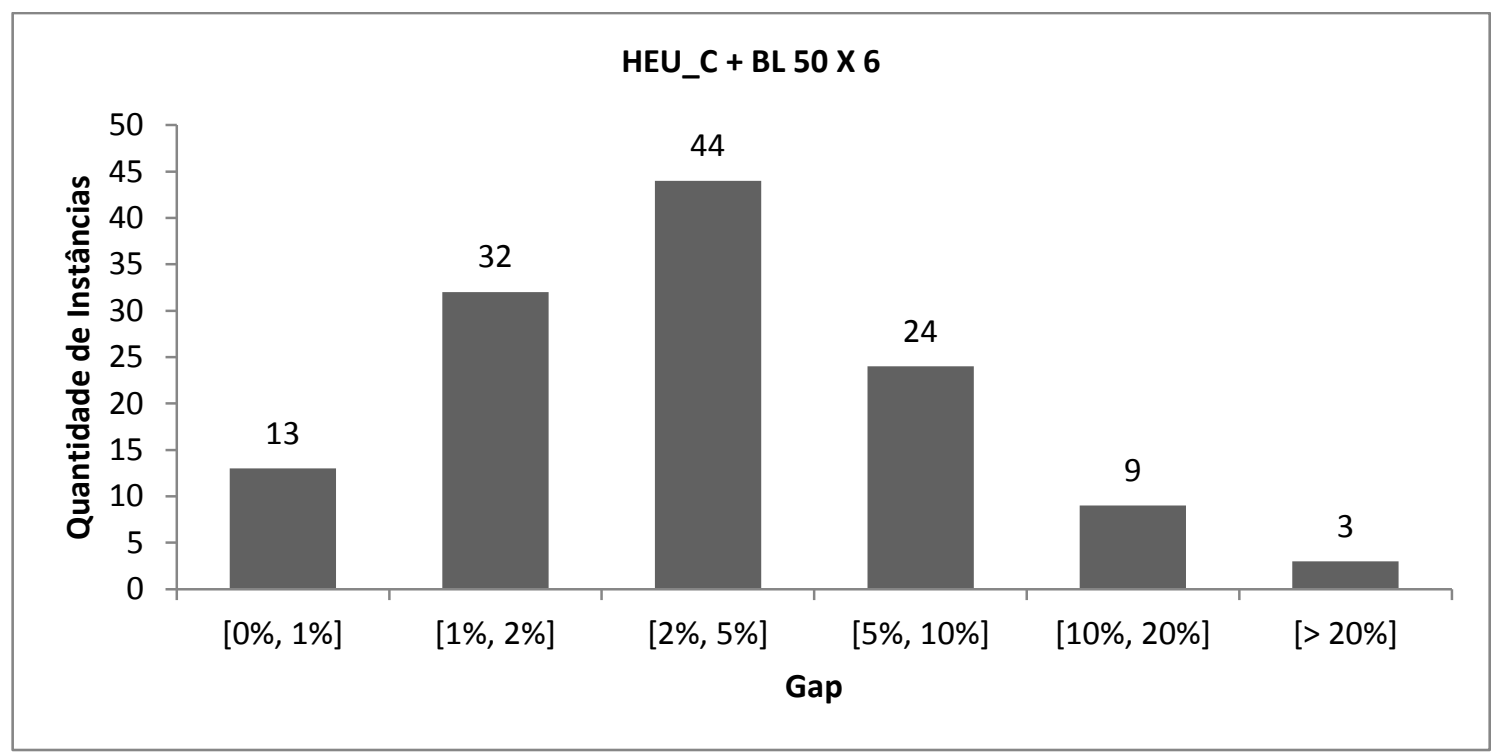

Figura 4.6 - Distribuição dos gaps para HEU_C + BL 50 x 6

Em continuidade, foi processado a metaheurística GRASP, a qual contempla, em sua estrutura, duas fases distintas: a fase construtiva e a fase de busca. Como o procedimento construtivo possui uma componente aleatória na escolha do elemento contido na lista restrita de candidatos, foram realizadas 5 replicações das 375 instâncias. São reportados os valores médios do tempo de processamento e do gap, nas tabelas 4.2 e 4.3 .

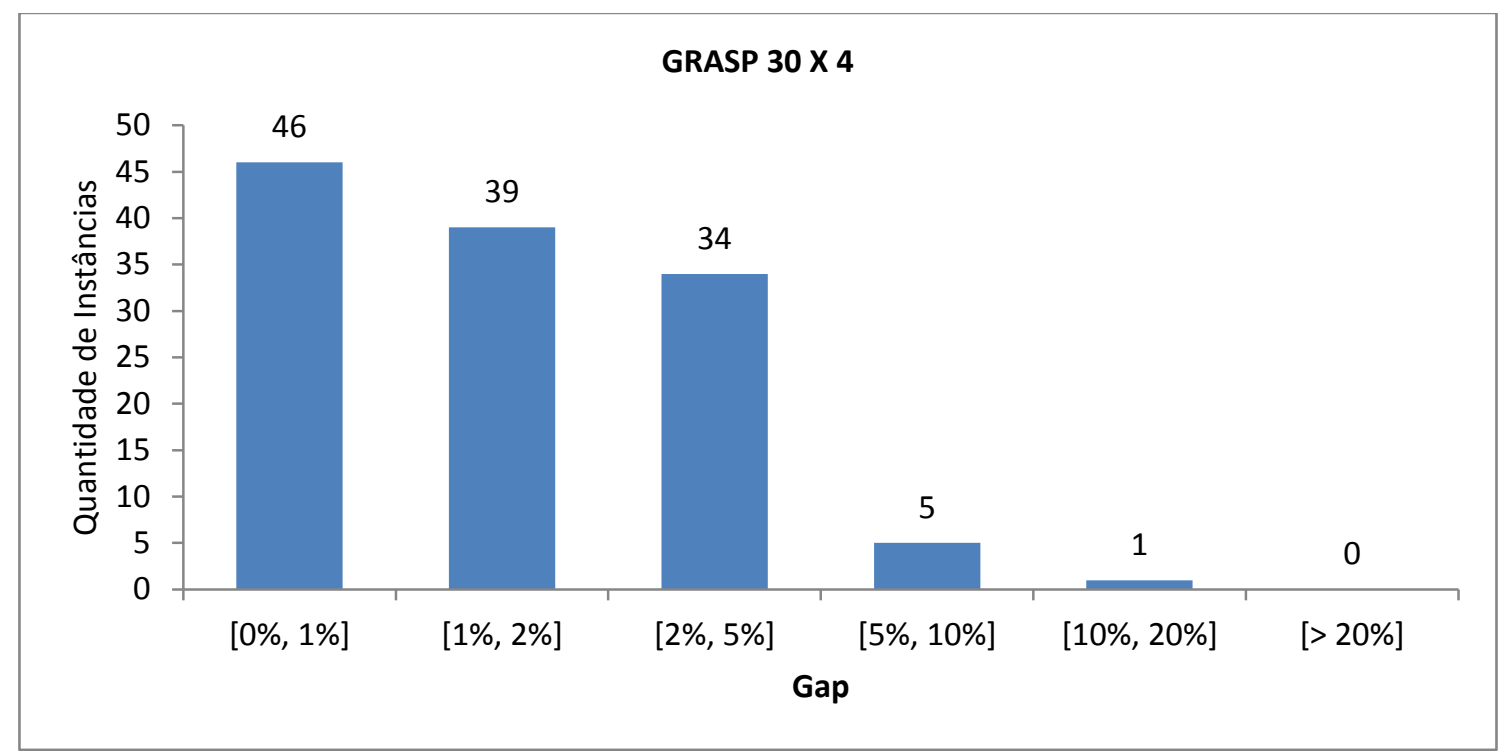

Figura 4.7 - Distribuição dos gaps para GRASP 30 x 4 


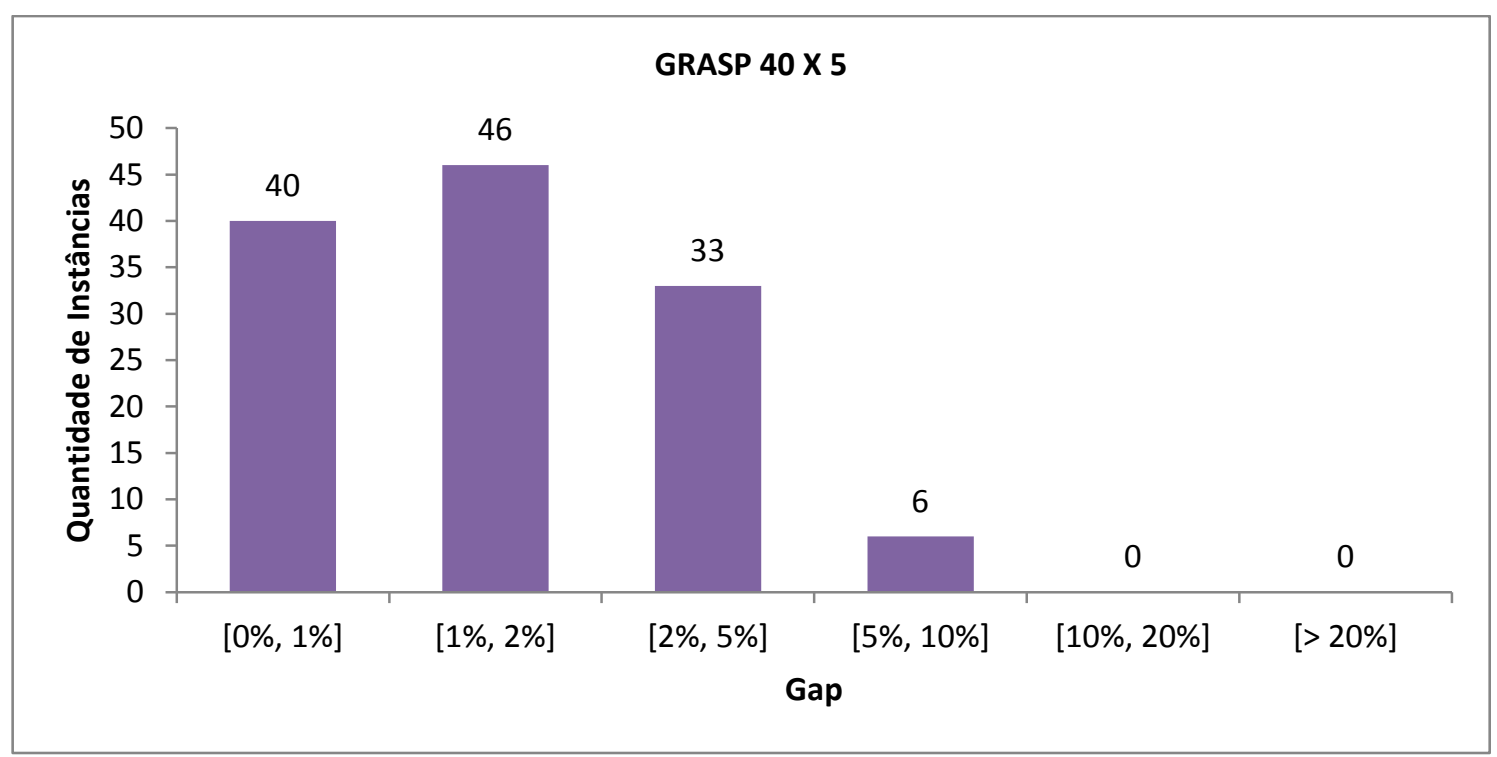

Figura 4.8 - Distribuição dos gaps para GRASP 40 x 5

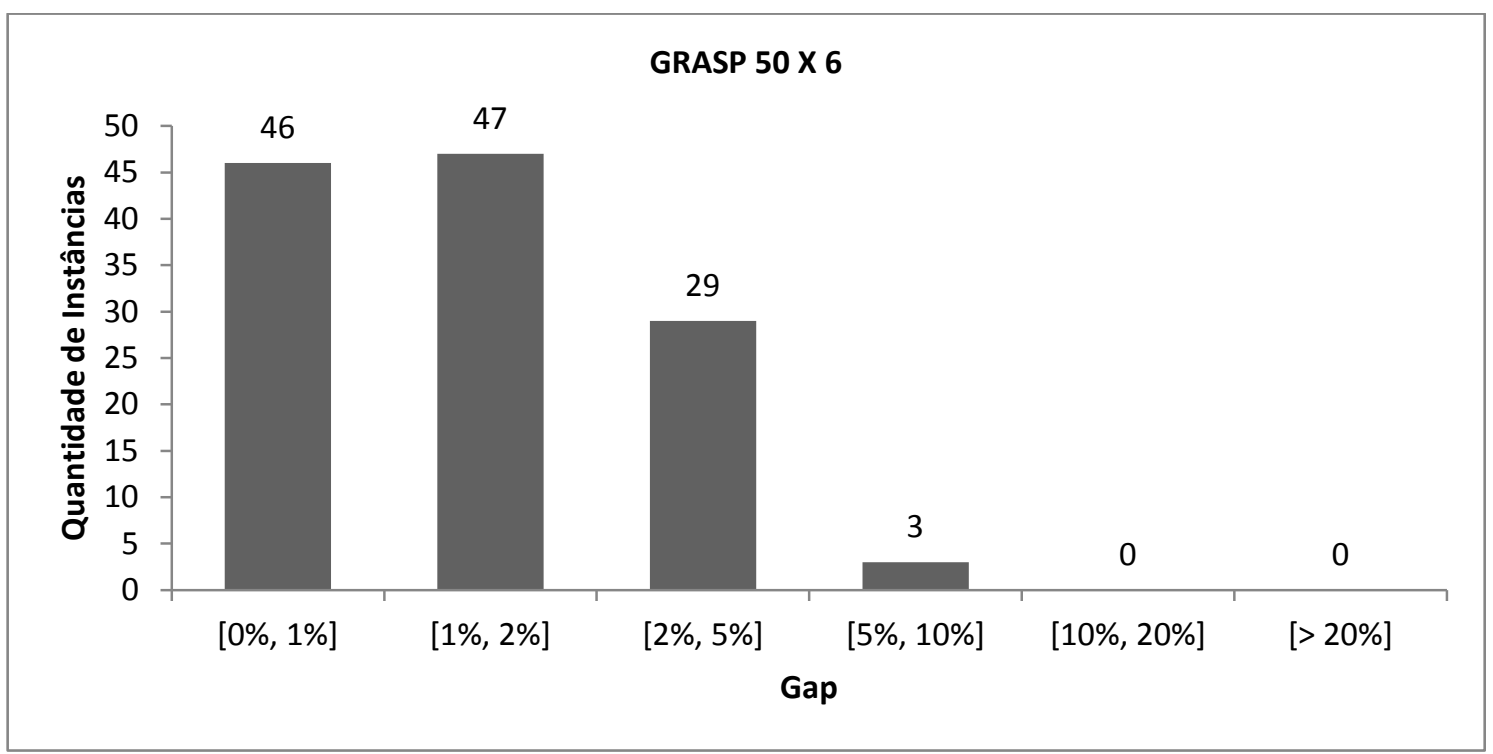

Figura 4.9 - Distribuição dos gaps para GRASP 50 x 6

Por último, foi processada a metaheurística GRASP PR, em que seis trajetórias foram exploradas, no caminho de aproximação entre a solução inicial e guia: path relinking forward, path relinking backward, path relinking mixed, path relinking randomized forward, path relinking randomized backward e path relinking randomized mixed. Os resultados indicados referem-se aos casos em que as 6 trajetórias foram exploradas ao mesmo tempo, com o suporte do recurso multi-threading de processamento. Os gaps médios que já eram bons na versão GRASP puro, foram 
melhorados, conforme a tabela 4.2. A distribuição dos gaps conforme as figuras 4.10, 4.11 e 4.12 mostra que a maior parte das instâncias possuem gap inferior a $2 \%$, sendo que apenas uma instância de 50 tarefas possui gap superior a 5\%. O tempo médio de processamento foi de 84,745 segundos para as instâncias de 30 tarefas, 211,255 segundos para as instâncias de 40 tarefas e 447,815 para as instâncias de 50 tarefas.

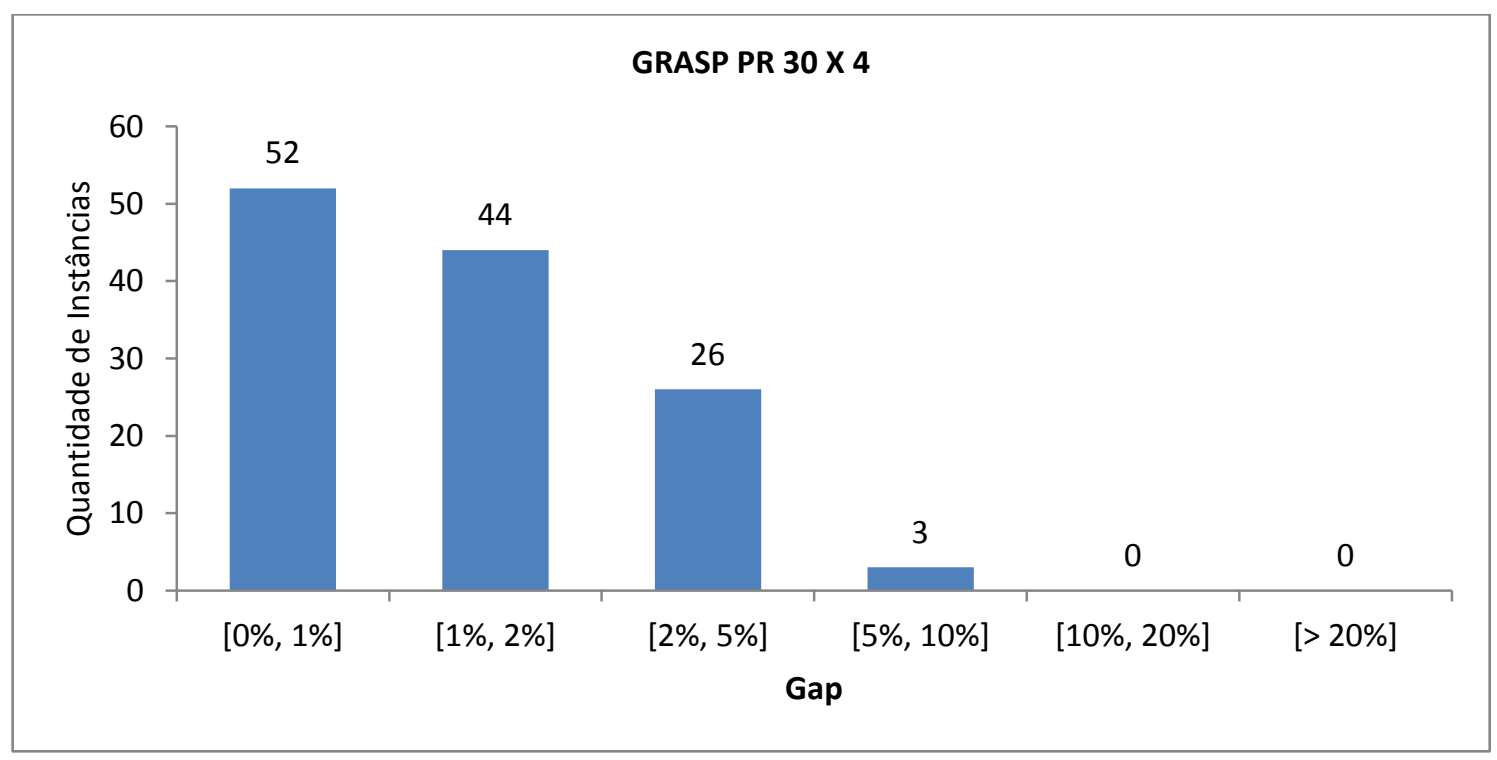

Figura 4.10 - Distribuição dos gaps para GRASP PR 30 x 4

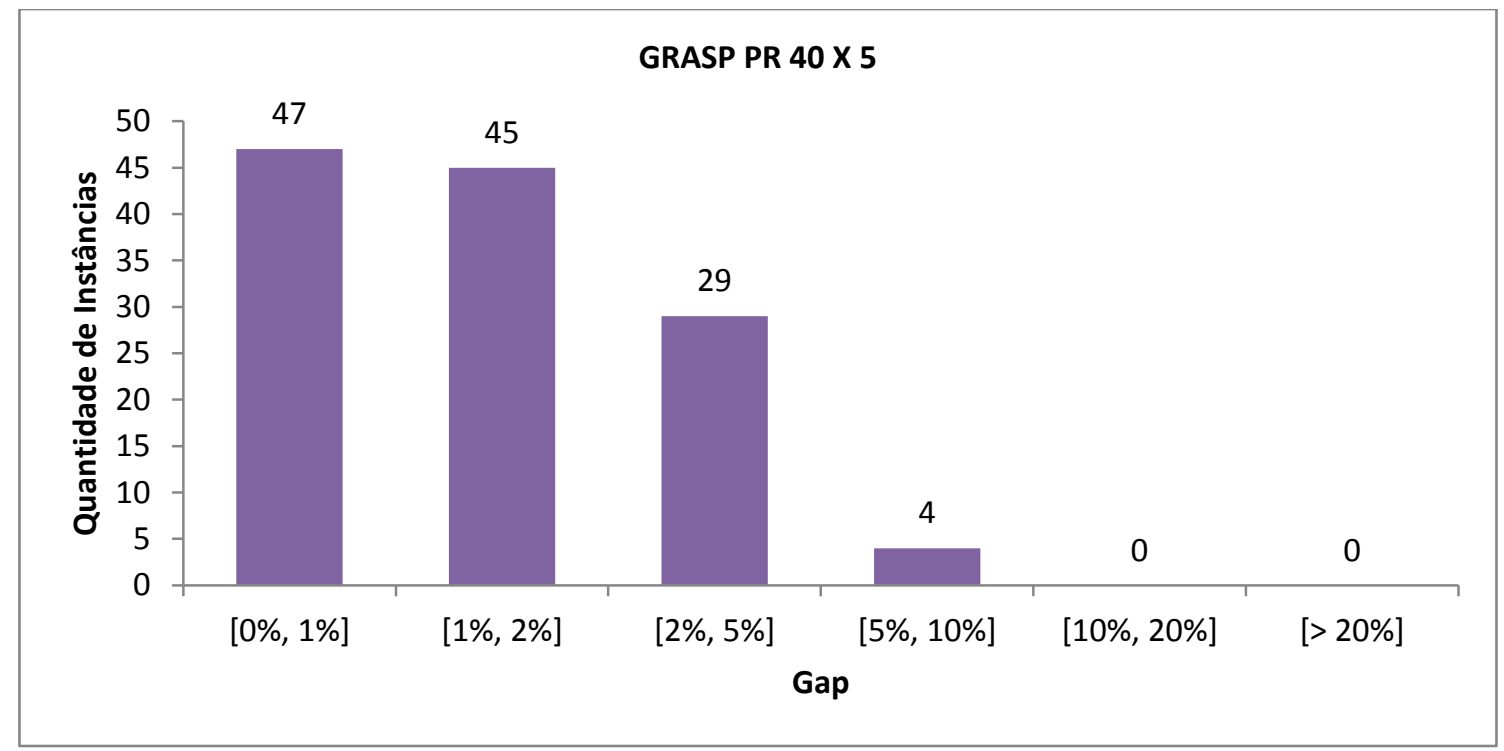

Figura 4.11 - Distribuição dos gaps para GRASP PR 40 x 5 


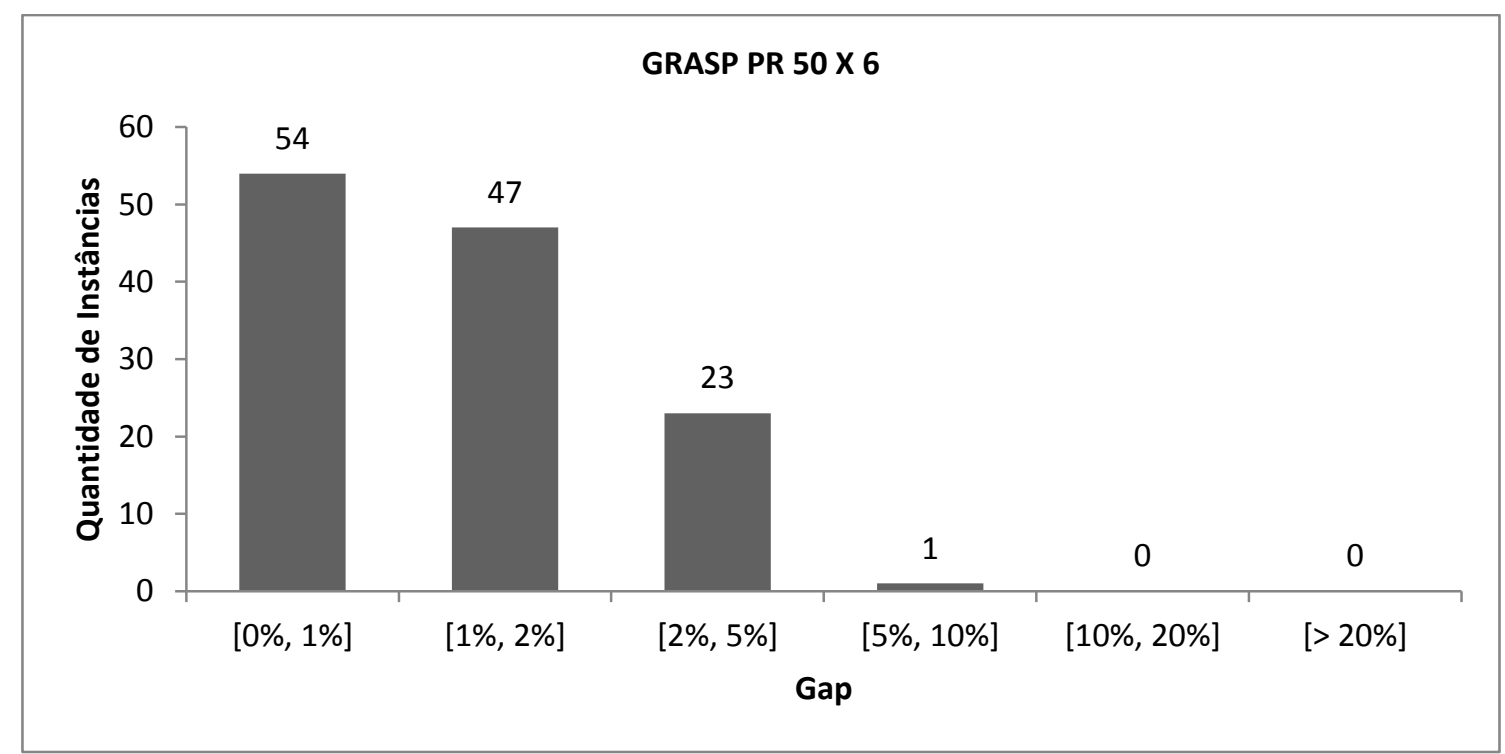

Figura 4.12 - Distribuição dos gaps para GRASP PR 50 x 6

\subsection{Discussão}

A estratégia de explorar múltiplas trajetórias simultaneamente possibilita atingir uma solução de qualidade em um tempo relativamente baixo. Esta abordagem pode ser ilustrada por meio do seguinte teste: foi selecionada uma instância e processada com as 6 trajetórias individuais (path relinking forward, path relinking backward, path relinking mixed, path relinking randomized forward, path relinking randomized backward e path relinking randomized mixed). E logo após, utilizando o processamento multi-threading. Os resultados obtidos estão destacados na tabela 4.4.

Tabela. 4.4 - Abordagem multi- threading x processamento individual

\begin{tabular}{lcc}
\hline \multicolumn{1}{c}{ Abordagem } & $\begin{array}{c}\text { Valor da Função } \\
\text { Objetivo (\$) }\end{array}$ & $\begin{array}{c}\text { Tempo } \\
\text { [Segundos] }\end{array}$ \\
\hline Multi-threading & 9390 & 89,534 \\
Path relinking forward & 9399 & 106,474 \\
Path relinking backward & 9392 & 101,76 \\
Path relinking mixed & 9401 & 110,894 \\
Path relinking randomized forward & 9403 & 113,472 \\
Path relinking randomized backward & 9398 & 108,862 \\
Path relinking randomized mixed & 9411 & 122,09 \\
\hline
\end{tabular}

De acordo com a tabela 4.4, a estratégia multi-threading consegue obter solução melhor do que o processamento individual e também empregando um tempo 
inferior. Em relação à melhor regra de ordenação, as que obtiveram as melhores soluções foram respectivamente (1), (2) e (4). Isto mostra que é vantajoso utilizar várias regras de ordenação na fase de construção do GRASP ao invés de fixar apenas uma.

A importância em mensurar o tempo que um determinado método emprega para alcançar uma dada solução é abordado em Resende; Ribeiro (2003a). Para medir o tempo que os algoritmos empregam para atingir uma solução (time-to-target value), é feita uma distribuição empírica em que é fixada uma solução a ser atingida (target value) e, em seguida, executa-se o algoritmo $T$ vezes de maneira independente, registrando o tempo que o algoritmo levou para encontrar uma solução melhor ou igual à solução fixada. Para cada algoritmo é associado ao i-ésimo tempo ordenado $t_{i} a$ probabilidade $p_{i}=\left(i-\frac{1}{2}\right) / T$ e plotam-se os pontos $z_{i}=\left(t_{i}, p_{i}\right)$ para $i=1, \ldots, T$. A figura 4.13 exemplifica uma instância em que foi processada utilizando o GRASP puro e logo após o GRASP PR com a estratégia multi-threading. É fácil perceber que o GRASP PR com multi-threading consegue atingir uma solução de qualidade com tempo muito inferior do que o GRASP puro.

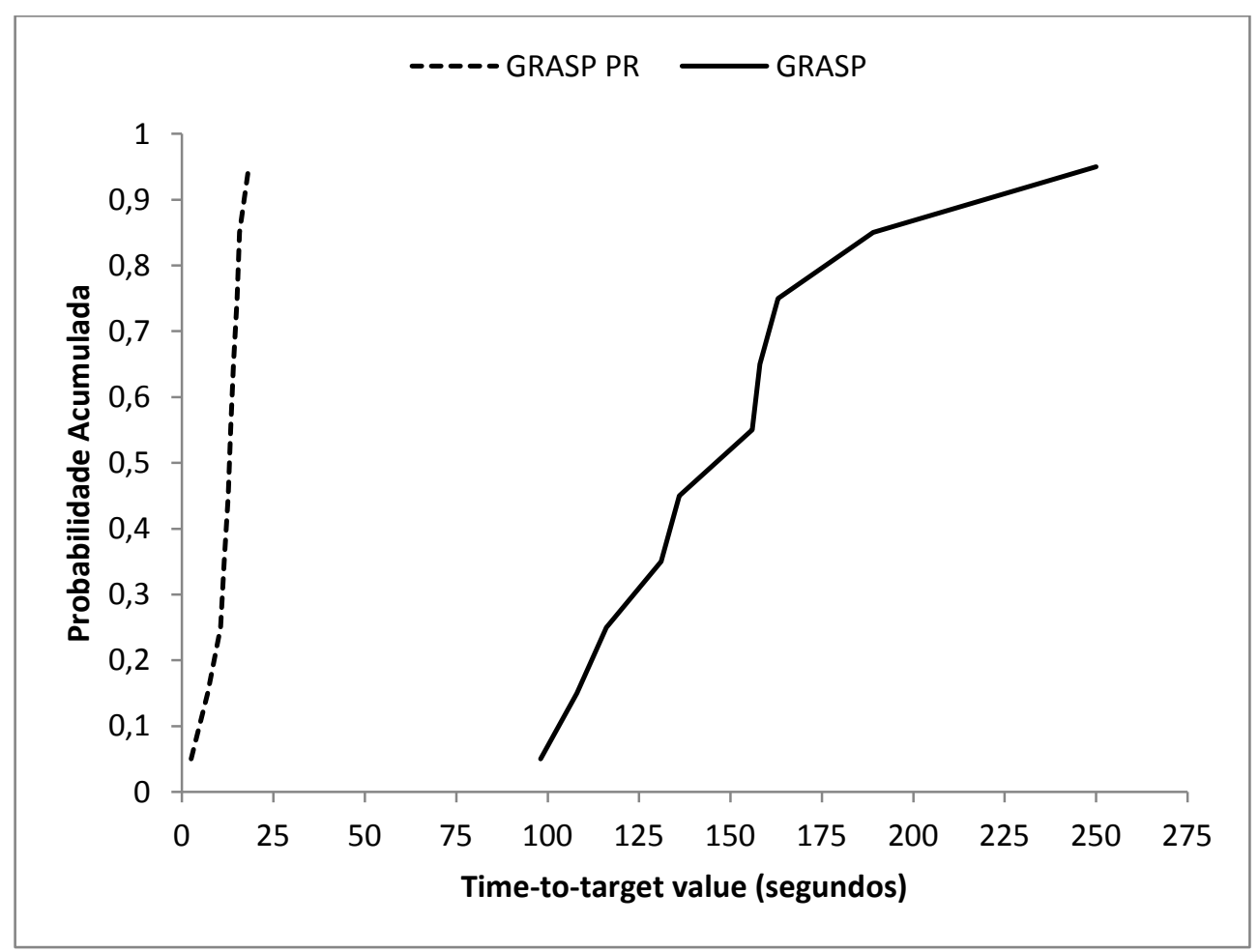

Figura 4.13 - Tempo para alcançar uma dada solução (GRASP PR x GRASP). 
Posteriormente, utilizou-se o conjunto de instâncias fornecido por Jouglet; Savourey (2011), o qual foi implementado com multi-threading e também sem multithreading. Para reforçar a eficácia do processamento multi-threading em relação ao processamento de uma única trajetória, foram realizados novos testes, envolvendo os seguintes portes de instâncias: 10 tarefas e 2 máquinas, 15 tarefas e 3 máquinas e 20 tarefas e 3 máquinas, sendo que cada porte possui 120 instâncias, e para cada instância foram realizadas 10 replicações. Cada instância foi processada até que a solução ótima fornecida pelos autores fosse alcançada. $\mathrm{O}$ artigo dos autores também relata o tempo empregado para a solução ótima ser alcançada, e por meio da tabela 4.5, percebe-se que o GRASP com path relinking obtém a solução ótima empregando tempo computacional muito inferior ao Branch and Bound utilizado por Jouglet; Savourey (2011).

Tabela 4.5 - Processamento multi-threading $x$ Branch and Bound

\begin{tabular}{|l|c|c|c|}
\hline \multirow{2}{*}{ Método } & \multicolumn{3}{c|}{$\begin{array}{c}\text { Tarefas m máquinas [Tempo em } \\
\text { milissegundos] }\end{array}$} \\
\cline { 2 - 4 } & $\mathbf{1 0 \times 2}$ & $\mathbf{1 5} \mathbf{3}$ & $\mathbf{2 0 \times 3}$ \\
\hline $\begin{array}{l}\text { Branch and Bound (Jouglet e Savourey); } \\
\text { Pentium 1.6 GHz }\end{array}$ & 39,075 & $10.099,58$ & $291.236,38$ \\
\hline $\begin{array}{l}\text { GRASP com Path Relinking (Backward); } \\
\text { Pentium 2.8 GHz }\end{array}$ & 31,549 & 54,005 & 52,782 \\
\hline $\begin{array}{l}\text { GRASP com Path Relinking } \\
\text { (Processamento Multi-threading); } 2.8 \mathrm{GHz}\end{array}$ & 18,997 & 31,033 & 32,098 \\
\hline
\end{tabular}

Ainda em relação a tabela 4.5, a estratégia multi-threading é comparada com uma versão do GRASP path relinking sem multi-threading, utilizando a estratégia backward, sendo que a implementação com o multi-threading fornece soluções melhores que à versão backward. É importante destacar que 66,07\%, 74,02\% e 64,44\% respectivamente, de 10, 15 e 20 tarefas, representam o quanto o GRASP com Path Relinking multi-threading é melhor que o GRASP com Path Relinking Backward. É importante ressaltar que, embora os hardwares sejam diferentes, o que impede que a comparação seja mais justa, os tempos de processamento possuem ordem de grandeza distinta, o que confirma a eficácia do método proposto.

Por último, cabe destacar que os gaps obtidos poderão, eventualmente, ser melhorados se os resultados dos métodos desenvolvidos forem comparados com os 
valores ótimos das funções objetivo, as invés dos limitantes obtidos pelo método de geração de colunas. Isto mostra que os resultados obtidos já são bastante satisfatórios. 


\section{CONCLUSÕES E RECOMENDAÇÕES}

A presente pesquisa estudou um problema real de programação de embarcações especializadas em operações de lançamento de risers e interligação submarina, que representa uma etapa importante do desenvolvimento de um campo petrolífero. As embarcações empregadas são as PLVs - pipe layer vessels e representam recursos críticos para as empresas petrolíferas.

Cada tarefa a ser realizada possui um potencial de produção associado, que diz respeito ao volume diário de produção esperado ao longo da vida útil do poço que será interligado. Assim, quando uma tarefa é adiada para a realização de outra, significa adiar o retorno sobre o investimento. Existem algumas restrições operacionais que devem ser consideradas e com isso, o objetivo é encontrar a sequência de execução das tarefas, de forma a minimizar as perdas financeiras pelo atraso no início da execução das mesmas em relação as respectivas datas de liberação.

O problema foi modelado e resolvido como um problema de máquinas paralelas não-relacionadas, empregando um modelo de programação linear inteira mista, baseado na formulação de van den Akker et al. (2000), em que a formulação utiliza uma escala de tempo discretizada. Para a geração dos limitantes inferiores, foi utilizada a técnica de geração de colunas, onde foi formulado empregando-se a decomposição de DantzigWolfe.

Os métodos de solução propostos foram: heurística construtiva, heurística construtiva com busca local (busca local inserção e busca local troca), GRASP e GRASP com path relinking, sendo que no path relinking, foram utilizadas algumas variações como path relinking forward, backward, mixed, randomized forward, randomized backward e randomized mixed. Por último, uma versão do path relinking explorando as diversas trajetórias simultaneamente, por meio da abordagem multithreading.

Os resultados destacam que as soluções fornecidas são de boa qualidade, tendo em vista que os gaps ficaram inferiores a $2 \%$ para a maioria das instâncias. A aplicação do path relinking contribuiu para a melhoraria da qualidade das soluções. Em todas as 
instâncias, o GRASP com path relinking, implementado com multi-threading, em média, foi mais eficaz e com tempo de processamento competitivo conforme destaca a tabela 4.3.

Apesar do bom desempenho das heurísticas propostas, principalmente o GRASP e o GRASP com path relinking, em que os gaps obtidos ficaram abaixo de $2 \%$ em média, é interessante testar novas abordagens, por exemplo, a combinação de uma solução inicial com múltiplas guias com processamento multi-threading. Novas estruturas de vizinhança para a busca local podem ser importantes, no caso de instâncias de maior porte por exemplo, a estratégia de vizinhança variável. Outras meta-heurísticas como a busca tabu, algoritmo genético, e a busca dispersa, estruturadas para ambiente multi-threading podem ser interessantes. Instâncias poderão ser desenvolvidas para cenários maiores; também é importante destacar a possível utilização de regras dinâmicas para a fase construtiva do GRASP (GRASP reativo) e também o processo evolucionário com as soluções de elite. 


\section{REFERÊNCIAS BIBLIOGRÁFICAS}

AARTS, E.; LENSTRA, J. K. Local Search in combinatorial optimization. Princeton University Press. New Jersey, 2003, 512 p.

ABEAM. Associação Brasileira das Empresas de Apoio Marítimo. Disponível em: <http://www.abeam.org.br>. Acesso em 10 Jul. 2010.

ALIDAEE, B.; ROSA, D. Scheduling parallel machines to minimize total weighted and unweighted tardiness, Computers \& Operations Research, 24:8, p.775-788, 1997.

ALLSEAS. Allseas'Equipment gallery. Disponível em <http://www.allseas.com/uk>. Acesso em 10 Jul. 2010.

AZIZOGLU, M.; KIRCA, O. Tardiness minimization on parallel machines. International Journal of Production Economics, 55, p.163-168, 1998.

AZIZOGLU, M.; KIRCA, O. Scheduling jobs on unrelated parallel machines to minimize regular total cost functions. IIE Transactions, 31, p.153-159, 1999.

BAKER, K. R. Introduction to Sequencing and Scheduling. New York: John Wiley \& Sons, Inc., 1974. 305p.

BAKER, K. R.; BERTRAND, J. W. M. A dynamic priority rule for scheduling against due-dates. Journal of Operations Management, 3:1, p.37-42, 1982.

BEASLEY, J. E. OR-Library: distributing test problems by electronic mail. Journal of the Operational Research Society, 41:11, p.1069-1072, 1990.

BERTRAND, J. W. M.; FRANSOO, J. C. Operations management research methodologies using quantitative modeling. International Journal of Operations \& Production Management, 22:2, p.241-254, 2002.

BISKUP, D.; HERRMANN, J. E GUPTA, J.N.D. Scheduling identical parallel machines to minimize total tardiness. International Journal of Production Economics, 115, 134-142, 2008.

BLAZEWICZ, J.; DROR, M.; WEGLARZ, J. Mathematical programming formulations for machine scheduling: a survey. European Journal of Operational Research, 51, p.283-300, 1991.

BLAZEWICZ, J.; DROZDOWSKI, M.; FORMANOWICZ, P.; KUBIAK, W.; SCHMIDT, G. Scheduling preemptable tasks on parallel processors with limited availability. Parallel Computing, 26, p.1195-1211, 2000.

BOUDIA, M.; LOULY, M.A.O. E PRINS, C. A reactive GRASP and path relinking for a combined production-distribution problem. Computers \& Operations Research, 34, 3402-3419, 2007. 
BRØNMO, G.; CHISTIANSEN, M.; FAGERHOLT, K.; NYGREEN, B. A multi-start local search heuristic for ship scheduling - a computational study. Computers \& Operations Research, 34, p.900-917, 2007a.

BRØNMO, G.; CHISTIANSEN, M.; NYGREEN, B. Ship routing and scheduling with flexible cargo sizes. Journal of the Operational Research Society, 58, p.1167-1177, $2007 \mathrm{~b}$.

BRØNMO, G.; NYGREEN, B.; LYSGAARD, J. Column generation approaches to ship scheduling with flexible cargo sizes. European Journal of Operational Research, 200, p.139-150, 2010.

BROWN, G.G.; GRAVES, G. W.; RONEN, D. Scheduling ocean transportation of crude oil. Management Science, 33:3, p.335-346, 1987.

BRUCKER, P.; JURISCH, B; KRAMER, A. Complexity of scheduling problems with multi-purpose machines. Annals of Operations Research, 70, p.57-73, 1997.

BRUCKER, P. Scheduling Algorithms. New York: Berlin: Springer, 2007. 371p.

BRUNO, J.; COFFMAN, J.; SETHI, R. Scheduling independent tasks to reduce mean finishing time. Communications of the ACM, 17:7, p.382-387, 1974.

CARROLL, D. C. Heuristic sequencing of jobs with single and multiple components. Ph.D. Thesis. SIoan School of Management, MIT, 1965.

CAO, D.; CHEN, M.; WAN, G. Parallel machine selection and job scheduling to minimize machine cost and job tardiness. Computers \& Operations Research, 32, p.1995-2012, 2005.

CHEN, Z. L.; POWELL, W. B. A column generation based decomposition algorithm for a parallel machine just-in-time scheduling problem. European Journal of Operational Research, 116, p.220-232, 1999.

CHENG, T. C. E.; SIN, C. C. S. A state-of-the-art review of parallel-machine scheduling research. European Journal of Operational Research, 47, p.271-292, 1990.

CRAUWELS, H. A. J.; POTTS, C. N.; VAN WASSENHOVE, L. N. Local search heuristics for the single machine total weighted tardiness scheduling problem. Informs Journal on Computing, 10, p.341-350, 1998.

DAVIS, E.; JAFFE, J. M. Algorithms for scheduling tasks on unrelated processors. Journal of the Association for Computing Machinery, 28, p.721-736, 1981.

DEMEULEMEESTER, E. L.; HERROELEN, W, S. Project scheduling: a research handbook. Norwell, Massachusetts: Kluwer Academic, 2002, 685 p. 
FAGERHOLT, K. A computer-based decision support system for vessel fleet scheduling-experience and future research. Decision Support Systems, 37, p.35-47, 2004.

FEO, T.A. E RESENDE, M.G.C. A probabilistic heuristic for a computationally difficult set covering problem. Operations Research Letter, 8, 67-71, 1989.

FEO, T. A.; RESENDE, M. G. C. Greedy randomized adaptive search procedures. Journal of Global Optimization, 6, p.109-133, 1995.

FULLER, J. A. Optimal solutions versus 'good' solutions: an analysis of heuristic decision making. Omega The International Journal of Management Science, 6:6, p.479-484, 1978.

GLASS, C. A.; POTTS, C. N.; SHADE, P. Unrelated parallel machine scheduling using local search. Mathematical and Computer Modeling, 20:2, p.41-52, 1994.

GLOVER, F. Tabu search and adaptive memory programming - advances, applications and challenges, em Barr, R. S.; Helgason, R.V. e Kennington, J. L. (Eds.), Interfaces in Computer Science and Operations Research. Kluwer Academic Publishers, Boston, $1-75,1996$.

GLOVER, F.; LAGUNA, M.; MARTÍ, R.; Fundamentals of Scatter Search and Path Relinking. Control and Cybernetics, 29:3, p.653-684, 2000.

GRAHAM, R. L. Bounds on multiprocessing timing anomalies. Siam Journal on Applied Mathematics, 17:2, p.416-429, 1969.

GRAHAM, R. L.; LAWLER, E. L.; LENSTRA, J. K.; RINNOOY, K. A. H. G. Optimization and approximation in deterministic sequencing and scheduling: a survey. Annals of Discrete Mathematics, 5, p.287-326, 1979.

HARIRI, A. M. A.; POTTS, C. N. Heuristics for scheduling unrelated parallel machines. Computers \& Operations Research, 18: 3, p.323-331, 1991.

HO, S.C. E GENDREAU, M. Path relinking for the vehicle routing problem. Journal of Heuristics, 12, 55-72, 2006

HOROWITZ, E.; SAHNI, S. Exact and approximate algorithms for scheduling nonidentical processors. Journal of the Association for Computing Machinery, 23:2, p.317-327, 1976.

IBARRA, O.H.; KIM, C.E. Heuristic algorithms for scheduling independent tasks on nonidentical processors. Journal of the Association for Computing Machinery, 24:2, p.280-289, 1977.

JANSEN, K.; PORKOLAB, L. Improved approximation schemes for scheduling unrelated parallel machines. Mathematics of Operations Research, 26:2, 324-338, 2001. 
JOUGLET, A.; SAVOUREY, D. Dominance rules for the parallel machine total weighted tardiness scheduling problem with release dates. Computers \& Operations Research, 38, p.1259-1266, 2011.

KOULAMAS, C. Decomposition and hybrid simulated annealing heuristics for the parallel-machine total tardiness problem. Naval Research Logistics, 44, p.109-125, 1997.

LAWLER, E. L.; LABETOULLE, J. On preemptive scheduling of unrelated parallel processors by linear programming. Journal of the Association for Computing Machinery, 25:4, 612-619, 1978.

LEE, C.Y. Parallel machines scheduling with nonsimultaneous machine available time. Discrete Applied Mathematics, 30, 53-61, 1991.

LENSTRA, J. K.; SHMOYS, D. B.; TARDOS, E. Approximation algorithms for scheduling unrelated parallel machines. Mathematical Programming, 46, p.259-271, 1990.

LIAW, C-F; LIN, Y-K; CHENG, C-Y; CHEN, M. Scheduling unrelated parallel machines to minimize total weighted tardiness. Computers \& Operations Research, 30, p.1777-1789, 2003.

LIN, Y. K.; PFUND, M. E.; FOWLER, J. W. Heuristics for minimizing regular performance measures in unrelated parallel machine scheduling problems. Computers \& Operations Research, 38, p.901-916, 2011.

McNAUGHTON, R. Scheduling with deadlines and loss functions. Management Science, 6, p.1-12, 1959.

MENDES, A. B. Programação de frota de apoio a operações "offshore" sujeita à requisição de múltiplas embarcações para uma mesma tarefa. 2007. 224 p. Tese (Doutorado). Escola Politécnica, Universidade de São Paulo. São Paulo, 2007.

MENDES, A. B.; QUEIROZ, M. M.; MOURA, V. C. Scheduling pipe layer vessels using tabu search. Alio-Informs Joint International Meeting, Book of abstracts, 1, p.66-66, 2010.

MILLER, D. M. An interactive, computer-aided ship scheduling system. European Journal of Operational Research, 32, p.363-379, 1987.

MORTON, T. E.; RACHAMADUGU, R. M.; VEPSALAINEN, A. Accurate mayopic heuristics for tardiness scheduling. GSIA Working Paper No, 36-83-84, CarnegieMellon University, PA, 1984.

MORTON, T. E.; PENTICO, D. W. Heuristic Scheduling Systems: with applications to production systems and project management. New York: John Wiley \& Sons, Inc., 1993. 695p. 
OR-LIBRARY. Disponível em: <http://people.brunel.ac.uk/ mastjjb/jeb/info.html> Acesso em 14 Nov. 2009.

OU, J.; LEUNG, J. Y.-T. Scheduling parallel machines with inclusive processing set restrictions. Naval Research Logistics, 55, p.328-338, 2008.

PANWALKAR, S.S.; SMITH, M.L.; KOULAMAS, C. A heuristic for the single machine tardiness problem. European Journal of Operational Research, 70, 304-310, 1993.

PIERSMA, N.; VAN DIJK, W. A local search heuristic for unrelated parallel machine scheduling with efficient neighborhood search. Mathematical and Computer Modeling, 24:9, p.11-19, 1996.

PINEDO, M. Scheduling: theory, algorithms, and systems. New Jersey: PrenticeHall; 2002.

POTTS, C. N. Analysis of a linear-programming heuristic for scheduling unrelated parallel machines. Discrete Applied Mathematics, 10, p.155-164, 1985.

PRAIS, M.; RIBEIRO, C. C. Reactive GRASP: an application to a matrix decomposition problem in TDMA traffic assignment, Informs Journal on Computing, 12, p.164-176, 2000.

RESENDE, M. G. C.; RIBEIRO, C. C. Greedy randomized adaptive search procedures. In: Glover, F.; Kochenberger, G. (eds). Handbook of Metaheuristics. Kluwer, 219249, $2003 \mathrm{a}$.

RESENDE, M.G.C.; RIBEIRO, C.C. Grasp with path relinking: recent advances and applications. AT \& T Labs Technical Report TD-5TU726, 1-24, 2003 b.

RESENDE, M.G.C.; WERNECK, R.F. A hybrid heuristic for the p-median problem. Journal of Heuristics, 10, 59-88, 2004.

RESENDE, M.G.C.; MARTÍ, R.; GALLEGO, M.; DUARTE, A. Grasp and path relinking for the max-min diversity problem. Computers \& Operations Research, 37, 498-508, 2010a.

RESENDE, M.G.C.; RIBEIRO, C.C.; GLOVER, F. E R. MARTÍ. Scatter search and path-relinking: Fundamentals, advances, and applications, em Gendreau, M. e Potvin, J.-Y. (Eds.). Handbook of Metaheuristics, Springer, New York, 87-107, 2010b.

RIBEIRO, C.C.; ROSSETI, I. Efficient parallel cooperative implementations of GRASP heuristics. Parallel Computing, 33, 21-35, 2007.

RIBEIRO, C.C.; ROSSETI, I.; VALLEJOS, R. On the use of run time distributions to evaluate and compare stochastic local search algorithms em Stützle, T.; Birattari, M. e Hoos, H.H. (Eds.). Lecture Notes in Computer Science, Springer-Verlag, Berlin Heidelberg, 16-30, 2009. 
RONEN, D. Ship scheduling: the last decade. European Journal of Operational Research, 71, p.325-333, 1993.

SHIM, S-O. E KIM, Y-D. Scheduling on parallel identical machines to minimize total tardiness. European Journal of Operational Research, 177, 135-146, 2007.

UNLU, Y.; MASON, S. J. Evaluation of mixed integer formulations for non-preemptive parallel machine scheduling problems. Computers \& Industrial Engineering, 58, p.785-800, 2010.

VAN DEN AKKER, J.M.; HURKENS, C.A.J. E SAVELSBERGH, M.W.P. Timeindexed formulations for machine scheduling problem: column generation. INFORMS Journal on Computing, 12, 111-124, 2000.

VOß, S. Metaheuristics: the state of the art. In: Nareyek, A. (ed). Local search for planning and scheduling, LNAI. 2148, Berlin, p.1-23, 2001.

ZANAKIS, S. H.; EVANS, J. R.; VAZACOPOULOS, A. A. Heuristic methods and applications: a categorized survey. European Journal of Operational Research, 43, p.88-110, 1989. 
APÊNDICE A - Gap Médio 30 x 4, 40 x 5 e 50 x 6
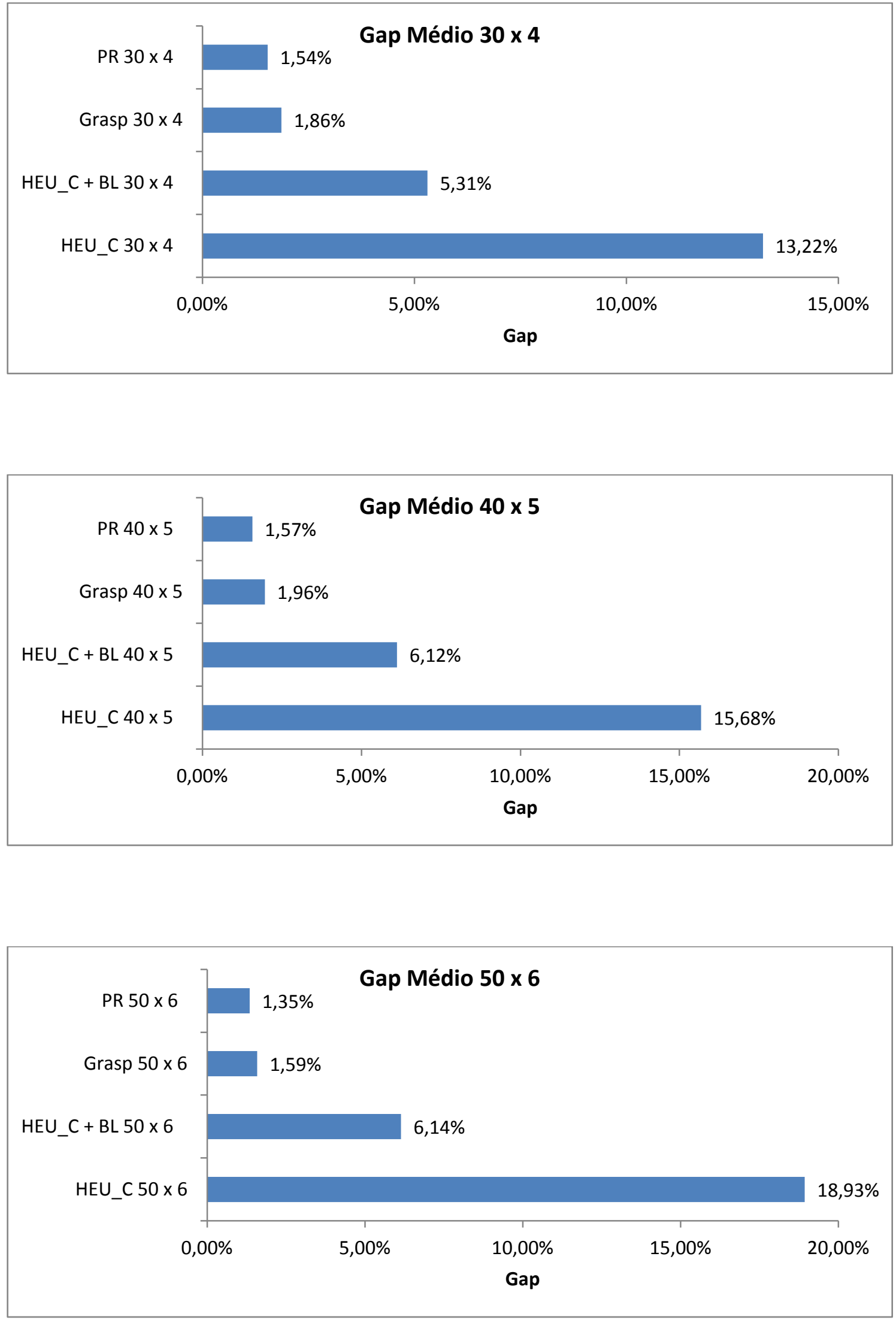
APÊNDICE B - Tempo médio de processamento 30x4, 40x5 e 50x6
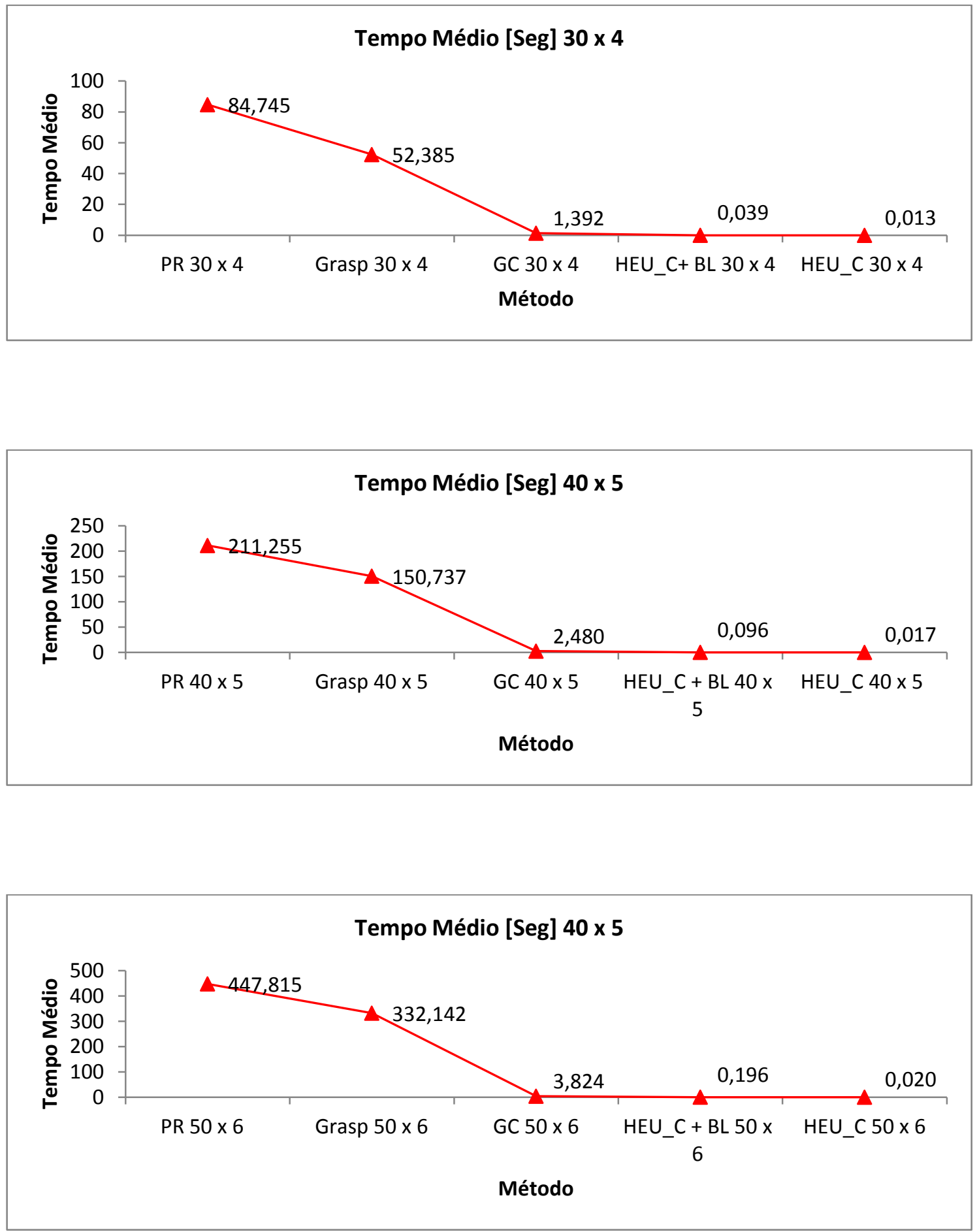
APÊNDICE C - Resultados GC x GRASP 30 x 4

\begin{tabular}{|c|c|c|c|c|c|}
\hline Instância & GC & Tempo [Seg] & Grasp $30 \times 4$ & Tempo [Seg] & Gap \% \\
\hline 1 & 15.417 & 1,000 & 15.546 & 50,434 & 0,83 \\
\hline 2 & 7.433 & 2,000 & 7.457 & 55,894 & 0,32 \\
\hline 3 & 16.530 & 2,000 & 16.649 & 57,236 & 0,71 \\
\hline 4 & 16.053 & 1,000 & 16.097 & 47,205 & 0,27 \\
\hline 5 & 6.992 & 1,000 & 7.054 & 49,264 & 0,88 \\
\hline 6 & 9.059 & 1,000 & 9.217 & 45,848 & 1,71 \\
\hline 7 & 6.447 & 1,000 & 6.519 & 53,398 & 1,10 \\
\hline 8 & 6.773 & 2,000 & 6.868 & 51,682 & 1,38 \\
\hline 9 & 10.539 & 2,000 & 10.589 & 58,110 & 0,47 \\
\hline 10 & 9.324 & 1,000 & 9.397 & 57,158 & 0,78 \\
\hline 11 & 9.430 & 2,000 & 9.525 & 64,381 & 1,00 \\
\hline 12 & 6.694 & 2,000 & 6.871 & 65,005 & 2,58 \\
\hline 13 & 4.835 & 1,000 & 4.936 & 60,512 & 2,05 \\
\hline 14 & 8.968 & 2,000 & 9.056 & 56,550 & 0,97 \\
\hline 15 & 4.257 & 1,000 & 4.330 & 56,612 & 1,69 \\
\hline 16 & 2.107 & 1,000 & 2.253 & 39,826 & 6,48 \\
\hline 17 & 1.999 & 2,000 & 2.083 & 63,226 & 4,03 \\
\hline 18 & 2.109 & 1,000 & 2.119 & 49,545 & 0,47 \\
\hline 19 & 3.706 & 1,000 & 3.838 & 59,670 & 3,44 \\
\hline 20 & 1.875 & 1,000 & 1.903 & 39,561 & 1,47 \\
\hline 21 & 1.958 & 1,000 & 2.015 & 42,229 & 2,83 \\
\hline 22 & 2.310 & 2,000 & 2.385 & 48,937 & 3,14 \\
\hline 23 & 2.456 & 1,000 & 2.494 & 43,680 & 1,52 \\
\hline 24 & 1.372 & 1,000 & 1.409 & 47,782 & 2,63 \\
\hline 25 & 1.798 & 1,000 & 2.057 & 43,336 & 12,59 \\
\hline 26 & 6.326 & 2,000 & 6.351 & 54,178 & 0,39 \\
\hline 27 & 9.809 & 2,000 & 9.816 & 54,459 & 0,07 \\
\hline 28 & 16.150 & 1,000 & 16.225 & 55,551 & 0,46 \\
\hline 29 & 14.081 & 2,000 & 14.135 & 46,971 & 0,38 \\
\hline 30 & 12.761 & 2,000 & 12.765 & 51,948 & 0,03 \\
\hline 31 & 8.187 & 2,000 & 8.273 & 70,262 & 1,04 \\
\hline 32 & 8.684 & 2,000 & 8.835 & 48,422 & 1,71 \\
\hline 33 & 6.440 & 1,000 & 6.471 & 57,486 & 0,48 \\
\hline 34 & 4.939 & 1,000 & 4.969 & 39,702 & 0,60 \\
\hline 35 & 4.366 & 2,000 & 4.478 & 57,844 & 2,50 \\
\hline 36 & 6.741 & 2,000 & 6.848 & 50,637 & 1,56 \\
\hline 37 & 7.648 & 1,000 & 7.792 & 54,288 & 1,85 \\
\hline 38 & 2.309 & 1,000 & 2.400 & 54,303 & 3,79 \\
\hline 39 & 4.830 & 1,000 & 4.975 & 48,188 & 2,91 \\
\hline 40 & 5.007 & 1,000 & 5.115 & 44,803 & 2,11 \\
\hline 41 & 3.922 & 2,000 & 3.928 & 49,311 & 0,15 \\
\hline 42 & 2.672 & 2,000 & 2.735 & 47,158 & 2,30 \\
\hline 43 & 1.755 & 1,000 & 1.765 & 34,834 & 0,57 \\
\hline 44 & 1.449 & 2,000 & 1.532 & 30,872 & 5,42 \\
\hline 45 & 3.542 & 2,000 & 3.651 & 56,128 & 2,99 \\
\hline 46 & 2.037 & 1,000 & 2.055 & 43,586 & 0,88 \\
\hline 47 & 2.577 & 2,000 & 2.599 & 35,224 & 0,85 \\
\hline 48 & 1.602 & 1,000 & 1.646 & 52,322 & 2,67 \\
\hline 49 & 1.711 & 1,000 & 1.827 & 46,472 & 6,35 \\
\hline 50 & 2.219 & 1,000 & 2.248 & 34,834 & 1,29 \\
\hline 51 & 9.481 & 2,000 & 9.543 & 49,046 & 0,65 \\
\hline 52 & 15.342 & 1,000 & 15.439 & 56,144 & 0,63 \\
\hline 53 & 7.480 & 2,000 & 7.512 & 58,780 & 0,43 \\
\hline 54 & 11.144 & 2,000 & 11.204 & 55,021 & 0,54 \\
\hline 55 & 10.736 & 1,000 & 10.821 & 51,729 & 0,79 \\
\hline 56 & 7.115 & 1,000 & 7.149 & 65,613 & 0,48 \\
\hline 57 & 7.484 & 1,000 & 7.546 & 56,503 & 0,82 \\
\hline 58 & 5.353 & 2,000 & 5.369 & 57,033 & 0,30 \\
\hline 59 & 7.662 & 2,000 & 7.700 & 60,075 & 0,49 \\
\hline 60 & 8.908 & 1,000 & 8.984 & 64,818 & 0,85 \\
\hline 61 & 6.398 & 1,000 & 6.507 & 60,496 & 1,68 \\
\hline 62 & 4.820 & 1,000 & 5.032 & 52,728 & 4,21 \\
\hline 63 & 5.546 & 2,000 & 5.631 & 54,178 & 1,51 \\
\hline 64 & 5.634 & 1,000 & 5.876 & 59,467 & 4,12 \\
\hline 65 & 6.809 & 2,000 & 6.995 & 56,674 & 2,66 \\
\hline
\end{tabular}


Continuação

\begin{tabular}{|c|c|c|c|c|c|}
\hline 66 & 4.388 & 2,000 & 4.665 & 52,369 & 5,94 \\
\hline 67 & 3.618 & 1,000 & 3.705 & 65,426 & 2,35 \\
\hline 68 & 3.437 & 1,000 & 3.586 & 56,269 & 4,16 \\
\hline 69 & 4.024 & 1,000 & 4.223 & 43,071 & 4,71 \\
\hline 70 & 5.092 & 1,000 & 5.241 & 53,508 & 2,84 \\
\hline 71 & 3.032 & 2,000 & 3.145 & 58,375 & 3,59 \\
\hline 72 & 1.391 & 2,000 & 1.435 & 48,890 & 3,07 \\
\hline 73 & 3.016 & 1,000 & 3.208 & 49,639 & 5,99 \\
\hline 74 & 2.718 & 1,000 & 2.790 & 44,350 & 2,58 \\
\hline 75 & 2.888 & 1,000 & 2.948 & 41,667 & 2,04 \\
\hline 76 & 10.469 & 1,000 & 10.528 & 48,734 & 0,56 \\
\hline 77 & 8.745 & 2,000 & 8.810 & 45,879 & 0,74 \\
\hline 78 & 8.652 & 1,000 & 8.751 & 45,942 & 1,13 \\
\hline 79 & 9.831 & 2,000 & 9.968 & 53,102 & 1,37 \\
\hline 80 & 7.737 & 1,000 & 7.815 & 48,453 & 1,00 \\
\hline 81 & 7.408 & 1,000 & 7.502 & 53,913 & 1,25 \\
\hline 82 & 9.421 & 1,000 & 9.531 & 65,582 & 1,15 \\
\hline 83 & 10.549 & 2,000 & 10.634 & 50,263 & 0,80 \\
\hline 84 & 11.406 & 1,000 & 11.506 & 54,194 & 0,87 \\
\hline 85 & 8.122 & 1,000 & 8.191 & 61,120 & 0,84 \\
\hline 86 & 7.484 & 1,000 & 7.692 & 49,810 & 2,70 \\
\hline 87 & 6.185 & 1,000 & 6.319 & 58,515 & 2,12 \\
\hline 88 & 7.909 & 2,000 & 8.023 & 50,185 & 1,42 \\
\hline 89 & 10.978 & 1,000 & 11.183 & 55,411 & 1,83 \\
\hline 90 & 8.826 & 2,000 & 8.943 & 56,269 & 1,31 \\
\hline 91 & 8.260 & 1,000 & 8.493 & 40,965 & 2,74 \\
\hline 92 & 5.554 & 1,000 & 5.744 & 48,328 & 3,31 \\
\hline 93 & 6.461 & 1,000 & 6.625 & 53,757 & 2,48 \\
\hline 94 & 7.778 & 1,000 & 7.925 & 68,998 & 1,85 \\
\hline 95 & 7.850 & 1,000 & 7.982 & 54,272 & 1,65 \\
\hline 96 & 3.676 & 2,000 & 3.847 & 41,901 & 4,45 \\
\hline 97 & 4.906 & 1,000 & 5.059 & 43,492 & 3,02 \\
\hline 98 & 1.601 & 1,000 & 1.676 & 53,352 & 4,47 \\
\hline 99 & 5.282 & 1,000 & 5.377 & 42,385 & 1,77 \\
\hline 100 & 7.419 & 1,000 & 7.610 & 40,591 & 2,51 \\
\hline 101 & 17.076 & 2,000 & 17.192 & 51,854 & 0,67 \\
\hline 102 & 8.986 & 1,000 & 9.120 & 41,074 & 1,47 \\
\hline 103 & 8.737 & 1,000 & 8.802 & 53,461 & 0,74 \\
\hline 104 & 12.099 & 1,000 & 12.268 & 57,798 & 1,38 \\
\hline 105 & 9.911 & 1,000 & 10.053 & 49,108 & 1,41 \\
\hline 106 & 11.008 & 2,000 & 11.202 & 32,931 & 1,73 \\
\hline 107 & 13.667 & 2,000 & 13.823 & 52,946 & 1,13 \\
\hline 108 & 12.375 & 2,000 & 12.529 & 57,891 & 1,23 \\
\hline 109 & 14.597 & 1,000 & 14.755 & 51,526 & 1,07 \\
\hline 110 & 10.668 & 1,000 & 10.781 & 51,012 & 1,05 \\
\hline 111 & 11.353 & 1,000 & 11.449 & 52,213 & 0,84 \\
\hline 112 & 16.857 & 2,000 & 17.017 & 55,348 & 0,94 \\
\hline 113 & 14.871 & 1,000 & 14.951 & 57,439 & 0,54 \\
\hline 114 & 14.882 & 2,000 & 15.039 & 56,674 & 1,04 \\
\hline 115 & 17.117 & 1,000 & 17.245 & 62,602 & 0,74 \\
\hline 116 & 7.988 & 2,000 & 8.119 & 55,894 & 1,61 \\
\hline 117 & 6.272 & 1,000 & 6.367 & 58,125 & 1,49 \\
\hline 118 & 11.147 & 2,000 & 11.251 & 56,643 & 0,92 \\
\hline 119 & 9.748 & 2,000 & 9.835 & 56,238 & 0,88 \\
\hline 120 & 8.002 & 1,000 & 8.121 & 44,990 & 1,47 \\
\hline 121 & 9.620 & 1,000 & 9.768 & 62,197 & 1,52 \\
\hline 122 & 16.018 & 2,000 & 16.158 & 70,262 & 0,87 \\
\hline 123 & 8.466 & 1,000 & 8.634 & 51,573 & 1,95 \\
\hline 124 & 9.410 & 2,000 & 9.546 & 60,918 & 1,42 \\
\hline 125 & 15.361 & 1,000 & 15.540 & 63,211 & 1,15 \\
\hline
\end{tabular}


APÊNDICE D - Resultados GC x GRASP 40 X 5

\begin{tabular}{|c|c|c|c|c|c|}
\hline Instância & GC & Tempo [Seg] & Grasp $40 \times 5$ & Tempo [Seg] & Gap \% \\
\hline 1 & 16.268 & 2,000 & 16.373 & 160,472 & 0,64 \\
\hline 2 & 12.354 & 3,000 & 12.465 & 146,609 & 0,89 \\
\hline 3 & 14.262 & 3,000 & 14.397 & 164,564 & 0,94 \\
\hline 4 & 18.806 & 2,000 & 18.927 & 180,164 & 0,64 \\
\hline 5 & 16.559 & 3,000 & 16.693 & 138,403 & 0,80 \\
\hline 6 & 11.196 & 2,000 & 11.355 & 135,501 & 1,40 \\
\hline 7 & 15.934 & 2,000 & 16.164 & 134,877 & 1,42 \\
\hline 8 & 15.577 & 2,000 & 15.763 & 167,169 & 1,18 \\
\hline 9 & 12.100 & 3,000 & 12.194 & 161,865 & 0,77 \\
\hline 10 & 10.656 & 2,000 & 10.728 & 156,889 & 0,67 \\
\hline 11 & 7.910 & 2,000 & 8.091 & 165,485 & 2,24 \\
\hline 12 & 5.238 & 2,000 & 5.346 & 145,726 & 2,02 \\
\hline 13 & 6.130 & 4,000 & 6.357 & 148,293 & 3,57 \\
\hline 14 & 10.998 & 3,000 & 11.155 & 179,718 & 1,41 \\
\hline 15 & 6.830 & 2,000 & 7.028 & 131,397 & 2,82 \\
\hline 16 & 2.257 & 3,000 & 2.286 & 117,858 & 1,27 \\
\hline 17 & 2.074 & 2,000 & 2.159 & 139,060 & 3,94 \\
\hline 18 & 2.698 & 2,000 & 2.889 & 159,469 & 6,61 \\
\hline 19 & 3.300 & 2,000 & 3.420 & 166,315 & 3,51 \\
\hline 20 & 2.395 & 2,000 & 2.488 & 133,020 & 3,74 \\
\hline 21 & 2.291 & 2,000 & 2.327 & 178,594 & 1,55 \\
\hline 22 & 891 & 3,000 & 924 & 148,600 & 3,57 \\
\hline 23 & 2.175 & 2,000 & 2.261 & 120,548 & 3,80 \\
\hline 24 & 2.079 & 2,000 & 2.214 & 144,636 & 6,10 \\
\hline 25 & 789 & 2,000 & 848 & 156,613 & 6,96 \\
\hline 26 & 13.673 & 2,000 & 13.680 & 192,675 & 0,05 \\
\hline 27 & 11.241 & 3,000 & 11.256 & 178,893 & 0,13 \\
\hline 28 & 9.602 & 2,000 & 9.651 & 197,503 & 0,51 \\
\hline 29 & 12.161 & 3,000 & 12.232 & 158,571 & 0,58 \\
\hline 30 & 13.194 & 3,000 & 13.236 & 154,015 & 0,32 \\
\hline 31 & 13.273 & 2,000 & 13.406 & 161,514 & 0,99 \\
\hline 32 & 5.918 & 1,000 & 6.034 & 153,270 & 1,92 \\
\hline 33 & 9.530 & 3,000 & 9.621 & 163,526 & 0,95 \\
\hline 34 & 10.353 & 3,000 & 10.439 & 163,247 & 0,82 \\
\hline 35 & 12.314 & 2,000 & 12.412 & 158,695 & 0,79 \\
\hline 36 & 6.470 & 2,000 & 6.515 & 163,930 & 0,69 \\
\hline 37 & 4.759 & 3,000 & 4.818 & 178,676 & 1,22 \\
\hline 38 & 5.565 & 2,000 & 5.634 & 167,428 & 1,22 \\
\hline 39 & 4.538 & 2,000 & 4.583 & 171,277 & 0,98 \\
\hline 40 & 6.867 & 2,000 & 6.978 & 146,634 & 1,59 \\
\hline 41 & 3.111 & 1,000 & 3.194 & 150,705 & 2,60 \\
\hline 42 & 3.012 & 1,000 & 3.048 & 144,772 & 1,18 \\
\hline 43 & 3.370 & 2,000 & 3.501 & 158,845 & 3,74 \\
\hline 44 & 3.829 & 3,000 & 4.022 & 144,902 & 4,80 \\
\hline 45 & 7.552 & 3,000 & 7.687 & 132,888 & 1,76 \\
\hline 46 & 1.035 & 3,000 & 1.056 & 132,197 & 1,99 \\
\hline 47 & 1.350 & 2,000 & 1.482 & 132,884 & 8,91 \\
\hline 48 & 1.703 & 2,000 & 1.762 & 135,981 & 3,35 \\
\hline 49 & 3.614 & 2,000 & 3.653 & 126,563 & 1,07 \\
\hline 50 & 2.169 & 2,000 & 2.409 & 142,981 & 9,96 \\
\hline 51 & 17.568 & 2,000 & 17.626 & 153,052 & 0,33 \\
\hline 52 & 16.600 & 3,000 & 16.702 & 131,920 & 0,61 \\
\hline 53 & 14.099 & 2,000 & 14.180 & 145,485 & 0,57 \\
\hline 54 & 16.217 & 4,000 & 16.285 & 139,105 & 0,42 \\
\hline 55 & 21.364 & 2,000 & 21.363 & 165,843 & 0,00 \\
\hline 56 & 8.516 & 2,000 & 8.577 & 134,160 & 0,71 \\
\hline 57 & 8.735 & 3,000 & 8.870 & 143,411 & 1,52 \\
\hline 58 & 10.568 & 3,000 & 10.673 & 150,977 & 0,98 \\
\hline 59 & 13.446 & 2,000 & 13.660 & 111,696 & 1,57 \\
\hline 60 & 15.392 & 4,000 & 15.462 & 144,569 & 0,45 \\
\hline 61 & 6.801 & 3,000 & 7.047 & 151,632 & 3,49 \\
\hline 62 & 11.354 & 3,000 & 11.488 & 151,195 & 1,17 \\
\hline 63 & 5.282 & 2,000 & 5.422 & 143,083 & 2,58 \\
\hline 64 & 6.746 & 2,000 & 6.918 & 149,058 & 2,49 \\
\hline 65 & 7.881 & 2,000 & 7.922 & 151,148 & 0,52 \\
\hline
\end{tabular}


Continuação

\begin{tabular}{|c|c|c|c|c|c|}
\hline 66 & 5.043 & 3,000 & 5.268 & 141,273 & 4,27 \\
\hline 67 & 8.324 & 3,000 & 8.648 & 118,607 & 3,75 \\
\hline 68 & 4.918 & 2,000 & 5.133 & 167,013 & 4,19 \\
\hline 69 & 4.314 & 2,000 & 4.404 & 121,503 & 2,04 \\
\hline 70 & 8.994 & 3,000 & 9.220 & 161,959 & 2,45 \\
\hline 71 & 4.768 & 3,000 & 4.937 & 153,285 & 3,42 \\
\hline 72 & 2.412 & 2,000 & 2.507 & 134,441 & 3,79 \\
\hline 73 & 3.328 & 4,000 & 3.448 & 144,971 & 3,48 \\
\hline 74 & 5.220 & 3,000 & 5.413 & 162,489 & 3,57 \\
\hline 75 & 5.939 & 2,000 & 6.235 & 177,855 & 4,75 \\
\hline 76 & 16.710 & 3,000 & 16.823 & 162,723 & 0,67 \\
\hline 77 & 17.545 & 2,000 & 17.667 & 163,316 & 0,69 \\
\hline 78 & 20.522 & 4,000 & 20.590 & 189,930 & 0,33 \\
\hline 79 & 16.139 & 2,000 & 16.350 & 167,279 & 1,29 \\
\hline 80 & 13.118 & 3,000 & 13.210 & 177,949 & 0,70 \\
\hline 81 & 10.847 & 3,000 & 11.034 & 174,720 & 1,69 \\
\hline 82 & 11.506 & 3,000 & 11.642 & 140,025 & 1,17 \\
\hline 83 & 12.304 & 3,000 & 12.460 & 164,018 & 1,25 \\
\hline 84 & 11.744 & 2,000 & 11.917 & 126,438 & 1,45 \\
\hline 85 & 10.649 & 2,000 & 10.825 & 140,556 & 1,63 \\
\hline 86 & 9.919 & 2,000 & 10.035 & 137,342 & 1,16 \\
\hline 87 & 11.926 & 3,000 & 12.162 & 138,013 & 1,94 \\
\hline 88 & 9.962 & 2,000 & 10.138 & 126,319 & 1,74 \\
\hline 89 & 10.901 & 4,000 & 11.098 & 156,047 & 1,78 \\
\hline 90 & 9.623 & 2,000 & 9.853 & 144,409 & 2,33 \\
\hline 91 & 13.182 & 2,000 & 13.383 & 150,914 & 1,50 \\
\hline 92 & 9.152 & 3,000 & 9.333 & 164,439 & 1,94 \\
\hline 93 & 7.381 & 2,000 & 7.404 & 149,963 & 0,31 \\
\hline 94 & 6.712 & 2,000 & 6.838 & 151,975 & 1,84 \\
\hline 95 & 6.392 & 3,000 & 6.531 & 136,359 & 2,13 \\
\hline 96 & 5.114 & 2,000 & 5.375 & 134,565 & 4,86 \\
\hline 97 & 4.379 & 2,000 & 4.665 & 132,803 & 6,13 \\
\hline 98 & 5.725 & 3,000 & 5.854 & 149,432 & 2,20 \\
\hline 99 & 8.494 & 3,000 & 8.773 & 156,437 & 3,18 \\
\hline 100 & 10.313 & 2,000 & 10.528 & 145,298 & 2,04 \\
\hline 101 & 13.236 & 3,000 & 13.409 & 146,593 & 1,29 \\
\hline 102 & 10.728 & 2,000 & 10.920 & 126,329 & 1,76 \\
\hline 103 & 18.927 & 2,000 & 19.125 & 149,370 & 1,04 \\
\hline 104 & 15.636 & 2,000 & 15.783 & 111,399 & 0,93 \\
\hline 105 & 17.608 & 2,000 & 17.762 & 130,603 & 0,87 \\
\hline 106 & 28.965 & 2,000 & 29.197 & 146,219 & 0,79 \\
\hline 107 & 24.379 & 3,000 & 24.622 & 147,981 & 0,99 \\
\hline 108 & 16.233 & 3,000 & 16.336 & 129,199 & 0,63 \\
\hline 109 & 16.520 & 4,000 & 16.717 & 144,534 & 1,18 \\
\hline 110 & 13.275 & 2,000 & 13.465 & 132,444 & 1,41 \\
\hline 111 & 13.592 & 2,000 & 13.760 & 163,753 & 1,22 \\
\hline 112 & 15.088 & 2,000 & 15.259 & 148,808 & 1,12 \\
\hline 113 & 18.774 & 3,000 & 18.959 & 174,626 & 0,98 \\
\hline 114 & 12.237 & 2,000 & 12.385 & 130,416 & 1,19 \\
\hline 115 & 21.701 & 2,000 & 21.914 & 170,009 & 0,97 \\
\hline 116 & 10.947 & 3,000 & 11.091 & 152,973 & 1,30 \\
\hline 117 & 14.926 & 2,000 & 15.016 & 156,203 & 0,60 \\
\hline 118 & 10.941 & 3,000 & 11.119 & 146,203 & 1,60 \\
\hline 119 & 15.538 & 5,000 & 15.705 & 150,774 & 1,06 \\
\hline 120 & 9.776 & 3,000 & 9.932 & 142,927 & 1,57 \\
\hline 121 & 9.086 & 2,000 & 9.224 & 185,219 & 1,50 \\
\hline 122 & 10.350 & 3,000 & 10.665 & 150,555 & 2,95 \\
\hline 123 & 15.316 & 3,000 & 15.498 & 161,663 & 1,17 \\
\hline 124 & 12.080 & 2,000 & 12.312 & 161,694 & 1,88 \\
\hline 125 & 14.363 & 3,000 & 14.560 & 156,171 & 1,35 \\
\hline
\end{tabular}


APÊNDICE E - Resultados GC x GRASP 50 X 6

\begin{tabular}{|c|c|c|c|c|c|}
\hline Instância & GC & Tempo [Seg] & Grasp $50 \times 6$ & Tempo [Seg] & Gap \% \\
\hline 1 & 23.300 & 5,000 & 23.461 & 346,343 & 0,69 \\
\hline 2 & 27.230 & 4,000 & 27.427 & 299,325 & 0,72 \\
\hline 3 & 20.964 & 5,000 & 21.077 & 370,344 & 0,54 \\
\hline 4 & 19.685 & 6,000 & 19.869 & 385,498 & 0,93 \\
\hline 5 & 18.169 & 5,000 & 18.170 & 335,755 & 0,01 \\
\hline 6 & 17.818 & 4,000 & 17.897 & 383,005 & 0,44 \\
\hline 7 & 16.788 & 7,000 & 16.816 & 404,185 & 0,17 \\
\hline 8 & 15.875 & 4,000 & 16.058 & 343,753 & 1,14 \\
\hline 9 & 11.768 & 4,000 & 11.952 & 345,837 & 1,54 \\
\hline 10 & 12.633 & 4,000 & 12.791 & 350,627 & 1,24 \\
\hline 11 & 15.054 & 3,000 & 15.210 & 303,592 & 1,03 \\
\hline 12 & 13.361 & 3,000 & 13.459 & 364,057 & 0,73 \\
\hline 13 & 10.604 & 3,000 & 10.763 & 258,149 & 1,48 \\
\hline 14 & 13.885 & 4,000 & 14.049 & 362,140 & 1,17 \\
\hline 15 & 12.450 & 4,000 & 12.652 & 314,012 & 1,60 \\
\hline 16 & 8.732 & 3,000 & 8.933 & 353,730 & 2,25 \\
\hline 17 & 12.989 & 4,000 & 13.188 & 342,061 & 1,51 \\
\hline 18 & 7.817 & 3,000 & 8.065 & 380,827 & 3,08 \\
\hline 19 & 5.246 & 3,000 & 5.397 & 345,385 & 2,80 \\
\hline 20 & 11.428 & 4,000 & 11.686 & 376,506 & 2,21 \\
\hline 21 & 4.304 & 3,000 & 4.527 & 287,524 & 4,93 \\
\hline 22 & 3.328 & 3,000 & 3.509 & 300,877 & 5,16 \\
\hline 23 & 4.485 & 3,000 & 4.638 & 309,599 & 3,30 \\
\hline 24 & 2.498 & 3,000 & 2.728 & 295,199 & 8,43 \\
\hline 25 & 6.081 & 2,000 & 6.257 & 348,723 & 2,81 \\
\hline 26 & 18.528 & 2,000 & 18.613 & 318,318 & 0,46 \\
\hline 27 & 22.599 & 5,000 & 22.769 & 354,323 & 0,75 \\
\hline 28 & 21.794 & 4,000 & 21.921 & 350,034 & 0,58 \\
\hline 29 & 18.824 & 4,000 & 18.894 & 340,470 & 0,37 \\
\hline 30 & 18.964 & 4,000 & 19.037 & 326,617 & 0,38 \\
\hline 31 & 16.037 & 3,000 & 16.191 & 284,045 & 0,95 \\
\hline 32 & 9.205 & 3,000 & 9.254 & 272,705 & 0,53 \\
\hline 33 & 15.720 & 6,000 & 15.831 & 382,637 & 0,70 \\
\hline 34 & 12.796 & 4,000 & 12.886 & 400,031 & 0,70 \\
\hline 35 & 14.131 & 5,000 & 14.168 & 315,463 & 0,26 \\
\hline 36 & 11.894 & 4,000 & 12.090 & 337,273 & 1,62 \\
\hline 37 & 10.907 & 3,000 & 10.952 & 359,518 & 0,41 \\
\hline 38 & 12.976 & 3,000 & 13.139 & 282,937 & 1,24 \\
\hline 39 & 11.165 & 3,000 & 11.365 & 291,814 & 1,76 \\
\hline 40 & 9.345 & 3,000 & 9.503 & 307,741 & 1,66 \\
\hline 41 & 12.929 & 3,000 & 13.108 & 330,471 & 1,37 \\
\hline 42 & 8.023 & 4,000 & 8.115 & 327,194 & 1,13 \\
\hline 43 & 5.928 & 3,000 & 6.113 & 338,146 & 3,03 \\
\hline 44 & 8.743 & 3,000 & 9.045 & 241,067 & 3,34 \\
\hline 45 & 9.334 & 4,000 & 9.733 & 351,422 & 4,10 \\
\hline 46 & 5.634 & 3,000 & 5.876 & 362,513 & 4,12 \\
\hline 47 & 2.802 & 4,000 & 2.978 & 337,085 & 5,91 \\
\hline 48 & 4.126 & 2,000 & 4.268 & 382,902 & 3,33 \\
\hline 49 & 5.948 & 3,000 & 6.103 & 281,533 & 2,54 \\
\hline 50 & 6.728 & 3,000 & 6.967 & 342,952 & 3,43 \\
\hline 51 & 16.507 & 3,000 & 16.561 & 339,409 & 0,33 \\
\hline 52 & 20.136 & 4,000 & 20.198 & 363,917 & 0,31 \\
\hline 53 & 18.094 & 4,000 & 18.160 & 337,568 & 0,36 \\
\hline 54 & 20.168 & 3,000 & 20.213 & 295,668 & 0,22 \\
\hline 55 & 23.157 & 4,000 & 23.238 & 315,806 & 0,35 \\
\hline 56 & 14.703 & 4,000 & 14.751 & 342,451 & 0,33 \\
\hline 57 & 15.734 & 4,000 & 15.859 & 342,919 & 0,79 \\
\hline 58 & 16.464 & 4,000 & 16.525 & 384,900 & 0,37 \\
\hline 59 & 15.565 & 3,000 & 15.682 & 283,982 & 0,75 \\
\hline 60 & 14.488 & 6,000 & 14.565 & 363,340 & 0,53 \\
\hline 61 & 11.345 & 3,000 & 11.505 & 328,708 & 1,39 \\
\hline 62 & 13.058 & 4,000 & 13.324 & 293,966 & 2,00 \\
\hline 63 & 11.511 & 4,000 & 11.715 & 383,574 & 1,74 \\
\hline 64 & 8.976 & 4,000 & 9.137 & 322,639 & 1,76 \\
\hline 65 & 9.318 & 4,000 & 9.539 & 378,768 & 2,32 \\
\hline
\end{tabular}


Continuação

\begin{tabular}{|c|c|c|c|c|c|}
\hline 66 & 14.299 & 3,000 & 14.632 & 393,729 & 2,28 \\
\hline 67 & 8.108 & 3,000 & 8.353 & 269,444 & 2,93 \\
\hline 68 & 13.424 & 3,000 & 13.768 & 368,769 & 2,50 \\
\hline 69 & 9.777 & 5,000 & 10.026 & 324,059 & 2,48 \\
\hline 70 & 11.600 & 3,000 & 11.880 & 324,886 & 2,36 \\
\hline 71 & 13.959 & 2,000 & 14.377 & 327,008 & 2,91 \\
\hline 72 & 16.575 & 4,000 & 16.896 & 356,413 & 1,90 \\
\hline 73 & 7.345 & 4,000 & 7.627 & 289,708 & 3,70 \\
\hline 74 & 7.972 & 5,000 & 8.176 & 327,428 & 2,50 \\
\hline 75 & 7.874 & 3,000 & 8.155 & 286,338 & 3,45 \\
\hline 76 & 23.774 & 5,000 & 23.940 & 336,867 & 0,69 \\
\hline 77 & 32.450 & 5,000 & 32.610 & 429,297 & 0,49 \\
\hline 78 & 31.574 & 4,000 & 31.761 & 314,512 & 0,59 \\
\hline 79 & 24.191 & 4,000 & 24.404 & 316,228 & 0,87 \\
\hline 80 & 21.434 & 5,000 & 21.561 & 289,178 & 0,59 \\
\hline 81 & 21.033 & 3,000 & 21.272 & 306,197 & 1,12 \\
\hline 82 & 19.407 & 4,000 & 19.644 & 388,830 & 1,21 \\
\hline 83 & 18.571 & 4,000 & 18.887 & 331,250 & 1,67 \\
\hline 84 & 17.673 & 5,000 & 17.907 & 340,253 & 1,31 \\
\hline 85 & 20.675 & 4,000 & 20.887 & 352,045 & 1,01 \\
\hline 86 & 23.996 & 5,000 & 24.251 & 379,330 & 1,05 \\
\hline 87 & 18.892 & 5,000 & 19.130 & 395,928 & 1,24 \\
\hline 88 & 18.138 & 4,000 & 18.312 & 336,072 & 0,95 \\
\hline 89 & 17.025 & 3,000 & 17.304 & 353,371 & 1,61 \\
\hline 90 & 20.835 & 4,000 & 21.086 & 367,396 & 1,19 \\
\hline 91 & 18.049 & 4,000 & 18.300 & 315,385 & 1,37 \\
\hline 92 & 14.912 & 5,000 & 15.105 & 331,110 & 1,28 \\
\hline 93 & 16.367 & 5,000 & 16.716 & 327,305 & 2,09 \\
\hline 94 & 11.286 & 4,000 & 11.637 & 256,012 & 3,02 \\
\hline 95 & 13.989 & 4,000 & 14.328 & 347,475 & 2,37 \\
\hline 96 & 11.832 & 4,000 & 12.133 & 343,029 & 2,48 \\
\hline 97 & 17.277 & 3,000 & 17.574 & 334,949 & 1,69 \\
\hline 98 & 22.669 & 4,000 & 23.026 & 373,932 & 1,55 \\
\hline 99 & 13.740 & 3,000 & 14.074 & 290,597 & 2,37 \\
\hline 100 & 12.885 & 3,000 & 13.107 & 381,904 & 1,69 \\
\hline 101 & 29.384 & 3,000 & 29.659 & 281,954 & 0,93 \\
\hline 102 & 24.716 & 5,000 & 24.980 & 289,334 & 1,06 \\
\hline 103 & 28.295 & 4,000 & 28.541 & 300,690 & 0,86 \\
\hline 104 & 28.594 & 5,000 & 28.796 & 310,752 & 0,70 \\
\hline 105 & 21.524 & 5,000 & 21.777 & 283,078 & 1,16 \\
\hline 106 & 24.259 & 4,000 & 24.528 & 334,214 & 1,10 \\
\hline 107 & 18.114 & 4,000 & 18.372 & 332,094 & 1,40 \\
\hline 108 & 26.604 & 4,000 & 26.871 & 309,535 & 0,99 \\
\hline 109 & 29.050 & 3,000 & 29.290 & 275,964 & 0,82 \\
\hline 110 & 19.312 & 4,000 & 19.540 & 291,595 & 1,17 \\
\hline 111 & 19.603 & 4,000 & 19.779 & 326,041 & 0,89 \\
\hline 112 & 21.292 & 4,000 & 21.471 & 330,408 & 0,83 \\
\hline 113 & 25.006 & 5,000 & 25.209 & 324,059 & 0,81 \\
\hline 114 & 22.318 & 3,000 & 22.560 & 329,066 & 1,07 \\
\hline 115 & 20.472 & 4,000 & 20.771 & 307,398 & 1,44 \\
\hline 116 & 16.656 & 4,000 & 16.912 & 330,986 & 1,51 \\
\hline 117 & 21.944 & 4,000 & 22.176 & 371,577 & 1,05 \\
\hline 118 & 20.639 & 3,000 & 20.892 & 339,082 & 1,21 \\
\hline 119 & 27.295 & 5,000 & 27.544 & 308,896 & 0,90 \\
\hline 120 & 20.005 & 4,000 & 20.182 & 298,320 & 0,88 \\
\hline 121 & 19.029 & 3,000 & 19.298 & 296,759 & 1,39 \\
\hline 122 & 14.864 & 3,000 & 15.140 & 293,108 & 1,82 \\
\hline 123 & 21.302 & 4,000 & 21.486 & 369,018 & 0,86 \\
\hline 124 & 16.005 & 4,000 & 16.271 & 322,468 & 1,63 \\
\hline 125 & 21.452 & 3,000 & 21.733 & 351,220 & 1,29 \\
\hline
\end{tabular}


APÊNDICE F - Resultados GC x HEU_C + BL 30 x 4

\begin{tabular}{|c|c|c|c|c|c|}
\hline Instância & GC & Tempo [Seg] & HEU_C + BL & Tempo [Seg] & Gap \% \\
\hline 1 & 15.417 & 1,000 & $1 \overline{5} .560$ & 0,046 & 0,92 \\
\hline 2 & 7.433 & 2,000 & 7.501 & 0,046 & 0,91 \\
\hline 3 & 16.530 & 2,000 & 16.848 & 0,062 & 1,89 \\
\hline 4 & 16.053 & 1,000 & 16.147 & 0,062 & 0,58 \\
\hline 5 & 6.992 & 1,000 & 7.150 & 0,046 & 2,21 \\
\hline 6 & 9.059 & 1,000 & 9.477 & 0,015 & 4,41 \\
\hline 7 & 6.447 & 1,000 & 6.580 & 0,031 & 2,02 \\
\hline 8 & 6.773 & 2,000 & 7.305 & 0,046 & 7,28 \\
\hline 9 & 10.539 & 2,000 & 10.763 & 0,031 & 2,08 \\
\hline 10 & 9.324 & 1,000 & 9.597 & 0,031 & 2,84 \\
\hline 11 & 9.430 & 2,000 & 9.750 & 0,046 & 3,28 \\
\hline 12 & 6.694 & 2,000 & 6.929 & 0,031 & 3,39 \\
\hline 13 & 4.835 & 1,000 & 5.261 & 0,046 & 8,10 \\
\hline 14 & 8.968 & 2,000 & 9.148 & 0,046 & 1,97 \\
\hline 15 & 4.257 & 1,000 & 4.403 & 0,031 & 3,32 \\
\hline 16 & 2.107 & 1,000 & 2.370 & 0,046 & 11,10 \\
\hline 17 & 1.999 & 2,000 & 2.140 & 0,031 & 6,59 \\
\hline 18 & 2.109 & 1,000 & 2.393 & 0,046 & 11,87 \\
\hline 19 & 3.706 & 1,000 & 3.911 & 0,046 & 5,24 \\
\hline 20 & 1.875 & 1,000 & 2.240 & 0,031 & 16,29 \\
\hline 21 & 1.958 & 1,000 & 2.087 & 0,046 & 6,18 \\
\hline 22 & 2.310 & 2,000 & 2.650 & 0,031 & 12,83 \\
\hline 23 & 2.456 & 1,000 & 2.624 & 0,046 & 6,40 \\
\hline 24 & 1.372 & 1,000 & 1.665 & 0,031 & 17,60 \\
\hline 25 & 1.798 & 1,000 & 2.328 & 0,046 & 22,77 \\
\hline 26 & 6.326 & 2,000 & 6.466 & 0,046 & 2,17 \\
\hline 27 & 9.809 & 2,000 & 9.938 & 0,046 & 1,30 \\
\hline 28 & 16.150 & 1,000 & 16.295 & 0,062 & 0,89 \\
\hline 29 & 14.081 & 2,000 & 14.205 & 0,031 & 0,87 \\
\hline 30 & 12.761 & 2,000 & 12.831 & 0,046 & 0,55 \\
\hline 31 & 8.187 & 2,000 & 8.414 & 0,046 & 2,70 \\
\hline 32 & 8.684 & 2,000 & 9.056 & 0,031 & 4,11 \\
\hline 33 & 6.440 & 1,000 & 6.553 & 0,062 & 1,72 \\
\hline 34 & 4.939 & 1,000 & 5.327 & 0,031 & 7,28 \\
\hline 35 & 4.366 & 2,000 & 4.728 & 0,046 & 7,66 \\
\hline 36 & 6.741 & 2,000 & 7.107 & 0,031 & 5,15 \\
\hline 37 & 7.648 & 1,000 & 8.150 & 0,046 & 6,16 \\
\hline 38 & 2.309 & 1,000 & 2.503 & 0,031 & 7,75 \\
\hline 39 & 4.830 & 1,000 & 5.015 & 0,046 & 3,69 \\
\hline 40 & 5.007 & 1,000 & 5.322 & 0,046 & 5,92 \\
\hline 41 & 3.922 & 2,000 & 4.109 & 0,046 & 4,55 \\
\hline 42 & 2.672 & 2,000 & 2.795 & 0,046 & 4,40 \\
\hline 43 & 1.755 & 1,000 & 1.986 & 0,031 & 11,63 \\
\hline 44 & 1.449 & 2,000 & 1.690 & 0,031 & 14,26 \\
\hline 45 & 3.542 & 2,000 & 4.052 & 0,031 & 12,59 \\
\hline 46 & 2.037 & 1,000 & 2.316 & 0,031 & 12,05 \\
\hline 47 & 2.577 & 2,000 & 2.934 & 0,046 & 12,17 \\
\hline 48 & 1.602 & 1,000 & 1.718 & 0,046 & 6,75 \\
\hline 49 & 1.711 & 1,000 & 2.006 & 0,031 & 14,71 \\
\hline 50 & 2.219 & 1,000 & 2.364 & 0,046 & 6,13 \\
\hline 51 & 9.481 & 2,000 & 9.647 & 0,046 & 1,72 \\
\hline 52 & 15.342 & 1,000 & 15.444 & 0,046 & 0,66 \\
\hline 53 & 7.480 & 2,000 & 7.720 & 0,015 & 3,11 \\
\hline 54 & 11.144 & 2,000 & 11.370 & 0,046 & 1,99 \\
\hline 55 & 10.736 & 1,000 & 10.854 & 0,046 & 1,09 \\
\hline 56 & 7.115 & 1,000 & 7.149 & 0,046 & 0,48 \\
\hline 57 & 7.484 & 1,000 & 7.826 & 0,031 & 4,37 \\
\hline 58 & 5.353 & 2,000 & 5.738 & 0,031 & 6,71 \\
\hline 59 & 7.662 & 2,000 & 7.929 & 0,046 & 3,37 \\
\hline 60 & 8.908 & 1,000 & 9.097 & 0,046 & 2,08 \\
\hline 61 & 6.398 & 1,000 & 7.294 & 0,031 & 12,28 \\
\hline 62 & 4.820 & 1,000 & 6.006 & 0,031 & 19,75 \\
\hline 63 & 5.546 & 2,000 & 5.977 & 0,031 & 7,21 \\
\hline 64 & 5.634 & 1,000 & 6.153 & 0,046 & 8,43 \\
\hline 65 & 6.809 & 2,000 & 7.181 & 0,062 & 5,18 \\
\hline
\end{tabular}


Continuação

\begin{tabular}{|c|c|c|c|c|c|}
\hline 66 & 4.388 & 2,000 & 4.974 & 0,031 & 11,78 \\
\hline 67 & 3.618 & 1,000 & 3.860 & 0,062 & 6,27 \\
\hline 68 & 3.437 & 1,000 & 4.149 & 0,031 & 17,16 \\
\hline 69 & 4.024 & 1,000 & 4.383 & 0,031 & 8,19 \\
\hline 70 & 5.092 & 1,000 & 5.804 & 0,031 & 12,27 \\
\hline 71 & 3.032 & 2,000 & 3.391 & 0,046 & 10,59 \\
\hline 72 & 1.391 & 2,000 & 1.490 & 0,031 & 6,64 \\
\hline 73 & 3.016 & 1,000 & 3.213 & 0,062 & 6,13 \\
\hline 74 & 2.718 & 1,000 & 3.281 & 0,031 & 17,16 \\
\hline 75 & 2.888 & 1,000 & 3.307 & 0,031 & 12,67 \\
\hline 76 & 10.469 & 1,000 & 10.778 & 0,015 & 2,87 \\
\hline 77 & 8.745 & 2,000 & 8.874 & 0,046 & 1,45 \\
\hline 78 & 8.652 & 1,000 & 8.781 & 0,031 & 1,47 \\
\hline 79 & 9.831 & 2,000 & 10.229 & 0,046 & 3,89 \\
\hline 80 & 7.737 & 1,000 & 7.886 & 0,031 & 1,89 \\
\hline 81 & 7.408 & 1,000 & 7.872 & 0,046 & 5,89 \\
\hline 82 & 9.421 & 1,000 & 9.619 & 0,046 & 2,06 \\
\hline 83 & 10.549 & 2,000 & 10.916 & 0,046 & 3,36 \\
\hline 84 & 11.406 & 1,000 & 11.551 & 0,046 & 1,26 \\
\hline 85 & 8.122 & 1,000 & 8.245 & 0,046 & 1,49 \\
\hline 86 & 7.484 & 1,000 & 7.741 & 0,031 & 3,32 \\
\hline 87 & 6.185 & 1,000 & 6.362 & 0,031 & 2,78 \\
\hline 88 & 7.909 & 2,000 & 8.112 & 0,031 & 2,50 \\
\hline 89 & 10.978 & 1,000 & 11.489 & 0,031 & 4,45 \\
\hline 90 & 8.826 & 2,000 & 9.113 & 0,031 & 3,15 \\
\hline 91 & 8.260 & 1,000 & 8.727 & 0,031 & 5,35 \\
\hline 92 & 5.554 & 1,000 & 6.218 & 0,031 & 10,68 \\
\hline 93 & 6.461 & 1,000 & 6.758 & 0,062 & 4,39 \\
\hline 94 & 7.778 & 1,000 & 8.113 & 0,046 & 4,13 \\
\hline 95 & 7.850 & 1,000 & 7.991 & 0,046 & 1,76 \\
\hline 96 & 3.676 & 2,000 & 4.120 & 0,031 & 10,78 \\
\hline 97 & 4.906 & 1,000 & 5.285 & 0,046 & 7,17 \\
\hline 98 & 1.601 & 1,000 & 1.758 & 0,062 & 8,93 \\
\hline 99 & 5.282 & 1,000 & 5.487 & 0,031 & 3,74 \\
\hline 100 & 7.419 & 1,000 & 7.976 & 0,046 & 6,98 \\
\hline 101 & 17.076 & 2,000 & 17.234 & 0,015 & 0,92 \\
\hline 102 & 8.986 & 1,000 & 9.134 & 0,031 & 1,62 \\
\hline 103 & 8.737 & 1,000 & 8.826 & 0,031 & 1,01 \\
\hline 104 & 12.099 & 1,000 & 12.301 & 0,062 & 1,64 \\
\hline 105 & 9.911 & 1,000 & 10.087 & 0,031 & 1,74 \\
\hline 106 & 11.008 & 2,000 & 11.294 & 0,031 & 2,53 \\
\hline 107 & 13.667 & 2,000 & 13.851 & 0,031 & 1,33 \\
\hline 108 & 12.375 & 2,000 & 12.582 & 0,046 & 1,65 \\
\hline 109 & 14.597 & 1,000 & 14.853 & 0,031 & 1,72 \\
\hline 110 & 10.668 & 1,000 & 10.827 & 0,031 & 1,47 \\
\hline 111 & 11.353 & 1,000 & 11.474 & 0,031 & 1,05 \\
\hline 112 & 16.857 & 2,000 & 17.041 & 0,031 & 1,08 \\
\hline 113 & 14.871 & 1,000 & 14.974 & 0,031 & 0,69 \\
\hline 114 & 14.882 & 2,000 & 15.093 & 0,037 & 1,40 \\
\hline 115 & 17.117 & 1,000 & 17.278 & 0,051 & 0,93 \\
\hline 116 & 7.988 & 2,000 & 8.188 & 0,021 & 2,44 \\
\hline 117 & 6.272 & 1,000 & 6.540 & 0,031 & 4,10 \\
\hline 118 & 11.147 & 2,000 & 11.323 & 0,042 & 1,55 \\
\hline 119 & 9.748 & 2,000 & 10.143 & 0,046 & 3,89 \\
\hline 120 & 8.002 & 1,000 & 8.434 & 0,030 & 5,12 \\
\hline 121 & 9.620 & 1,000 & 9.848 & 0,046 & 2,32 \\
\hline 122 & 16.018 & 2,000 & 16.648 & 0,051 & 3,78 \\
\hline 123 & 8.466 & 1,000 & 8.720 & 0,035 & 2,91 \\
\hline 124 & 9.410 & 2,000 & 9.670 & 0,046 & 2,69 \\
\hline 125 & 15.361 & 1,000 & 15.642 & 0,031 & 1,80 \\
\hline
\end{tabular}


APÊNDICE G - Resultados HEU_C + BL 40 x 5

\begin{tabular}{|c|c|c|c|c|c|}
\hline Instância & GC & Tempo [Seg] & HEU_C + BL & Tempo [Seg] & Gap \% \\
\hline 1 & 16.268 & 2,000 & 16.528 & 0,062 & 1,57 \\
\hline 2 & 12.354 & 3,000 & 12.589 & 0,093 & 1,87 \\
\hline 3 & 14.262 & 3,000 & 14.514 & 0,124 & 1,74 \\
\hline 4 & 18.806 & 2,000 & 18.972 & 0,124 & 0,87 \\
\hline 5 & 16.559 & 3,000 & 17.229 & 0,109 & 3,89 \\
\hline 6 & 11.196 & 2,000 & 11.640 & 0,124 & 3,81 \\
\hline 7 & 15.934 & 2,000 & 16.443 & 0,109 & 3,10 \\
\hline 8 & 15.577 & 2,000 & 15.844 & 0,140 & 1,69 \\
\hline 9 & 12.100 & 3,000 & 12.433 & 0,078 & 2,68 \\
\hline 10 & 10.656 & 2,000 & 11.000 & 0,109 & 3,13 \\
\hline 11 & 7.910 & 2,000 & 8.529 & 0,078 & 7,26 \\
\hline 12 & 5.238 & 2,000 & 5.615 & 0,109 & 6,71 \\
\hline 13 & 6.130 & 4,000 & 6.708 & 0,093 & 8,62 \\
\hline 14 & 10.998 & 3,000 & 11.487 & 0,109 & 4,26 \\
\hline 15 & 6.830 & 2,000 & 7.655 & 0,078 & 10,78 \\
\hline 16 & 2.257 & 3,000 & 2.989 & 0,078 & 24,49 \\
\hline 17 & 2.074 & 2,000 & 2.366 & 0,109 & 12,34 \\
\hline 18 & 2.698 & 2,000 & 3.058 & 0,140 & 11,77 \\
\hline 19 & 3.300 & 2,000 & 3.508 & 0,093 & 5,93 \\
\hline 20 & 2.395 & 2,000 & 2.866 & 0,078 & 16,43 \\
\hline 21 & 2.291 & 2,000 & 2.453 & 0,109 & 6,60 \\
\hline 22 & 891 & 3,000 & 994 & 0,078 & 10,36 \\
\hline 23 & 2.175 & 2,000 & 2.566 & 0,078 & 15,24 \\
\hline 24 & 2.079 & 2,000 & 2.810 & 0,078 & 26,01 \\
\hline 25 & 789 & 2,000 & 920 & 0,093 & 14,24 \\
\hline 26 & 13.673 & 2,000 & 13.752 & 0,109 & 0,57 \\
\hline 27 & 11.241 & 3,000 & 11.659 & 0,109 & 3,59 \\
\hline 28 & 9.602 & 2,000 & 9.909 & 0,109 & 3,10 \\
\hline 29 & 12.161 & 3,000 & 12.318 & 0,109 & 1,27 \\
\hline 30 & 13.194 & 3,000 & 13.285 & 0,093 & 0,68 \\
\hline 31 & 13.273 & 2,000 & 13.803 & 0,109 & 3,84 \\
\hline 32 & 5.918 & 1,000 & 6.307 & 0,093 & 6,17 \\
\hline 33 & 9.530 & 3,000 & 9.929 & 0,078 & 4,02 \\
\hline 34 & 10.353 & 3,000 & 10.529 & 0,093 & 1,67 \\
\hline 35 & 12.314 & 2,000 & 12.837 & 0,078 & 4,07 \\
\hline 36 & 6.470 & 2,000 & 6.604 & 0,124 & 2,03 \\
\hline 37 & 4.759 & 3,000 & 4.935 & 0,140 & 3,57 \\
\hline 38 & 5.565 & 2,000 & 5.872 & 0,093 & 5,23 \\
\hline 39 & 4.538 & 2,000 & 5.060 & 0,078 & 10,32 \\
\hline 40 & 6.867 & 2,000 & 7.312 & 0,062 & 6,09 \\
\hline 41 & 3.111 & 1,000 & 3.596 & 0,078 & 13,49 \\
\hline 42 & 3.012 & 1,000 & 3.460 & 0,093 & 12,95 \\
\hline 43 & 3.370 & 2,000 & 3.912 & 0,078 & 13,85 \\
\hline 44 & 3.829 & 3,000 & 4.174 & 0,109 & 8,27 \\
\hline 45 & 7.552 & 3,000 & 8.022 & 0,093 & 5,86 \\
\hline 46 & 1.035 & 3,000 & 1.214 & 0,078 & 14,74 \\
\hline 47 & 1.350 & 2,000 & 1.733 & 0,124 & 22,10 \\
\hline 48 & 1.703 & 2,000 & 2.129 & 0,109 & 20,01 \\
\hline 49 & 3.614 & 2,000 & 3.863 & 0,046 & 6,45 \\
\hline 50 & 2.169 & 2,000 & 2.672 & 0,109 & 18,82 \\
\hline 51 & 17.568 & 2,000 & 17.890 & 0,093 & 1,80 \\
\hline 52 & 16.600 & 3,000 & 16.880 & 0,109 & 1,66 \\
\hline 53 & 14.099 & 2,000 & 14.600 & 0,062 & 3,43 \\
\hline 54 & 16.217 & 4,000 & 16.806 & 0,062 & 3,50 \\
\hline 55 & 21.364 & 2,000 & 21.426 & 0,124 & 0,29 \\
\hline 56 & 8.516 & 2,000 & 8.780 & 0,109 & 3,01 \\
\hline 57 & 8.735 & 3,000 & 9.046 & 0,078 & 3,44 \\
\hline 58 & 10.568 & 3,000 & 11.150 & 0,093 & 5,22 \\
\hline 59 & 13.446 & 2,000 & 14.144 & 0,093 & 4,93 \\
\hline 60 & 15.392 & 4,000 & 15.933 & 0,078 & 3,40 \\
\hline 61 & 6.801 & 3,000 & 7.146 & 0,093 & 4,83 \\
\hline 62 & 11.354 & 3,000 & 11.625 & 0,109 & 2,33 \\
\hline 63 & 5.282 & 2,000 & 5.587 & 0,078 & 5,46 \\
\hline 64 & 6.746 & 2,000 & 7.549 & 0,078 & 10,64 \\
\hline 65 & 7.881 & 2,000 & 8.196 & 0,109 & 3,84 \\
\hline
\end{tabular}


Continuação

\begin{tabular}{|c|c|c|c|c|c|}
\hline 66 & 5.043 & 3,000 & 5.477 & 0,124 & 7,92 \\
\hline 67 & 8.324 & 3,000 & 9.029 & 0,078 & 7,81 \\
\hline 68 & 4.918 & 2,000 & 5.544 & 0,078 & 11,29 \\
\hline 69 & 4.314 & 2,000 & 5.130 & 0,062 & 15,91 \\
\hline 70 & 8.994 & 3,000 & 9.478 & 0,124 & 5,11 \\
\hline 71 & 4.768 & 3,000 & 5.161 & 0,156 & 7,61 \\
\hline 72 & 2.412 & 2,000 & 2.860 & 0,124 & 15,66 \\
\hline 73 & 3.328 & 4,000 & 3.698 & 0,124 & 10,01 \\
\hline 74 & 5.220 & 3,000 & 5.903 & 0,078 & 11,57 \\
\hline 75 & 5.939 & 2,000 & 7.098 & 0,078 & 16,33 \\
\hline 76 & 16.710 & 3,000 & 17.037 & 0,124 & 1,92 \\
\hline 77 & 17.545 & 2,000 & 17.748 & 0,124 & 1,14 \\
\hline 78 & 20.522 & 4,000 & 20.929 & 0,124 & 1,94 \\
\hline 79 & 16.139 & 2,000 & 16.363 & 0,124 & 1,37 \\
\hline 80 & 13.118 & 3,000 & 13.210 & 0,140 & 0,70 \\
\hline 81 & 10.847 & 3,000 & 11.245 & 0,093 & 3,54 \\
\hline 82 & 11.506 & 3,000 & 12.081 & 0,109 & 4,76 \\
\hline 83 & 12.304 & 3,000 & 12.996 & 0,093 & 5,32 \\
\hline 84 & 11.744 & 2,000 & 12.343 & 0,093 & 4,85 \\
\hline 85 & 10.649 & 2,000 & 11.361 & 0,109 & 6,27 \\
\hline 86 & 9.919 & 2,000 & 10.378 & 0,078 & 4,42 \\
\hline 87 & 11.926 & 3,000 & 12.455 & 0,109 & 4,25 \\
\hline 88 & 9.962 & 2,000 & 10.628 & 0,078 & 6,27 \\
\hline 89 & 10.901 & 4,000 & 11.546 & 0,062 & 5,59 \\
\hline 90 & 9.623 & 2,000 & 10.191 & 0,093 & 5,57 \\
\hline 91 & 13.182 & 2,000 & 13.752 & 0,093 & 4,14 \\
\hline 92 & 9.152 & 3,000 & 9.464 & 0,093 & 3,30 \\
\hline 93 & 7.381 & 2,000 & 7.634 & 0,093 & 3,31 \\
\hline 94 & 6.712 & 2,000 & 7.129 & 0,093 & 5,85 \\
\hline 95 & 6.392 & 3,000 & 6.862 & 0,093 & 6,85 \\
\hline 96 & 5.114 & 2,000 & 5.546 & 0,093 & 7,79 \\
\hline 97 & 4.379 & 2,000 & 5.213 & 0,046 & 16,00 \\
\hline 98 & 5.725 & 3,000 & 6.590 & 0,124 & 13,13 \\
\hline 99 & 8.494 & 3,000 & 9.217 & 0,109 & 7,84 \\
\hline 100 & 10.313 & 2,000 & 11.036 & 0,062 & 6,55 \\
\hline 101 & 13.236 & 3,000 & 13.420 & 0,093 & 1,37 \\
\hline 102 & 10.728 & 2,000 & 10.944 & 0,093 & 1,97 \\
\hline 103 & 18.927 & 2,000 & 19.178 & 0,078 & 1,31 \\
\hline 104 & 15.636 & 2,000 & 15.856 & 0,031 & 1,39 \\
\hline 105 & 17.608 & 2,000 & 17.866 & 0,062 & 1,44 \\
\hline 106 & 28.965 & 2,000 & 29.425 & 0,109 & 1,56 \\
\hline 107 & 24.379 & 3,000 & 24.917 & 0,078 & 2,16 \\
\hline 108 & 16.233 & 3,000 & 16.380 & 0,062 & 0,90 \\
\hline 109 & 16.520 & 4,000 & 16.892 & 0,078 & 2,20 \\
\hline 110 & 13.275 & 2,000 & 13.522 & 0,124 & 1,83 \\
\hline 111 & 13.592 & 2,000 & 13.966 & 0,093 & 2,68 \\
\hline 112 & 15.088 & 2,000 & 15.495 & 0,093 & 2,63 \\
\hline 113 & 18.774 & 3,000 & 19.035 & 0,124 & 1,37 \\
\hline 114 & 12.237 & 2,000 & 12.651 & 0,078 & 3,27 \\
\hline 115 & 21.701 & 2,000 & 22.107 & 0,078 & 1,84 \\
\hline 116 & 10.947 & 3,000 & 11.254 & 0,093 & 2,73 \\
\hline 117 & 14.926 & 2,000 & 15.055 & 0,062 & 0,86 \\
\hline 118 & 10.941 & 3,000 & 11.567 & 0,062 & 5,41 \\
\hline 119 & 15.538 & 5,000 & 15.972 & 0,124 & 2,72 \\
\hline 120 & 9.776 & 3,000 & 10.651 & 0,109 & 8,22 \\
\hline 121 & 9.086 & 2,000 & 9.511 & 0,140 & 4,47 \\
\hline 122 & 10.350 & 3,000 & 10.969 & 0,093 & 5,64 \\
\hline 123 & 15.316 & 3,000 & 15.783 & 0,093 & 2,96 \\
\hline 124 & 12.080 & 2,000 & 12.362 & 0,124 & 2,28 \\
\hline 125 & 14.363 & 3,000 & 14.931 & 0,078 & 3,80 \\
\hline
\end{tabular}


APÊNDICE H - Resultados HEU_C + BL 50 X 6

\begin{tabular}{|c|c|c|c|c|c|}
\hline Instância & GC & Tempo [Seg] & HEU_C + BL & Tempo [Seg] & Gap \% \\
\hline 1 & 23.300 & 5,000 & 23.556 & 0,234 & 1,09 \\
\hline 2 & 27.230 & 4,000 & 27.488 & 0,249 & 0,94 \\
\hline 3 & 20.964 & 5,000 & 21.199 & 0,265 & 1,11 \\
\hline 4 & 19.685 & 6,000 & 19.997 & 0,171 & 1,56 \\
\hline 5 & 18.169 & 5,000 & 18.248 & 0,234 & 0,43 \\
\hline 6 & 17.818 & 4,000 & 18.051 & 0,234 & 1,29 \\
\hline 7 & 16.788 & 7,000 & 16.829 & 0,218 & 0,24 \\
\hline 8 & 15.875 & 4,000 & 16.281 & 0,156 & 2,49 \\
\hline 9 & 11.768 & 4,000 & 12.128 & 0,234 & 2,97 \\
\hline 10 & 12.633 & 4,000 & 12.978 & 0,171 & 2,66 \\
\hline 11 & 15.054 & 3,000 & 15.726 & 0,171 & 4,27 \\
\hline 12 & 13.361 & 3,000 & 13.680 & 0,234 & 2,33 \\
\hline 13 & 10.604 & 3,000 & 10.963 & 0,140 & 3,27 \\
\hline 14 & 13.885 & 4,000 & 14.299 & 0,327 & 2,90 \\
\hline 15 & 12.450 & 4,000 & 12.979 & 0,171 & 4,08 \\
\hline 16 & 8.732 & 3,000 & 9.219 & 0,218 & 5,28 \\
\hline 17 & 12.989 & 4,000 & 14.006 & 0,140 & 7,26 \\
\hline 18 & 7.817 & 3,000 & 8.723 & 0,202 & 10,39 \\
\hline 19 & 5.246 & 3,000 & 5.772 & 0,202 & 9,11 \\
\hline 20 & 11.428 & 4,000 & 12.267 & 0,218 & 6,84 \\
\hline 21 & 4.304 & 3,000 & 4.743 & 0,171 & 9,26 \\
\hline 22 & 3.328 & 3,000 & 3.640 & 0,249 & 8,57 \\
\hline 23 & 4.485 & 3,000 & 5.554 & 0,093 & 19,25 \\
\hline 24 & 2.498 & 3,000 & 3.005 & 0,202 & 16,87 \\
\hline 25 & 6.081 & 2,000 & 106.704 & 0,187 & 94,30 \\
\hline 26 & 18.528 & 2,000 & 18.899 & 0,218 & 1,96 \\
\hline 27 & 22.599 & 5,000 & 22.868 & 0,280 & 1,18 \\
\hline 28 & 21.794 & 4,000 & 22.210 & 0,327 & 1,87 \\
\hline 29 & 18.824 & 4,000 & 18.967 & 0,234 & 0,75 \\
\hline 30 & 18.964 & 4,000 & 19.141 & 0,171 & 0,92 \\
\hline 31 & 16.037 & 3,000 & 16.229 & 0,171 & 1,18 \\
\hline 32 & 9.205 & 3,000 & 9.521 & 0,171 & 3,32 \\
\hline 33 & 15.720 & 6,000 & 16.206 & 0,249 & 3,00 \\
\hline 34 & 12.796 & 4,000 & 13.130 & 0,218 & 2,54 \\
\hline 35 & 14.131 & 5,000 & 14.374 & 0,218 & 1,69 \\
\hline 36 & 11.894 & 4,000 & 12.304 & 0,202 & 3,33 \\
\hline 37 & 10.907 & 3,000 & 11.278 & 0,218 & 3,29 \\
\hline 38 & 12.976 & 3,000 & 13.575 & 0,187 & 4,41 \\
\hline 39 & 11.165 & 3,000 & 111.770 & 0,218 & 90,01 \\
\hline 40 & 9.345 & 3,000 & 10.055 & 0,124 & 7,06 \\
\hline 41 & 12.929 & 3,000 & 13.646 & 0,171 & 5,25 \\
\hline 42 & 8.023 & 4,000 & 108.782 & 0,140 & 92,62 \\
\hline 43 & 5.928 & 3,000 & 6.263 & 0,312 & 5,35 \\
\hline 44 & 8.743 & 3,000 & 9.777 & 0,109 & 10,58 \\
\hline 45 & 9.334 & 4,000 & 9.989 & 0,218 & 6,56 \\
\hline 46 & 5.634 & 3,000 & 6.248 & 0,280 & 9,83 \\
\hline 47 & 2.802 & 4,000 & 3.273 & 0,312 & 14,39 \\
\hline 48 & 4.126 & 2,000 & 4.571 & 0,202 & 9,74 \\
\hline 49 & 5.948 & 3,000 & 6.751 & 0,109 & 11,89 \\
\hline 50 & 6.728 & 3,000 & 7.546 & 0,202 & 10,84 \\
\hline 51 & 16.507 & 3,000 & 16.854 & 0,202 & 2,06 \\
\hline 52 & 20.136 & 4,000 & 20.316 & 0,249 & 0,89 \\
\hline 53 & 18.094 & 4,000 & 18.266 & 0,296 & 0,94 \\
\hline 54 & 20.168 & 3,000 & 20.266 & 0,187 & 0,48 \\
\hline 55 & 23.157 & 4,000 & 23.339 & 0,265 & 0,78 \\
\hline 56 & 14.703 & 4,000 & 14.978 & 0,234 & 1,84 \\
\hline 57 & 15.734 & 4,000 & 16.117 & 0,218 & 2,38 \\
\hline 58 & 16.464 & 4,000 & 16.799 & 0,187 & 1,99 \\
\hline 59 & 15.565 & 3,000 & 15.873 & 0,109 & 1,94 \\
\hline 60 & 14.488 & 6,000 & 14.720 & 0,156 & 1,58 \\
\hline 61 & 11.345 & 3,000 & 12.070 & 0,171 & 6,01 \\
\hline 62 & 13.058 & 4,000 & 13.923 & 0,218 & 6,21 \\
\hline 63 & 11.511 & 4,000 & 12.336 & 0,187 & 6,69 \\
\hline 64 & 8.976 & 4,000 & 9.713 & 0,109 & 7,59 \\
\hline 65 & 9.318 & 4,000 & 9.583 & 0,249 & 2,77 \\
\hline
\end{tabular}


Continuação

\begin{tabular}{|c|c|c|c|c|c|}
\hline 66 & 14.299 & 3,000 & 15.025 & 0,187 & 4,83 \\
\hline 67 & 8.108 & 3,000 & 8.807 & 0,109 & 7,94 \\
\hline 68 & 13.424 & 3,000 & 14.344 & 0,171 & 6,41 \\
\hline 69 & 9.777 & 5,000 & 10.224 & 0,078 & 4,37 \\
\hline 70 & 11.600 & 3,000 & 12.349 & 0,140 & 6,07 \\
\hline 71 & 13.959 & 2,000 & 15.143 & 0,140 & 7,82 \\
\hline 72 & 16.575 & 4,000 & 17.376 & 0,249 & 4,61 \\
\hline 73 & 7.345 & 4,000 & 8.775 & 0,109 & 16,30 \\
\hline 74 & 7.972 & 5,000 & 9.042 & 0,156 & 11,83 \\
\hline 75 & 7.874 & 3,000 & 8.337 & 0,202 & 5,55 \\
\hline 76 & 23.774 & 5,000 & 24.111 & 0,265 & 1,40 \\
\hline 77 & 32.450 & 5,000 & 32.693 & 0,218 & 0,74 \\
\hline 78 & 31.574 & 4,000 & 31.880 & 0,156 & 0,96 \\
\hline 79 & 24.191 & 4,000 & 24.819 & 0,187 & 2,53 \\
\hline 80 & 21.434 & 5,000 & 21.704 & 0,140 & 1,24 \\
\hline 81 & 21.033 & 3,000 & 21.376 & 0,171 & 1,60 \\
\hline 82 & 19.407 & 4,000 & 19.932 & 0,171 & 2,63 \\
\hline 83 & 18.571 & 4,000 & 18.950 & 0,187 & 2,00 \\
\hline 84 & 17.673 & 5,000 & 18.071 & 0,140 & 2,20 \\
\hline 85 & 20.675 & 4,000 & 21.046 & 0,218 & 1,76 \\
\hline 86 & 23.996 & 5,000 & 24.456 & 0,187 & 1,88 \\
\hline 87 & 18.892 & 5,000 & 19.652 & 0,187 & 3,87 \\
\hline 88 & 18.138 & 4,000 & 18.529 & 0,156 & 2,11 \\
\hline 89 & 17.025 & 3,000 & 17.685 & 0,187 & 3,73 \\
\hline 90 & 20.835 & 4,000 & 21.622 & 0,156 & 3,64 \\
\hline 91 & 18.049 & 4,000 & 18.608 & 0,218 & 3,00 \\
\hline 92 & 14.912 & 5,000 & 15.752 & 0,156 & 5,33 \\
\hline 93 & 16.367 & 5,000 & 16.970 & 0,249 & 3,55 \\
\hline 94 & 11.286 & 4,000 & 11.798 & 0,078 & 4,34 \\
\hline 95 & 13.989 & 4,000 & 14.738 & 0,202 & 5,08 \\
\hline 96 & 11.832 & 4,000 & 12.294 & 0,187 & 3,76 \\
\hline 97 & 17.277 & 3,000 & 17.797 & 0,202 & 2,92 \\
\hline 98 & 22.669 & 4,000 & 23.934 & 0,296 & 5,29 \\
\hline 99 & 13.740 & 3,000 & 14.326 & 0,156 & 4,09 \\
\hline 100 & 12.885 & 3,000 & 13.410 & 0,202 & 3,91 \\
\hline 101 & 29.384 & 3,000 & 29.698 & 0,171 & 1,06 \\
\hline 102 & 24.716 & 5,000 & 25.098 & 0,171 & 1,52 \\
\hline 103 & 28.295 & 4,000 & 28.603 & 0,124 & 1,08 \\
\hline 104 & 28.594 & 5,000 & 28.869 & 0,124 & 0,95 \\
\hline 105 & 21.524 & 5,000 & 21.834 & 0,140 & 1,42 \\
\hline 106 & 24.259 & 4,000 & 24.580 & 0,187 & 1,31 \\
\hline 107 & 18.114 & 4,000 & 18.401 & 0,218 & 1,56 \\
\hline 108 & 26.604 & 4,000 & 26.950 & 0,202 & 1,28 \\
\hline 109 & 29.050 & 3,000 & 29.339 & 0,124 & 0,99 \\
\hline 110 & 19.312 & 4,000 & 19.652 & 0,202 & 1,73 \\
\hline 111 & 19.603 & 4,000 & 19.942 & 0,156 & 1,70 \\
\hline 112 & 21.292 & 4,000 & 21.854 & 0,187 & 2,57 \\
\hline 113 & 25.006 & 5,000 & 25.421 & 0,218 & 1,63 \\
\hline 114 & 22.318 & 3,000 & 22.624 & 0,202 & 1,35 \\
\hline 115 & 20.472 & 4,000 & 21.040 & 0,249 & 2,70 \\
\hline 116 & 16.656 & 4,000 & 17.270 & 0,187 & 3,56 \\
\hline 117 & 21.944 & 4,000 & 22.337 & 0,265 & 1,76 \\
\hline 118 & 20.639 & 3,000 & 21.085 & 0,171 & 2,12 \\
\hline 119 & 27.295 & 5,000 & 27.924 & 0,187 & 2,25 \\
\hline 120 & 20.005 & 4,000 & 20.502 & 0,187 & 2,42 \\
\hline 121 & 19.029 & 3,000 & 19.771 & 0,171 & 3,75 \\
\hline 122 & 14.864 & 3,000 & 15.545 & 0,234 & 4,38 \\
\hline 123 & 21.302 & 4,000 & 21.555 & 0,202 & 1,17 \\
\hline 124 & 16.005 & 4,000 & 16.845 & 0,280 & 4,99 \\
\hline 125 & 21.452 & 3,000 & 22.067 & 0,296 & 2,79 \\
\hline
\end{tabular}


APÊNDICE I - Resultados HEU_C 30 x 4

\begin{tabular}{|c|c|c|c|c|c|}
\hline Instância & GC & Tempo [Seg] & HEU_C 30 & Tempo [Seg] & Gap \% \\
\hline 1 & 15.417 & 1,000 & 15.923 & 0,000 & 3,18 \\
\hline 2 & 7.433 & 2,000 & 7.865 & 0,015 & 5,49 \\
\hline 3 & 16.530 & 2,000 & 18.042 & 0,000 & 8,38 \\
\hline 4 & 16.053 & 1,000 & 16.498 & 0,015 & 2,70 \\
\hline 5 & 6.992 & 1,000 & 7.613 & 0,015 & 8,16 \\
\hline 6 & 9.059 & 1,000 & 9.568 & 0,015 & 5,32 \\
\hline 7 & 6.447 & 1,000 & 6.674 & 0,000 & 3,40 \\
\hline 8 & 6.773 & 2,000 & 7.615 & 0,015 & 11,06 \\
\hline 9 & 10.539 & 2,000 & 12.256 & 0,015 & 14,01 \\
\hline 10 & 9.324 & 1,000 & 9.647 & 0,015 & 3,35 \\
\hline 11 & 9.430 & 2,000 & 10.046 & 0,015 & 6,13 \\
\hline 12 & 6.694 & 2,000 & 7.281 & 0,015 & 8,06 \\
\hline 13 & 4.835 & 1,000 & 5.820 & 0,000 & 16,92 \\
\hline 14 & 8.968 & 2,000 & 10.167 & 0,015 & 11,79 \\
\hline 15 & 4.257 & 1,000 & 5.366 & 0,015 & 20,67 \\
\hline 16 & 2.107 & 1,000 & 2.943 & 0,015 & 28,41 \\
\hline 17 & 1.999 & 2,000 & 2.749 & 0,031 & 27,28 \\
\hline 18 & 2.109 & 1,000 & 2.488 & 0,031 & 15,23 \\
\hline 19 & 3.706 & 1,000 & 5.185 & 0,015 & 28,52 \\
\hline 20 & 1.875 & 1,000 & 2.508 & 0,015 & 25,24 \\
\hline 21 & 1.958 & 1,000 & 2.696 & 0,015 & 27,37 \\
\hline 22 & 2.310 & 2,000 & 2.703 & 0,015 & 14,54 \\
\hline 23 & 2.456 & 1,000 & 3.140 & 0,015 & 21,78 \\
\hline 24 & 1.372 & 1,000 & 2.047 & 0,015 & 32,98 \\
\hline 25 & 1.798 & 1,000 & 3.711 & 0,015 & 51,55 \\
\hline 26 & 6.326 & 2,000 & 7.076 & 0,015 & 10,60 \\
\hline 27 & 9.809 & 2,000 & 10.196 & 0,015 & 3,80 \\
\hline 28 & 16.150 & 1,000 & 17.270 & 0,015 & 6,49 \\
\hline 29 & 14.081 & 2,000 & 14.918 & 0,015 & 5,61 \\
\hline 30 & 12.761 & 2,000 & 13.325 & 0,015 & 4,23 \\
\hline 31 & 8.187 & 2,000 & 8.940 & 0,015 & 8,42 \\
\hline 32 & 8.684 & 2,000 & 9.291 & 0,015 & 6,53 \\
\hline 33 & 6.440 & 1,000 & 7.509 & 0,015 & 14,24 \\
\hline 34 & 4.939 & 1,000 & 5.774 & 0,015 & 14,46 \\
\hline 35 & 4.366 & 2,000 & 4.818 & 0,015 & 9,38 \\
\hline 36 & 6.741 & 2,000 & 7.612 & 0,015 & 11,44 \\
\hline 37 & 7.648 & 1,000 & 8.435 & 0,015 & 9,33 \\
\hline 38 & 2.309 & 1,000 & 2.704 & 0,015 & 14,61 \\
\hline 39 & 4.830 & 1,000 & 5.521 & 0,000 & 12,52 \\
\hline 40 & 5.007 & 1,000 & 6.067 & 0,015 & 17,47 \\
\hline 41 & 3.922 & 2,000 & 4.973 & 0,000 & 21,13 \\
\hline 42 & 2.672 & 2,000 & 3.697 & 0,015 & 27,73 \\
\hline 43 & 1.755 & 1,000 & 2.623 & 0,015 & 33,09 \\
\hline 44 & 1.449 & 2,000 & 2.053 & 0,015 & 29,42 \\
\hline 45 & 3.542 & 2,000 & 4.774 & 0,015 & 25,81 \\
\hline 46 & 2.037 & 1,000 & 2.779 & 0,015 & 26,70 \\
\hline 47 & 2.577 & 2,000 & 3.177 & 0,000 & 18,89 \\
\hline 48 & 1.602 & 1,000 & 2.915 & 0,015 & 45,04 \\
\hline 49 & 1.711 & 1,000 & 2.416 & 0,015 & 29,18 \\
\hline 50 & 2.219 & 1,000 & 2.624 & 0,000 & 15,43 \\
\hline 51 & 9.481 & 2,000 & 9.969 & 0,015 & 4,90 \\
\hline 52 & 15.342 & 1,000 & 15.971 & 0,015 & 3,94 \\
\hline 53 & 7.480 & 2,000 & 7.720 & 0,015 & 3,11 \\
\hline 54 & 11.144 & 2,000 & 11.661 & 0,015 & 4,43 \\
\hline 55 & 10.736 & 1,000 & 11.133 & 0,015 & 3,57 \\
\hline 56 & 7.115 & 1,000 & 7.626 & 0,000 & 6,70 \\
\hline 57 & 7.484 & 1,000 & 7.924 & 0,015 & 5,55 \\
\hline 58 & 5.353 & 2,000 & 5.926 & 0,000 & 9,67 \\
\hline 59 & 7.662 & 2,000 & 8.135 & 0,015 & 5,81 \\
\hline 60 & 8.908 & 1,000 & 9.526 & 0,000 & 6,49 \\
\hline 61 & 6.398 & 1,000 & 8.162 & 0,015 & 21,61 \\
\hline 62 & 4.820 & 1,000 & 6.786 & 0,015 & 28,97 \\
\hline 63 & 5.546 & 2,000 & 6.472 & 0,015 & 14,31 \\
\hline 64 & 5.634 & 1,000 & 7.071 & 0,015 & 20,32 \\
\hline 65 & 6.809 & 2,000 & 9.021 & 0,015 & 24,52 \\
\hline
\end{tabular}


Continuação

\begin{tabular}{|c|c|c|c|c|c|}
\hline 66 & 4.388 & 2,000 & 6.185 & 0,015 & 29,05 \\
\hline 67 & 3.618 & 1,000 & 4.789 & 0,015 & 24,45 \\
\hline 68 & 3.437 & 1,000 & 4.878 & 0,015 & 29,54 \\
\hline 69 & 4.024 & 1,000 & 4.755 & 0,015 & 15,37 \\
\hline 70 & 5.092 & 1,000 & 6.696 & 0,000 & 23,95 \\
\hline 71 & 3.032 & 2,000 & 4.250 & 0,015 & 28,66 \\
\hline 72 & 1.391 & 2,000 & 1.867 & 0,015 & 25,50 \\
\hline 73 & 3.016 & 1,000 & 4.458 & 0,000 & 32,35 \\
\hline 74 & 2.718 & 1,000 & 4.125 & 0,015 & 34,11 \\
\hline 75 & 2.888 & 1,000 & 3.571 & 0,015 & 19,13 \\
\hline 76 & 10.469 & 1,000 & 10.866 & 0,000 & 3,65 \\
\hline 77 & 8.745 & 2,000 & 8.994 & 0,015 & 2,77 \\
\hline 78 & 8.652 & 1,000 & 9.303 & 0,015 & 7,00 \\
\hline 79 & 9.831 & 2,000 & 10.534 & 0,015 & 6,67 \\
\hline 80 & 7.737 & 1,000 & 8.151 & 0,015 & 5,08 \\
\hline 81 & 7.408 & 1,000 & 8.377 & 0,000 & 11,57 \\
\hline 82 & 9.421 & 1,000 & 10.370 & 0,015 & 9,15 \\
\hline 83 & 10.549 & 2,000 & 11.796 & 0,015 & 10,57 \\
\hline 84 & 11.406 & 1,000 & 12.631 & 0,015 & 9,70 \\
\hline 85 & 8.122 & 1,000 & 8.852 & 0,015 & 8,25 \\
\hline 86 & 7.484 & 1,000 & 8.006 & 0,015 & 6,52 \\
\hline 87 & 6.185 & 1,000 & 6.557 & 0,015 & 5,67 \\
\hline 88 & 7.909 & 2,000 & 8.488 & 0,015 & 6,82 \\
\hline 89 & 10.978 & 1,000 & 12.727 & 0,015 & 13,74 \\
\hline 90 & 8.826 & 2,000 & 10.031 & 0,015 & 12,01 \\
\hline 91 & 8.260 & 1,000 & 8.893 & 0,015 & 7,12 \\
\hline 92 & 5.554 & 1,000 & 6.935 & 0,015 & 19,91 \\
\hline 93 & 6.461 & 1,000 & 7.764 & 0,015 & 16,78 \\
\hline 94 & 7.778 & 1,000 & 8.570 & 0,015 & 9,24 \\
\hline 95 & 7.850 & 1,000 & 9.002 & 0,015 & 12,80 \\
\hline 96 & 3.676 & 2,000 & 5.080 & 0,015 & 27,64 \\
\hline 97 & 4.906 & 1,000 & 5.664 & 0,015 & 13,38 \\
\hline 98 & 1.601 & 1,000 & 2.043 & 0,015 & 21,63 \\
\hline 99 & 5.282 & 1,000 & 5.902 & 0,000 & 10,50 \\
\hline 100 & 7.419 & 1,000 & 8.376 & 0,015 & 11,43 \\
\hline 101 & 17.076 & 2,000 & 17.414 & 0,015 & 1,94 \\
\hline 102 & 8.986 & 1,000 & 9.206 & 0,015 & 2,39 \\
\hline 103 & 8.737 & 1,000 & 8.855 & 0,015 & 1,33 \\
\hline 104 & 12.099 & 1,000 & 12.603 & 0,015 & 4,00 \\
\hline 105 & 9.911 & 1,000 & 10.237 & 0,015 & 3,18 \\
\hline 106 & 11.008 & 2,000 & 11.957 & 0,015 & 7,94 \\
\hline 107 & 13.667 & 2,000 & 14.425 & 0,000 & 5,25 \\
\hline 108 & 12.375 & 2,000 & 12.955 & 0,015 & 4,48 \\
\hline 109 & 14.597 & 1,000 & 15.079 & 0,015 & 3,20 \\
\hline 110 & 10.668 & 1,000 & 11.416 & 0,000 & 6,55 \\
\hline 111 & 11.353 & 1,000 & 11.724 & 0,015 & 3,16 \\
\hline 112 & 16.857 & 2,000 & 17.585 & 0,015 & 4,14 \\
\hline 113 & 14.871 & 1,000 & 15.541 & 0,015 & 4,31 \\
\hline 114 & 14.882 & 2,000 & 15.231 & 0,015 & 2,29 \\
\hline 115 & 17.117 & 1,000 & 17.918 & 0,015 & 4,47 \\
\hline 116 & 7.988 & 2,000 & 8.454 & 0,000 & 5,51 \\
\hline 117 & 6.272 & 1,000 & 6.759 & 0,015 & 7,21 \\
\hline 118 & 11.147 & 2,000 & 12.076 & 0,015 & 7,69 \\
\hline 119 & 9.748 & 2,000 & 10.611 & 0,015 & 8,13 \\
\hline 120 & 8.002 & 1,000 & 8.771 & 0,031 & 8,77 \\
\hline 121 & 9.620 & 1,000 & 10.129 & 0,015 & 5,03 \\
\hline 122 & 16.018 & 2,000 & 18.309 & 0,015 & 12,51 \\
\hline 123 & 8.466 & 1,000 & 9.193 & 0,015 & 7,91 \\
\hline 124 & 9.410 & 2,000 & 10.434 & 0,015 & 9,81 \\
\hline 125 & 15.361 & 1,000 & 15.763 & 0,015 & 2,55 \\
\hline
\end{tabular}


APÊNDICE J - HEU_C 40 x 5

\begin{tabular}{|c|c|c|c|c|c|}
\hline Instância & GC & Tempo [Seg] & HEU_C 40 & Tempo [Seg] & Gap \% \\
\hline 1 & 16.268 & 2,000 & 16.958 & 0,015 & 4,07 \\
\hline 2 & 12.354 & 3,000 & 13.287 & 0,000 & 7,02 \\
\hline 3 & 14.262 & 3,000 & 15.070 & 0,015 & 5,36 \\
\hline 4 & 18.806 & 2,000 & 19.511 & 0,031 & 3,61 \\
\hline 5 & 16.559 & 3,000 & 18.108 & 0,031 & 8,55 \\
\hline 6 & 11.196 & 2,000 & 12.239 & 0,031 & 8,52 \\
\hline 7 & 15.934 & 2,000 & 17.122 & 0,015 & 6,94 \\
\hline 8 & 15.577 & 2,000 & 17.471 & 0,031 & 10,84 \\
\hline 9 & 12.100 & 3,000 & 13.200 & 0,015 & 8,33 \\
\hline 10 & 10.656 & 2,000 & 11.877 & 0,015 & 10,28 \\
\hline 11 & 7.910 & 2,000 & 9.055 & 0,031 & 12,64 \\
\hline 12 & 5.238 & 2,000 & 6.717 & 0,015 & 22,02 \\
\hline 13 & 6.130 & 4,000 & 7.708 & 0,031 & 20,47 \\
\hline 14 & 10.998 & 3,000 & 12.722 & 0,015 & 13,55 \\
\hline 15 & 6.830 & 2,000 & 8.543 & 0,015 & 20,05 \\
\hline 16 & 2.257 & 3,000 & 4.267 & 0,015 & 47,11 \\
\hline 17 & 2.074 & 2,000 & 3.096 & 0,031 & 33,01 \\
\hline 18 & 2.698 & 2,000 & 4.406 & 0,031 & 38,77 \\
\hline 19 & 3.300 & 2,000 & 4.335 & 0,015 & 23,88 \\
\hline 20 & 2.395 & 2,000 & 3.691 & 0,015 & 35,11 \\
\hline 21 & 2.291 & 2,000 & 3.040 & 0,031 & 24,64 \\
\hline 22 & 891 & 3,000 & 1.847 & 0,031 & 51,76 \\
\hline 23 & 2.175 & 2,000 & 2.937 & 0,015 & 25,94 \\
\hline 24 & 2.079 & 2,000 & 3.027 & 0,015 & 31,32 \\
\hline 25 & 789 & 2,000 & 1.364 & 0,015 & 42,16 \\
\hline 26 & 13.673 & 2,000 & 14.141 & 0,031 & 3,31 \\
\hline 27 & 11.241 & 3,000 & 12.714 & 0,015 & 11,59 \\
\hline 28 & 9.602 & 2,000 & 11.130 & 0,031 & 13,73 \\
\hline 29 & 12.161 & 3,000 & 13.714 & 0,015 & 11,32 \\
\hline 30 & 13.194 & 3,000 & 13.735 & 0,015 & 3,94 \\
\hline 31 & 13.273 & 2,000 & 14.915 & 0,031 & 11,01 \\
\hline 32 & 5.918 & 1,000 & 6.886 & 0,015 & 14,06 \\
\hline 33 & 9.530 & 3,000 & 10.704 & 0,015 & 10,97 \\
\hline 34 & 10.353 & 3,000 & 10.945 & 0,015 & 5,41 \\
\hline 35 & 12.314 & 2,000 & 13.639 & 0,015 & 9,71 \\
\hline 36 & 6.470 & 2,000 & 7.833 & 0,031 & 17,40 \\
\hline 37 & 4.759 & 3,000 & 6.186 & 0,015 & 23,07 \\
\hline 38 & 5.565 & 2,000 & 6.913 & 0,015 & 19,50 \\
\hline 39 & 4.538 & 2,000 & 5.748 & 0,015 & 21,05 \\
\hline 40 & 6.867 & 2,000 & 7.611 & 0,015 & 9,78 \\
\hline 41 & 3.111 & 1,000 & 4.177 & 0,015 & 25,52 \\
\hline 42 & 3.012 & 1,000 & 4.333 & 0,015 & 30,49 \\
\hline 43 & 3.370 & 2,000 & 4.211 & 0,015 & 19,97 \\
\hline 44 & 3.829 & 3,000 & 5.391 & 0,015 & 28,97 \\
\hline 45 & 7.552 & 3,000 & 8.601 & 0,015 & 12,20 \\
\hline 46 & 1.035 & 3,000 & 1.773 & 0,015 & 41,62 \\
\hline 47 & 1.350 & 2,000 & 3.428 & 0,015 & 60,62 \\
\hline 48 & 1.703 & 2,000 & 3.132 & 0,015 & 45,63 \\
\hline 49 & 3.614 & 2,000 & 3.904 & 0,015 & 7,43 \\
\hline 50 & 2.169 & 2,000 & 4.476 & 0,015 & 51,54 \\
\hline 51 & 17.568 & 2,000 & 18.248 & 0,000 & 3,73 \\
\hline 52 & 16.600 & 3,000 & 17.720 & 0,015 & 6,32 \\
\hline 53 & 14.099 & 2,000 & 14.960 & 0,015 & 5,76 \\
\hline 54 & 16.217 & 4,000 & 17.239 & 0,015 & 5,93 \\
\hline 55 & 21.364 & 2,000 & 22.857 & 0,015 & 6,53 \\
\hline 56 & 8.516 & 2,000 & 10.072 & 0,015 & 15,45 \\
\hline 57 & 8.735 & 3,000 & 9.829 & 0,015 & 11,13 \\
\hline 58 & 10.568 & 3,000 & 11.415 & 0,015 & 7,42 \\
\hline 59 & 13.446 & 2,000 & 15.088 & 0,015 & 10,88 \\
\hline 60 & 15.392 & 4,000 & 16.262 & 0,031 & 5,35 \\
\hline 61 & 6.801 & 3,000 & 7.554 & 0,031 & 9,97 \\
\hline 62 & 11.354 & 3,000 & 13.198 & 0,015 & 13,97 \\
\hline 63 & 5.282 & 2,000 & 6.552 & 0,015 & 19,38 \\
\hline 64 & 6.746 & 2,000 & 7.978 & 0,015 & 15,44 \\
\hline 65 & 7.881 & 2,000 & 9.732 & 0,015 & 19,02 \\
\hline
\end{tabular}


Continuação

\begin{tabular}{|c|c|c|c|c|c|}
\hline 66 & 5.043 & 3,000 & 6.481 & 0,015 & 22,19 \\
\hline 67 & 8.324 & 3,000 & 10.145 & 0,015 & 17,95 \\
\hline 68 & 4.918 & 2,000 & 6.640 & 0,015 & 25,93 \\
\hline 69 & 4.314 & 2,000 & 5.535 & 0,015 & 22,06 \\
\hline 70 & 8.994 & 3,000 & 9.758 & 0,015 & 7,83 \\
\hline 71 & 4.768 & 3,000 & 6.575 & 0,015 & 27,48 \\
\hline 72 & 2.412 & 2,000 & 3.720 & 0,015 & 35,16 \\
\hline 73 & 3.328 & 4,000 & 5.162 & 0,015 & 35,53 \\
\hline 74 & 5.220 & 3,000 & 6.896 & 0,015 & 24,30 \\
\hline 75 & 5.939 & 2,000 & 9.070 & 0,015 & 34,52 \\
\hline 76 & 16.710 & 3,000 & 17.411 & 0,015 & 4,03 \\
\hline 77 & 17.545 & 2,000 & 18.476 & 0,015 & 5,04 \\
\hline 78 & 20.522 & 4,000 & 22.170 & 0,015 & 7,43 \\
\hline 79 & 16.139 & 2,000 & 17.105 & 0,015 & 5,65 \\
\hline 80 & 13.118 & 3,000 & 14.349 & 0,015 & 8,58 \\
\hline 81 & 10.847 & 3,000 & 11.742 & 0,015 & 7,62 \\
\hline 82 & 11.506 & 3,000 & 12.865 & 0,015 & 10,56 \\
\hline 83 & 12.304 & 3,000 & 13.654 & 0,015 & 9,89 \\
\hline 84 & 11.744 & 2,000 & 13.896 & 0,015 & 15,49 \\
\hline 85 & 10.649 & 2,000 & 12.311 & 0,015 & 13,50 \\
\hline 86 & 9.919 & 2,000 & 11.184 & 0,015 & 11,31 \\
\hline 87 & 11.926 & 3,000 & 14.464 & 0,015 & 17,55 \\
\hline 88 & 9.962 & 2,000 & 10.804 & 0,015 & 7,79 \\
\hline 89 & 10.901 & 4,000 & 12.437 & 0,015 & 12,35 \\
\hline 90 & 9.623 & 2,000 & 10.668 & 0,015 & 9,80 \\
\hline 91 & 13.182 & 2,000 & 14.674 & 0,015 & 10,17 \\
\hline 92 & 9.152 & 3,000 & 11.591 & 0,015 & 21,04 \\
\hline 93 & 7.381 & 2,000 & 8.693 & 0,000 & 15,09 \\
\hline 94 & 6.712 & 2,000 & 8.059 & 0,015 & 16,71 \\
\hline 95 & 6.392 & 3,000 & 8.339 & 0,015 & 23,35 \\
\hline 96 & 5.114 & 2,000 & 6.496 & 0,031 & 21,27 \\
\hline 97 & 4.379 & 2,000 & 6.180 & 0,015 & 29,14 \\
\hline 98 & 5.725 & 3,000 & 7.738 & 0,015 & 26,01 \\
\hline 99 & 8.494 & 3,000 & 10.770 & 0,015 & 21,13 \\
\hline 100 & 10.313 & 2,000 & 11.365 & 0,015 & 9,26 \\
\hline 101 & 13.236 & 3,000 & 13.711 & 0,015 & 3,46 \\
\hline 102 & 10.728 & 2,000 & 11.171 & 0,015 & 3,97 \\
\hline 103 & 18.927 & 2,000 & 19.766 & 0,015 & 4,24 \\
\hline 104 & 15.636 & 2,000 & 15.899 & 0,015 & 1,65 \\
\hline 105 & 17.608 & 2,000 & 17.998 & 0,031 & 2,17 \\
\hline 106 & 28.965 & 2,000 & 29.968 & 0,031 & 3,35 \\
\hline 107 & 24.379 & 3,000 & 26.328 & 0,015 & 7,40 \\
\hline 108 & 16.233 & 3,000 & 16.793 & 0,015 & 3,33 \\
\hline 109 & 16.520 & 4,000 & 17.465 & 0,031 & 5,41 \\
\hline 110 & 13.275 & 2,000 & 14.321 & 0,015 & 7,30 \\
\hline 111 & 13.592 & 2,000 & 14.337 & 0,015 & 5,20 \\
\hline 112 & 15.088 & 2,000 & 15.957 & 0,015 & 5,45 \\
\hline 113 & 18.774 & 3,000 & 19.813 & 0,015 & 5,24 \\
\hline 114 & 12.237 & 2,000 & 13.113 & 0,031 & 6,68 \\
\hline 115 & 21.701 & 2,000 & 22.410 & 0,031 & 3,16 \\
\hline 116 & 10.947 & 3,000 & 12.179 & 0,015 & 10,12 \\
\hline 117 & 14.926 & 2,000 & 15.833 & 0,015 & 5,73 \\
\hline 118 & 10.941 & 3,000 & 11.914 & 0,015 & 8,17 \\
\hline 119 & 15.538 & 5,000 & 17.098 & 0,015 & 9,12 \\
\hline 120 & 9.776 & 3,000 & 11.799 & 0,015 & 17,15 \\
\hline 121 & 9.086 & 2,000 & 11.260 & 0,015 & 19,31 \\
\hline 122 & 10.350 & 3,000 & 12.130 & 0,015 & 14,67 \\
\hline 123 & 15.316 & 3,000 & 16.844 & 0,015 & 9,07 \\
\hline 124 & 12.080 & 2,000 & 14.348 & 0,015 & 15,81 \\
\hline 125 & 14.363 & 3,000 & 15.636 & 0,015 & 8,14 \\
\hline
\end{tabular}


APÊNDICE K - Resultados HEU_C 50 x 6

\begin{tabular}{|c|c|c|c|c|c|}
\hline Instância & GC & Tempo [Seg] & HEU_C 50 & Tempo [Seg] & Gap \% \\
\hline 1 & 23.300 & 5,000 & 24.601 & 0,000 & 5,29 \\
\hline 2 & 27.230 & 4,000 & 28.626 & 0,015 & 4,88 \\
\hline 3 & 20.964 & 5,000 & 22.098 & 0,031 & 5,13 \\
\hline 4 & 19.685 & 6,000 & 20.493 & 0,015 & 3,94 \\
\hline 5 & 18.169 & 5,000 & 19.634 & 0,031 & 7,46 \\
\hline 6 & 17.818 & 4,000 & 18.805 & 0,015 & 5,25 \\
\hline 7 & 16.788 & 7,000 & 17.320 & 0,031 & 3,07 \\
\hline 8 & 15.875 & 4,000 & 17.187 & 0,031 & 7,63 \\
\hline 9 & 11.768 & 4,000 & 12.561 & 0,015 & 6,31 \\
\hline 10 & 12.633 & 4,000 & 13.580 & 0,015 & 6,97 \\
\hline 11 & 15.054 & 3,000 & 16.996 & 0,031 & 11,43 \\
\hline 12 & 13.361 & 3,000 & 14.855 & 0,031 & 10,06 \\
\hline 13 & 10.604 & 3,000 & 11.576 & 0,015 & 8,40 \\
\hline 14 & 13.885 & 4,000 & 16.447 & 0,031 & 15,58 \\
\hline 15 & 12.450 & 4,000 & 13.888 & 0,031 & 10,35 \\
\hline 16 & 8.732 & 3,000 & 12.721 & 0,015 & 31,36 \\
\hline 17 & 12.989 & 4,000 & 16.167 & 0,031 & 19,66 \\
\hline 18 & 7.817 & 3,000 & 9.419 & 0,031 & 17,01 \\
\hline 19 & 5.246 & 3,000 & 7.240 & 0,031 & 27,54 \\
\hline 20 & 11.428 & 4,000 & 13.062 & 0,031 & 12,51 \\
\hline 21 & 4.304 & 3,000 & 6.121 & 0,031 & 29,68 \\
\hline 22 & 3.328 & 3,000 & 4.546 & 0,015 & 26,79 \\
\hline 23 & 4.485 & 3,000 & 6.049 & 0,015 & 25,86 \\
\hline 24 & 2.498 & 3,000 & 104.507 & 0,031 & 97,61 \\
\hline 25 & 6.081 & 2,000 & 107.746 & 0,015 & 94,36 \\
\hline 26 & 18.528 & 2,000 & 122.977 & 0,031 & 84,93 \\
\hline 27 & 22.599 & 5,000 & 23.944 & 0,015 & 5,62 \\
\hline 28 & 21.794 & 4,000 & 23.468 & 0,015 & 7,13 \\
\hline 29 & 18.824 & 4,000 & 19.899 & 0,015 & 5,40 \\
\hline 30 & 18.964 & 4,000 & 19.572 & 0,015 & 3,11 \\
\hline 31 & 16.037 & 3,000 & 17.270 & 0,015 & 7,14 \\
\hline 32 & 9.205 & 3,000 & 10.410 & 0,031 & 11,58 \\
\hline 33 & 15.720 & 6,000 & 18.404 & 0,015 & 14,58 \\
\hline 34 & 12.796 & 4,000 & 14.507 & 0,015 & 11,79 \\
\hline 35 & 14.131 & 5,000 & 15.676 & 0,031 & 9,86 \\
\hline 36 & 11.894 & 4,000 & 13.830 & 0,015 & 14,00 \\
\hline 37 & 10.907 & 3,000 & 12.108 & 0,015 & 9,92 \\
\hline 38 & 12.976 & 3,000 & 114.484 & 0,015 & 88,67 \\
\hline 39 & 11.165 & 3,000 & 112.851 & 0,015 & 90,11 \\
\hline 40 & 9.345 & 3,000 & 110.605 & 0,015 & 91,55 \\
\hline 41 & 12.929 & 3,000 & 14.845 & 0,015 & 12,91 \\
\hline 42 & 8.023 & 4,000 & 109.259 & 0,015 & 92,66 \\
\hline 43 & 5.928 & 3,000 & 7.359 & 0,031 & 19,45 \\
\hline 44 & 8.743 & 3,000 & 11.132 & 0,031 & 21,46 \\
\hline 45 & 9.334 & 4,000 & 11.590 & 0,015 & 19,47 \\
\hline 46 & 5.634 & 3,000 & 8.396 & 0,015 & 32,90 \\
\hline 47 & 2.802 & 4,000 & 5.954 & 0,015 & 52,94 \\
\hline 48 & 4.126 & 2,000 & 5.805 & 0,015 & 28,92 \\
\hline 49 & 5.948 & 3,000 & 7.839 & 0,031 & 24,12 \\
\hline 50 & 6.728 & 3,000 & 108.701 & 0,031 & 93,81 \\
\hline 51 & 16.507 & 3,000 & 18.357 & 0,015 & 10,08 \\
\hline 52 & 20.136 & 4,000 & 123.942 & 0,015 & 83,75 \\
\hline 53 & 18.094 & 4,000 & 19.665 & 0,031 & 7,99 \\
\hline 54 & 20.168 & 3,000 & 120.897 & 0,015 & 83,32 \\
\hline 55 & 23.157 & 4,000 & 24.423 & 0,015 & 5,18 \\
\hline 56 & 14.703 & 4,000 & 20.001 & 0,015 & 26,49 \\
\hline 57 & 15.734 & 4,000 & 17.646 & 0,015 & 10,84 \\
\hline 58 & 16.464 & 4,000 & 17.307 & 0,015 & 4,87 \\
\hline 59 & 15.565 & 3,000 & 17.027 & 0,015 & 8,59 \\
\hline 60 & 14.488 & 6,000 & 14.998 & 0,015 & 3,40 \\
\hline 61 & 11.345 & 3,000 & 13.569 & 0,015 & 16,39 \\
\hline 62 & 13.058 & 4,000 & 14.794 & 0,015 & 11,73 \\
\hline 63 & 11.511 & 4,000 & 13.692 & 0,015 & 15,93 \\
\hline 64 & 8.976 & 4,000 & 10.114 & 0,015 & 11,25 \\
\hline 65 & 9.318 & 4,000 & 10.858 & 0,031 & 14,18 \\
\hline
\end{tabular}


Continuação

\begin{tabular}{|c|c|c|c|c|c|}
\hline 66 & 14.299 & 3,000 & 17.167 & 0,031 & 16,71 \\
\hline 67 & 8.108 & 3,000 & 9.626 & 0,031 & 15,77 \\
\hline 68 & 13.424 & 3,000 & 14.972 & 0,031 & 10,34 \\
\hline 69 & 9.777 & 5,000 & 10.639 & 0,015 & 8,10 \\
\hline 70 & 11.600 & 3,000 & 12.949 & 0,015 & 10,42 \\
\hline 71 & 13.959 & 2,000 & 16.545 & 0,031 & 15,63 \\
\hline 72 & 16.575 & 4,000 & 18.891 & 0,015 & 12,26 \\
\hline 73 & 7.345 & 4,000 & 9.645 & 0,015 & 23,85 \\
\hline 74 & 7.972 & 5,000 & 9.736 & 0,015 & 18,12 \\
\hline 75 & 7.874 & 3,000 & 9.419 & 0,015 & 16,40 \\
\hline 76 & 23.774 & 5,000 & 25.805 & 0,015 & 7,87 \\
\hline 77 & 32.450 & 5,000 & 33.843 & 0,015 & 4,12 \\
\hline 78 & 31.574 & 4,000 & 32.432 & 0,015 & 2,65 \\
\hline 79 & 24.191 & 4,000 & 26.024 & 0,031 & 7,04 \\
\hline 80 & 21.434 & 5,000 & 22.560 & 0,031 & 4,99 \\
\hline 81 & 21.033 & 3,000 & 22.130 & 0,015 & 4,96 \\
\hline 82 & 19.407 & 4,000 & 20.903 & 0,015 & 7,16 \\
\hline 83 & 18.571 & 4,000 & 19.925 & 0,015 & 6,80 \\
\hline 84 & 17.673 & 5,000 & 18.386 & 0,015 & 3,88 \\
\hline 85 & 20.675 & 4,000 & 21.526 & 0,031 & 3,95 \\
\hline 86 & 23.996 & 5,000 & 26.269 & 0,015 & 8,65 \\
\hline 87 & 18.892 & 5,000 & 21.077 & 0,015 & 10,37 \\
\hline 88 & 18.138 & 4,000 & 19.179 & 0,015 & 5,43 \\
\hline 89 & 17.025 & 3,000 & 118.793 & 0,015 & 85,67 \\
\hline 90 & 20.835 & 4,000 & 22.560 & 0,015 & 7,65 \\
\hline 91 & 18.049 & 4,000 & 20.200 & 0,015 & 10,65 \\
\hline 92 & 14.912 & 5,000 & 17.163 & 0,015 & 13,12 \\
\hline 93 & 16.367 & 5,000 & 18.367 & 0,015 & 10,89 \\
\hline 94 & 11.286 & 4,000 & 13.027 & 0,015 & 13,36 \\
\hline 95 & 13.989 & 4,000 & 15.440 & 0,015 & 9,40 \\
\hline 96 & 11.832 & 4,000 & 12.838 & 0,015 & 7,84 \\
\hline 97 & 17.277 & 3,000 & 18.778 & 0,015 & 7,99 \\
\hline 98 & 22.669 & 4,000 & 26.069 & 0,015 & 13,04 \\
\hline 99 & 13.740 & 3,000 & 115.318 & 0,031 & 88,09 \\
\hline 100 & 12.885 & 3,000 & 13.994 & 0,015 & 7,92 \\
\hline 101 & 29.384 & 3,000 & 30.021 & 0,031 & 2,12 \\
\hline 102 & 24.716 & 5,000 & 25.358 & 0,031 & 2,53 \\
\hline 103 & 28.295 & 4,000 & 28.826 & 0,015 & 1,84 \\
\hline 104 & 28.594 & 5,000 & 28.988 & 0,015 & 1,36 \\
\hline 105 & 21.524 & 5,000 & 22.161 & 0,015 & 2,87 \\
\hline 106 & 24.259 & 4,000 & 24.946 & 0,015 & 2,75 \\
\hline 107 & 18.114 & 4,000 & 19.008 & 0,031 & 4,70 \\
\hline 108 & 26.604 & 4,000 & 27.497 & 0,031 & 3,25 \\
\hline 109 & 29.050 & 3,000 & 29.486 & 0,015 & 1,48 \\
\hline 110 & 19.312 & 4,000 & 20.229 & 0,015 & 4,53 \\
\hline 111 & 19.603 & 4,000 & 20.606 & 0,015 & 4,87 \\
\hline 112 & 21.292 & 4,000 & 22.214 & 0,015 & 4,15 \\
\hline 113 & 25.006 & 5,000 & 26.330 & 0,015 & 5,03 \\
\hline 114 & 22.318 & 3,000 & 23.372 & 0,031 & 4,51 \\
\hline 115 & 20.472 & 4,000 & 21.834 & 0,031 & 6,24 \\
\hline 116 & 16.656 & 4,000 & 17.880 & 0,031 & 6,85 \\
\hline 117 & 21.944 & 4,000 & 23.921 & 0,015 & 8,26 \\
\hline 118 & 20.639 & 3,000 & 21.921 & 0,015 & 5,85 \\
\hline 119 & 27.295 & 5,000 & 28.969 & 0,015 & 5,78 \\
\hline 120 & 20.005 & 4,000 & 21.222 & 0,031 & 5,73 \\
\hline 121 & 19.029 & 3,000 & 20.882 & 0,031 & 8,87 \\
\hline 122 & 14.864 & 3,000 & 116.079 & 0,015 & 87,19 \\
\hline 123 & 21.302 & 4,000 & 22.864 & 0,015 & 6,83 \\
\hline 124 & 16.005 & 4,000 & 17.434 & 0,015 & 8,20 \\
\hline 125 & 21.452 & 3,000 & 23.166 & 0,015 & 7,40 \\
\hline
\end{tabular}


APÊNDICE L - Resultados GRASP PR 30 X 4

\begin{tabular}{|c|c|c|c|c|c|}
\hline Instância & GC & Tempo [Seg] & PR 30 & Tempo [Seg] & Gap \% \\
\hline 1 & 15.417 & 1,000 & 15.531 & 80,074 & 0,73 \\
\hline 2 & 7.433 & 2,000 & 7.456 & 86,829 & 0,31 \\
\hline 3 & 16.530 & 2,000 & 16.646 & 91,010 & 0,70 \\
\hline 4 & 16.053 & 1,000 & 16.089 & 77,844 & 0,22 \\
\hline 5 & 6.992 & 1,000 & 7.049 & 80,870 & 0,81 \\
\hline 6 & 9.059 & 1,000 & 9.212 & 76,096 & 1,66 \\
\hline 7 & 6.447 & 1,000 & 6.488 & 87,812 & 0,63 \\
\hline 8 & 6.773 & 2,000 & 6.855 & 82,305 & 1,20 \\
\hline 9 & 10.539 & 2,000 & 10.568 & 91,977 & 0,27 \\
\hline 10 & 9.324 & 1,000 & 9.390 & 90,136 & 0,70 \\
\hline 11 & 9.430 & 2,000 & 9.525 & 99,559 & 1,00 \\
\hline 12 & 6.694 & 2,000 & 6.841 & 98,404 & 2,15 \\
\hline 13 & 4.835 & 1,000 & 4.931 & 96,610 & 1,95 \\
\hline 14 & 8.968 & 2,000 & 8.984 & 90,604 & 0,18 \\
\hline 15 & 4.257 & 1,000 & 4.320 & 90,916 & 1,46 \\
\hline 16 & 2.107 & 1,000 & 2.163 & 70,980 & 2,59 \\
\hline 17 & 1.999 & 2,000 & 2.083 & 96,002 & 4,03 \\
\hline 18 & 2.109 & 1,000 & 2.119 & 82,914 & 0,47 \\
\hline 19 & 3.706 & 1,000 & 3.813 & 93,069 & 2,81 \\
\hline 20 & 1.875 & 1,000 & 1.903 & 72,181 & 1,47 \\
\hline 21 & 1.958 & 1,000 & 1.989 & 73,678 & 1,56 \\
\hline 22 & 2.310 & 2,000 & 2.388 & 81,354 & 3,27 \\
\hline 23 & 2.456 & 1,000 & 2.484 & 74,739 & 1,13 \\
\hline 24 & 1.372 & 1,000 & 1.397 & 80,620 & 1,79 \\
\hline 25 & 1.798 & 1,000 & 1.991 & 77,220 & 9,69 \\
\hline 26 & 6.326 & 2,000 & 6.341 & 86,486 & 0,24 \\
\hline 27 & 9.809 & 2,000 & 9.813 & 87,469 & 0,04 \\
\hline 28 & 16.150 & 1,000 & 16.207 & 88,592 & 0,35 \\
\hline 29 & 14.081 & 2,000 & 14.126 & 77,812 & 0,32 \\
\hline 30 & 12.761 & 2,000 & 12.764 & 84,084 & 0,02 \\
\hline 31 & 8.187 & 2,000 & 8.273 & 102,055 & 1,04 \\
\hline 32 & 8.684 & 2,000 & 8.820 & 80,230 & 1,54 \\
\hline 33 & 6.440 & 1,000 & 6.469 & 88,327 & 0,45 \\
\hline 34 & 4.939 & 1,000 & 4.961 & 71,448 & 0,44 \\
\hline 35 & 4.366 & 2,000 & 4.478 & 92,352 & 2,50 \\
\hline 36 & 6.741 & 2,000 & 6.833 & 81,822 & 1,35 \\
\hline 37 & 7.648 & 1,000 & 7.702 & 87,235 & 0,70 \\
\hline 38 & 2.309 & 1,000 & 2.388 & 89,824 & 3,31 \\
\hline 39 & 4.830 & 1,000 & 4.911 & 82,898 & 1,65 \\
\hline 40 & 5.007 & 1,000 & 5.044 & 77,469 & 0,73 \\
\hline 41 & 3.922 & 2,000 & 3.928 & 81,088 & 0,15 \\
\hline 42 & 2.672 & 2,000 & 2.727 & 79,029 & 2,02 \\
\hline 43 & 1.755 & 1,000 & 1.755 & 64,740 & 0,00 \\
\hline 44 & 1.449 & 2,000 & 1.459 & 59,077 & 0,69 \\
\hline 45 & 3.542 & 2,000 & 3.649 & 89,934 & 2,93 \\
\hline 46 & 2.037 & 1,000 & 2.044 & 73,710 & 0,34 \\
\hline 47 & 2.577 & 2,000 & 2.588 & 66,877 & 0,43 \\
\hline 48 & 1.602 & 1,000 & 1.628 & 84,052 & 1,60 \\
\hline 49 & 1.711 & 1,000 & 1.793 & 78,249 & 4,57 \\
\hline 50 & 2.219 & 1,000 & 2.248 & 65,457 & 1,29 \\
\hline 51 & 9.481 & 2,000 & 9.526 & 80,605 & 0,47 \\
\hline 52 & 15.342 & 1,000 & 15.439 & 87,235 & 0,63 \\
\hline 53 & 7.480 & 2,000 & 7.508 & 93,693 & 0,37 \\
\hline 54 & 11.144 & 2,000 & 11.202 & 84,442 & 0,52 \\
\hline 55 & 10.736 & 1,000 & 10.813 & 83,538 & 0,71 \\
\hline 56 & 7.115 & 1,000 & 7.149 & 100,058 & 0,48 \\
\hline 57 & 7.484 & 1,000 & 7.520 & 89,902 & 0,48 \\
\hline 58 & 5.353 & 2,000 & 5.360 & 90,994 & 0,13 \\
\hline 59 & 7.662 & 2,000 & 7.691 & 94,598 & 0,38 \\
\hline 60 & 8.908 & 1,000 & 8.970 & 99,606 & 0,69 \\
\hline 61 & 6.398 & 1,000 & 6.492 & 93,927 & 1,45 \\
\hline 62 & 4.820 & 1,000 & 4.993 & 83,928 & 3,46 \\
\hline 63 & 5.546 & 2,000 & 5.631 & 90,183 & 1,51 \\
\hline 64 & 5.634 & 1,000 & 5.851 & 95,160 & 3,71 \\
\hline 65 & 6.809 & 2,000 & 6.942 & 89,200 & 1,92 \\
\hline
\end{tabular}


Continuação

\begin{tabular}{|c|c|c|c|c|c|}
\hline 66 & 4.388 & 2,000 & 4.629 & 85,503 & 5,21 \\
\hline 67 & 3.618 & 1,000 & 3.705 & 102,507 & 2,35 \\
\hline 68 & 3.437 & 1,000 & 3.548 & 91,650 & 3,13 \\
\hline 69 & 4.024 & 1,000 & 4.213 & 75,051 & 4,49 \\
\hline 70 & 5.092 & 1,000 & 5.236 & 88,608 & 2,75 \\
\hline 71 & 3.032 & 2,000 & 3.143 & 92,866 & 3,53 \\
\hline 72 & 1.391 & 2,000 & 1.435 & 79,778 & 3,07 \\
\hline 73 & 3.016 & 1,000 & 3.180 & 82,867 & 5,16 \\
\hline 74 & 2.718 & 1,000 & 2.785 & 73,273 & 2,41 \\
\hline 75 & 2.888 & 1,000 & 2.902 & 71,791 & 0,48 \\
\hline 76 & 10.469 & 1,000 & 10.523 & 78,546 & 0,51 \\
\hline 77 & 8.745 & 2,000 & 8.810 & 73,616 & 0,74 \\
\hline 78 & 8.652 & 1,000 & 8.745 & 79,918 & 1,06 \\
\hline 79 & 9.831 & 2,000 & 9.968 & 82,430 & 1,37 \\
\hline 80 & 7.737 & 1,000 & 7.808 & 78,078 & 0,91 \\
\hline 81 & 7.408 & 1,000 & 7.503 & 87,921 & 1,27 \\
\hline 82 & 9.421 & 1,000 & 9.525 & 97,656 & 1,09 \\
\hline 83 & 10.549 & 2,000 & 10.625 & 82,867 & 0,72 \\
\hline 84 & 11.406 & 1,000 & 11.500 & 84,661 & 0,82 \\
\hline 85 & 8.122 & 1,000 & 8.186 & 95,082 & 0,78 \\
\hline 86 & 7.484 & 1,000 & 7.661 & 82,492 & 2,31 \\
\hline 87 & 6.185 & 1,000 & 6.293 & 92,102 & 1,72 \\
\hline 88 & 7.909 & 2,000 & 8.015 & 85,924 & 1,32 \\
\hline 89 & 10.978 & 1,000 & 11.171 & 86,798 & 1,73 \\
\hline 90 & 8.826 & 2,000 & 8.940 & 88,732 & 1,28 \\
\hline 91 & 8.260 & 1,000 & 8.397 & 72,274 & 1,63 \\
\hline 92 & 5.554 & 1,000 & 5.730 & 84,708 & 3,07 \\
\hline 93 & 6.461 & 1,000 & 6.602 & 88,842 & 2,14 \\
\hline 94 & 7.778 & 1,000 & 7.925 & 103,521 & 1,85 \\
\hline 95 & 7.850 & 1,000 & 7.961 & 88,296 & 1,39 \\
\hline 96 & 3.676 & 2,000 & 3.847 & 72,274 & 4,45 \\
\hline 97 & 4.906 & 1,000 & 5.043 & 75,207 & 2,72 \\
\hline 98 & 1.601 & 1,000 & 1.669 & 88,202 & 4,07 \\
\hline 99 & 5.282 & 1,000 & 5.372 & 70,980 & 1,68 \\
\hline 100 & 7.419 & 1,000 & 7.607 & 71,494 & 2,47 \\
\hline 101 & 17.076 & 2,000 & 17.186 & 81,697 & 0,64 \\
\hline 102 & 8.986 & 1,000 & 9.120 & 71,229 & 1,47 \\
\hline 103 & 8.737 & 1,000 & 8.801 & 86,921 & 0,73 \\
\hline 104 & 12.099 & 1,000 & 12.265 & 88,623 & 1,35 \\
\hline 105 & 9.911 & 1,000 & 10.053 & 79,232 & 1,41 \\
\hline 106 & 11.008 & 2,000 & 11.189 & 59,108 & 1,62 \\
\hline 107 & 13.667 & 2,000 & 13.823 & 87,172 & 1,13 \\
\hline 108 & 12.375 & 2,000 & 12.529 & 86,439 & 1,23 \\
\hline 109 & 14.597 & 1,000 & 14.754 & 83,319 & 1,06 \\
\hline 110 & 10.668 & 1,000 & 10.781 & 82,352 & 1,05 \\
\hline 111 & 11.353 & 1,000 & 11.447 & 83,054 & 0,82 \\
\hline 112 & 16.857 & 2,000 & 17.013 & 86,704 & 0,92 \\
\hline 113 & 14.871 & 1,000 & 14.950 & 86,611 & 0,53 \\
\hline 114 & 14.882 & 2,000 & 15.039 & 89,154 & 1,04 \\
\hline 115 & 17.117 & 1,000 & 17.245 & 95,082 & 0,74 \\
\hline 116 & 7.988 & 2,000 & 8.119 & 89,403 & 1,61 \\
\hline 117 & 6.272 & 1,000 & 6.363 & 90,604 & 1,43 \\
\hline 118 & 11.147 & 2,000 & 11.251 & 86,018 & 0,92 \\
\hline 119 & 9.748 & 2,000 & 9.832 & 87,950 & 0,85 \\
\hline 120 & 8.002 & 1,000 & 8.117 & 77,033 & 1,42 \\
\hline 121 & 9.620 & 1,000 & 9.767 & 96,393 & 1,51 \\
\hline 122 & 16.018 & 2,000 & 16.148 & 104,166 & 0,81 \\
\hline 123 & 8.466 & 1,000 & 8.620 & 83,460 & 1,79 \\
\hline 124 & 9.410 & 2,000 & 9.492 & 97,000 & 0,86 \\
\hline 125 & 15.361 & 1,000 & 15.540 & 96,751 & 1,15 \\
\hline
\end{tabular}


APÊNDICE M - Resultados GRASP PR 40 X 5

\begin{tabular}{|c|c|c|c|c|c|}
\hline Instância & GC & Tempo [Seg] & PR 40 & Tempo [Seg] & Gap \% \\
\hline 1 & 16.268 & 2,000 & 16.358 & 223,995 & 0,55 \\
\hline 2 & 12.354 & 3,000 & 12.461 & 205,319 & 0,86 \\
\hline 3 & 14.262 & 3,000 & 14.398 & 227,231 & 0,94 \\
\hline 4 & 18.806 & 2,000 & 18.924 & 245,045 & 0,62 \\
\hline 5 & 16.559 & 3,000 & 16.677 & 201,224 & 0,71 \\
\hline 6 & 11.196 & 2,000 & 11.291 & 199,196 & 0,84 \\
\hline 7 & 15.934 & 2,000 & 16.148 & 194,220 & 1,33 \\
\hline 8 & 15.577 & 2,000 & 15.738 & 230,381 & 1,02 \\
\hline 9 & 12.100 & 3,000 & 12.150 & 224,453 & 0,41 \\
\hline 10 & 10.656 & 2,000 & 10.709 & 220,007 & 0,49 \\
\hline 11 & 7.910 & 2,000 & 8.062 & 236,699 & 1,89 \\
\hline 12 & 5.238 & 2,000 & 5.344 & 206,731 & 1,98 \\
\hline 13 & 6.130 & 4,000 & 6.304 & 206,918 & 2,76 \\
\hline 14 & 10.998 & 3,000 & 11.167 & 236,215 & 1,51 \\
\hline 15 & 6.830 & 2,000 & 7.000 & 194,017 & 2,43 \\
\hline 16 & 2.257 & 3,000 & 2.274 & 175,328 & 0,75 \\
\hline 17 & 2.074 & 2,000 & 2.121 & 198,479 & 2,22 \\
\hline 18 & 2.698 & 2,000 & 2.869 & 219,570 & 5,96 \\
\hline 19 & 3.300 & 2,000 & 3.356 & 219,383 & 1,67 \\
\hline 20 & 2.395 & 2,000 & 2.453 & 192,363 & 2,36 \\
\hline 21 & 2.291 & 2,000 & 2.324 & 236,012 & 1,42 \\
\hline 22 & 891 & 3,000 & 918 & 205,623 & 2,94 \\
\hline 23 & 2.175 & 2,000 & 2.226 & 171,413 & 2,29 \\
\hline 24 & 2.079 & 2,000 & 2.175 & 204,001 & 4,41 \\
\hline 25 & 789 & 2,000 & 840 & 210,397 & 6,07 \\
\hline 26 & 13.673 & 2,000 & 13.673 & 245,794 & 0,00 \\
\hline 27 & 11.241 & 3,000 & 11.246 & 226,871 & 0,04 \\
\hline 28 & 9.602 & 2,000 & 9.643 & 254,436 & 0,43 \\
\hline 29 & 12.161 & 3,000 & 12.228 & 214,250 & 0,55 \\
\hline 30 & 13.194 & 3,000 & 13.229 & 203,892 & 0,26 \\
\hline 31 & 13.273 & 2,000 & 13.387 & 213,751 & 0,85 \\
\hline 32 & 5.918 & 1,000 & 5.994 & 207,246 & 1,27 \\
\hline 33 & 9.530 & 3,000 & 9.616 & 221,879 & 0,89 \\
\hline 34 & 10.353 & 3,000 & 10.431 & 218,057 & 0,75 \\
\hline 35 & 12.314 & 2,000 & 12.456 & 217,105 & 1,14 \\
\hline 36 & 6.470 & 2,000 & 6.504 & 220,709 & 0,52 \\
\hline 37 & 4.759 & 3,000 & 4.778 & 233,142 & 0,40 \\
\hline 38 & 5.565 & 2,000 & 5.604 & 229,648 & 0,70 \\
\hline 39 & 4.538 & 2,000 & 4.573 & 229,258 & 0,77 \\
\hline 40 & 6.867 & 2,000 & 6.958 & 208,899 & 1,31 \\
\hline 41 & 3.111 & 1,000 & 3.187 & 204,859 & 2,38 \\
\hline 42 & 3.012 & 1,000 & 3.016 & 200,694 & 0,13 \\
\hline 43 & 3.370 & 2,000 & 3.466 & 218,400 & 2,77 \\
\hline 44 & 3.829 & 3,000 & 3.999 & 198,501 & 4,25 \\
\hline 45 & 7.552 & 3,000 & 7.660 & 194,469 & 1,41 \\
\hline 46 & 1.035 & 3,000 & 1.046 & 185,281 & 1,05 \\
\hline 47 & 1.350 & 2,000 & 1.426 & 190,023 & 5,33 \\
\hline 48 & 1.703 & 2,000 & 1.727 & 194,906 & 1,39 \\
\hline 49 & 3.614 & 2,000 & 3.651 & 187,247 & 1,01 \\
\hline 50 & 2.169 & 2,000 & 2.349 & 203,377 & 7,66 \\
\hline 51 & 17.568 & 2,000 & 17.620 & 209,180 & 0,30 \\
\hline 52 & 16.600 & 3,000 & 16.683 & 187,481 & 0,50 \\
\hline 53 & 14.099 & 2,000 & 14.162 & 209,165 & 0,44 \\
\hline 54 & 16.217 & 4,000 & 16.277 & 204,734 & 0,37 \\
\hline 55 & 21.364 & 2,000 & 21.364 & 222,752 & 0,00 \\
\hline 56 & 8.516 & 2,000 & 8.571 & 195,733 & 0,64 \\
\hline 57 & 8.735 & 3,000 & 8.840 & 204,656 & 1,19 \\
\hline 58 & 10.568 & 3,000 & 10.651 & 214,079 & 0,78 \\
\hline 59 & 13.446 & 2,000 & 13.592 & 173,503 & 1,07 \\
\hline 60 & 15.392 & 4,000 & 15.441 & 204,329 & 0,32 \\
\hline 61 & 6.801 & 3,000 & 6.999 & 212,019 & 2,83 \\
\hline 62 & 11.354 & 3,000 & 11.437 & 219,117 & 0,73 \\
\hline 63 & 5.282 & 2,000 & 5.420 & 207,527 & 2,55 \\
\hline 64 & 6.746 & 2,000 & 6.887 & 216,013 & 2,05 \\
\hline 65 & 7.881 & 2,000 & 7.891 & 214,547 & 0,13 \\
\hline
\end{tabular}


Continuação

\begin{tabular}{|c|c|c|c|c|c|}
\hline 66 & 5.043 & 3,000 & 5.201 & 207,121 & 3,04 \\
\hline 67 & 8.324 & 3,000 & 8.612 & 179,696 & 3,34 \\
\hline 68 & 4.918 & 2,000 & 5.112 & 234,203 & 3,79 \\
\hline 69 & 4.314 & 2,000 & 4.341 & 184,766 & 0,62 \\
\hline 70 & 8.994 & 3,000 & 9.135 & 230,896 & 1,54 \\
\hline 71 & 4.768 & 3,000 & 4.886 & 218,696 & 2,42 \\
\hline 72 & 2.412 & 2,000 & 2.483 & 196,373 & 2,86 \\
\hline 73 & 3.328 & 4,000 & 3.401 & 202,269 & 2,15 \\
\hline 74 & 5.220 & 3,000 & 5.369 & 224,999 & 2,78 \\
\hline 75 & 5.939 & 2,000 & 6.154 & 237,884 & 3,49 \\
\hline 76 & 16.710 & 3,000 & 16.812 & 222,315 & 0,61 \\
\hline 77 & 17.545 & 2,000 & 17.660 & 225,763 & 0,65 \\
\hline 78 & 20.522 & 4,000 & 20.590 & 253,625 & 0,33 \\
\hline 79 & 16.139 & 2,000 & 16.332 & 229,460 & 1,18 \\
\hline 80 & 13.118 & 3,000 & 13.205 & 241,082 & 0,66 \\
\hline 81 & 10.847 & 3,000 & 11.028 & 243,797 & 1,64 \\
\hline 82 & 11.506 & 3,000 & 11.640 & 203,049 & 1,15 \\
\hline 83 & 12.304 & 3,000 & 12.438 & 223,376 & 1,08 \\
\hline 84 & 11.744 & 2,000 & 11.873 & 186,061 & 1,09 \\
\hline 85 & 10.649 & 2,000 & 10.821 & 200,475 & 1,59 \\
\hline 86 & 9.919 & 2,000 & 10.028 & 199,633 & 1,09 \\
\hline 87 & 11.926 & 3,000 & 12.091 & 200,631 & 1,36 \\
\hline 88 & 9.962 & 2,000 & 10.128 & 184,298 & 1,64 \\
\hline 89 & 10.901 & 4,000 & 11.062 & 222,237 & 1,46 \\
\hline 90 & 9.623 & 2,000 & 9.854 & 203,736 & 2,34 \\
\hline 91 & 13.182 & 2,000 & 13.359 & 212,737 & 1,32 \\
\hline 92 & 9.152 & 3,000 & 9.351 & 230,116 & 2,13 \\
\hline 93 & 7.381 & 2,000 & 7.395 & 215,186 & 0,19 \\
\hline 94 & 6.712 & 2,000 & 6.832 & 218,649 & 1,76 \\
\hline 95 & 6.392 & 3,000 & 6.523 & 199,961 & 2,01 \\
\hline 96 & 5.114 & 2,000 & 5.337 & 199,586 & 4,18 \\
\hline 97 & 4.379 & 2,000 & 4.584 & 194,984 & 4,47 \\
\hline 98 & 5.725 & 3,000 & 5.855 & 212,597 & 2,22 \\
\hline 99 & 8.494 & 3,000 & 8.761 & 224,827 & 3,05 \\
\hline 100 & 10.313 & 2,000 & 10.501 & 207,714 & 1,79 \\
\hline 101 & 13.236 & 3,000 & 13.407 & 203,720 & 1,28 \\
\hline 102 & 10.728 & 2,000 & 10.913 & 185,952 & 1,70 \\
\hline 103 & 18.927 & 2,000 & 19.121 & 204,719 & 1,01 \\
\hline 104 & 15.636 & 2,000 & 15.779 & 168,230 & 0,91 \\
\hline 105 & 17.608 & 2,000 & 17.757 & 190,023 & 0,84 \\
\hline 106 & 28.965 & 2,000 & 29.193 & 201,536 & 0,78 \\
\hline 107 & 24.379 & 3,000 & 24.622 & 205,483 & 0,99 \\
\hline 108 & 16.233 & 3,000 & 16.326 & 185,109 & 0,57 \\
\hline 109 & 16.520 & 4,000 & 16.703 & 204,953 & 1,10 \\
\hline 110 & 13.275 & 2,000 & 13.446 & 195,437 & 1,27 \\
\hline 111 & 13.592 & 2,000 & 13.756 & 223,907 & 1,19 \\
\hline 112 & 15.088 & 2,000 & 15.251 & 205,467 & 1,07 \\
\hline 113 & 18.774 & 3,000 & 18.955 & 236,402 & 0,95 \\
\hline 114 & 12.237 & 2,000 & 12.372 & 192,207 & 1,09 \\
\hline 115 & 21.701 & 2,000 & 21.900 & 232,892 & 0,91 \\
\hline 116 & 10.947 & 3,000 & 11.085 & 214,859 & 1,24 \\
\hline 117 & 14.926 & 2,000 & 15.014 & 212,706 & 0,59 \\
\hline 118 & 10.941 & 3,000 & 11.125 & 209,867 & 1,65 \\
\hline 119 & 15.538 & 5,000 & 15.678 & 211,271 & 0,89 \\
\hline 120 & 9.776 & 3,000 & 9.921 & 209,352 & 1,46 \\
\hline 121 & 9.086 & 2,000 & 9.215 & 251,082 & 1,40 \\
\hline 122 & 10.350 & 3,000 & 10.624 & 213,767 & 2,58 \\
\hline 123 & 15.316 & 3,000 & 15.485 & 224,952 & 1,09 \\
\hline 124 & 12.080 & 2,000 & 12.309 & 225,701 & 1,86 \\
\hline 125 & 14.363 & 3,000 & 14.533 & 222,737 & 1,17 \\
\hline
\end{tabular}


APÊNDICE N - Resultados GRASP PR 50 x 6

\begin{tabular}{|c|c|c|c|c|c|}
\hline Instância & GC & Tempo [Seg] & PR 50 & Tempo [Seg] & Gap \% \\
\hline 1 & 23.300 & 5,000 & 23.458 & 445,327 & 0,67 \\
\hline 2 & 27.230 & 4,000 & 27.401 & 398,721 & 0,62 \\
\hline 3 & 20.964 & 5,000 & 21.071 & 472,446 & 0,51 \\
\hline 4 & 19.685 & 6,000 & 19.858 & 478,374 & 0,87 \\
\hline 5 & 18.169 & 5,000 & 18.172 & 429,515 & 0,02 \\
\hline 6 & 17.818 & 4,000 & 17.881 & 477,626 & 0,35 \\
\hline 7 & 16.788 & 7,000 & 16.807 & 495,098 & 0,11 \\
\hline 8 & 15.875 & 4,000 & 16.062 & 458,375 & 1,16 \\
\hline 9 & 11.768 & 4,000 & 11.946 & 464,428 & 1,49 \\
\hline 10 & 12.633 & 4,000 & 12.753 & 469,358 & 0,94 \\
\hline 11 & 15.054 & 3,000 & 15.190 & 409,734 & 0,90 \\
\hline 12 & 13.361 & 3,000 & 13.466 & 488,982 & 0,78 \\
\hline 13 & 10.604 & 3,000 & 10.733 & 368,425 & 1,20 \\
\hline 14 & 13.885 & 4,000 & 14.032 & 481,292 & 1,05 \\
\hline 15 & 12.450 & 4,000 & 12.603 & 429,889 & 1,21 \\
\hline 16 & 8.732 & 3,000 & 8.867 & 470,216 & 1,52 \\
\hline 17 & 12.989 & 4,000 & 13.184 & 458,968 & 1,48 \\
\hline 18 & 7.817 & 3,000 & 7.993 & 500,074 & 2,20 \\
\hline 19 & 5.246 & 3,000 & 5.335 & 470,512 & 1,67 \\
\hline 20 & 11.428 & 4,000 & 11.618 & 499,029 & 1,64 \\
\hline 21 & 4.304 & 3,000 & 4.501 & 405,694 & 4,38 \\
\hline 22 & 3.328 & 3,000 & 3.490 & 419,609 & 4,64 \\
\hline 23 & 4.485 & 3,000 & 4.626 & 423,915 & 3,05 \\
\hline 24 & 2.498 & 3,000 & 2.664 & 411,949 & 6,23 \\
\hline 25 & 6.081 & 2,000 & 6.304 & 467,111 & 3,54 \\
\hline 26 & 18.528 & 2,000 & 18.607 & 440,575 & 0,42 \\
\hline 27 & 22.599 & 5,000 & 22.765 & 469,857 & 0,73 \\
\hline 28 & 21.794 & 4,000 & 21.917 & 465,738 & 0,56 \\
\hline 29 & 18.824 & 4,000 & 18.888 & 454,116 & 0,34 \\
\hline 30 & 18.964 & 4,000 & 19.024 & 439,655 & 0,32 \\
\hline 31 & 16.037 & 3,000 & 16.152 & 396,490 & 0,71 \\
\hline 32 & 9.205 & 3,000 & 9.249 & 385,585 & 0,48 \\
\hline 33 & 15.720 & 6,000 & 15.809 & 505,924 & 0,56 \\
\hline 34 & 12.796 & 4,000 & 12.887 & 517,265 & 0,71 \\
\hline 35 & 14.131 & 5,000 & 14.145 & 431,559 & 0,10 \\
\hline 36 & 11.894 & 4,000 & 12.070 & 453,492 & 1,46 \\
\hline 37 & 10.907 & 3,000 & 10.935 & 470,730 & 0,26 \\
\hline 38 & 12.976 & 3,000 & 13.089 & 397,379 & 0,86 \\
\hline 39 & 11.165 & 3,000 & 11.317 & 410,140 & 1,34 \\
\hline 40 & 9.345 & 3,000 & 9.477 & 422,199 & 1,39 \\
\hline 41 & 12.929 & 3,000 & 13.091 & 450,793 & 1,24 \\
\hline 42 & 8.023 & 4,000 & 8.086 & 444,257 & 0,78 \\
\hline 43 & 5.928 & 3,000 & 6.017 & 466,815 & 1,48 \\
\hline 44 & 8.743 & 3,000 & 8.974 & 352,451 & 2,57 \\
\hline 45 & 9.334 & 4,000 & 9.621 & 472,712 & 2,98 \\
\hline 46 & 5.634 & 3,000 & 5.812 & 482,930 & 3,06 \\
\hline 47 & 2.802 & 4,000 & 2.927 & 457,954 & 4,27 \\
\hline 48 & 4.126 & 2,000 & 4.222 & 509,122 & 2,27 \\
\hline 49 & 5.948 & 3,000 & 6.055 & 396,053 & 1,77 \\
\hline 50 & 6.728 & 3,000 & 6.937 & 467,595 & 3,01 \\
\hline 51 & 16.507 & 3,000 & 16.558 & 455,926 & 0,31 \\
\hline 52 & 20.136 & 4,000 & 20.190 & 473,960 & 0,27 \\
\hline 53 & 18.094 & 4,000 & 18.153 & 453,773 & 0,33 \\
\hline 54 & 20.168 & 3,000 & 20.212 & 401,217 & 0,22 \\
\hline 55 & 23.157 & 4,000 & 23.226 & 429,936 & 0,30 \\
\hline 56 & 14.703 & 4,000 & 14.742 & 457,486 & 0,26 \\
\hline 57 & 15.734 & 4,000 & 15.838 & 457,221 & 0,66 \\
\hline 58 & 16.464 & 4,000 & 16.490 & 505,628 & 0,16 \\
\hline 59 & 15.565 & 3,000 & 15.636 & 390,125 & 0,45 \\
\hline 60 & 14.488 & 6,000 & 14.557 & 476,939 & 0,47 \\
\hline 61 & 11.345 & 3,000 & 11.498 & 447,081 & 1,33 \\
\hline 62 & 13.058 & 4,000 & 13.249 & 411,871 & 1,44 \\
\hline 63 & 11.511 & 4,000 & 11.661 & 505,784 & 1,29 \\
\hline 64 & 8.976 & 4,000 & 9.125 & 443,929 & 1,63 \\
\hline 65 & 9.318 & 4,000 & 9.515 & 497,188 & 2,07 \\
\hline
\end{tabular}


Continuação

\begin{tabular}{|c|c|c|c|c|c|}
\hline 66 & 14.299 & 3,000 & 14.649 & 519,387 & 2,39 \\
\hline 67 & 8.108 & 3,000 & 8.335 & 379,065 & 2,72 \\
\hline 68 & 13.424 & 3,000 & 13.743 & 493,756 & 2,32 \\
\hline 69 & 9.777 & 5,000 & 10.010 & 442,026 & 2,33 \\
\hline 70 & 11.600 & 3,000 & 11.869 & 439,561 & 2,27 \\
\hline 71 & 13.959 & 2,000 & 14.282 & 443,976 & 2,26 \\
\hline 72 & 16.575 & 4,000 & 16.859 & 479,638 & 1,68 \\
\hline 73 & 7.345 & 4,000 & 7.555 & 400,593 & 2,78 \\
\hline 74 & 7.972 & 5,000 & 8.154 & 445,521 & 2,23 \\
\hline 75 & 7.874 & 3,000 & 8.105 & 408,985 & 2,85 \\
\hline 76 & 23.774 & 5,000 & 23.926 & 454,147 & 0,64 \\
\hline 77 & 32.450 & 5,000 & 32.612 & 548,528 & 0,50 \\
\hline 78 & 31.574 & 4,000 & 31.748 & 432,885 & 0,55 \\
\hline 79 & 24.191 & 4,000 & 24.393 & 428,251 & 0,83 \\
\hline 80 & 21.434 & 5,000 & 21.554 & 400,998 & 0,56 \\
\hline 81 & 21.033 & 3,000 & 21.265 & 410,374 & 1,09 \\
\hline 82 & 19.407 & 4,000 & 19.643 & 507,110 & 1,20 \\
\hline 83 & 18.571 & 4,000 & 18.847 & 447,424 & 1,46 \\
\hline 84 & 17.673 & 5,000 & 17.879 & 452,541 & 1,15 \\
\hline 85 & 20.675 & 4,000 & 20.875 & 470,996 & 0,96 \\
\hline 86 & 23.996 & 5,000 & 24.232 & 496,907 & 0,97 \\
\hline 87 & 18.892 & 5,000 & 19.120 & 521,852 & 1,19 \\
\hline 88 & 18.138 & 4,000 & 18.317 & 455,957 & 0,98 \\
\hline 89 & 17.025 & 3,000 & 17.258 & 470,060 & 1,35 \\
\hline 90 & 20.835 & 4,000 & 21.082 & 482,633 & 1,17 \\
\hline 91 & 18.049 & 4,000 & 18.280 & 438,766 & 1,26 \\
\hline 92 & 14.912 & 5,000 & 15.054 & 442,338 & 0,94 \\
\hline 93 & 16.367 & 5,000 & 16.693 & 441,090 & 1,95 \\
\hline 94 & 11.286 & 4,000 & 11.577 & 372,216 & 2,51 \\
\hline 95 & 13.989 & 4,000 & 14.265 & 462,930 & 1,93 \\
\hline 96 & 11.832 & 4,000 & 12.085 & 464,334 & 2,09 \\
\hline 97 & 17.277 & 3,000 & 17.588 & 448,672 & 1,77 \\
\hline 98 & 22.669 & 4,000 & 23.014 & 486,003 & 1,50 \\
\hline 99 & 13.740 & 3,000 & 13.929 & 408,627 & 1,36 \\
\hline 100 & 12.885 & 3,000 & 13.093 & 495,534 & 1,59 \\
\hline 101 & 29.384 & 3,000 & 29.655 & 389,891 & 0,91 \\
\hline 102 & 24.716 & 5,000 & 24.975 & 399,813 & 1,04 \\
\hline 103 & 28.295 & 4,000 & 28.537 & 410,639 & 0,85 \\
\hline 104 & 28.594 & 5,000 & 28.791 & 418,002 & 0,68 \\
\hline 105 & 21.524 & 5,000 & 21.770 & 392,652 & 1,13 \\
\hline 106 & 24.259 & 4,000 & 24.515 & 449,249 & 1,04 \\
\hline 107 & 18.114 & 4,000 & 18.362 & 447,829 & 1,35 \\
\hline 108 & 26.604 & 4,000 & 26.878 & 414,149 & 1,02 \\
\hline 109 & 29.050 & 3,000 & 29.292 & 377,785 & 0,83 \\
\hline 110 & 19.312 & 4,000 & 19.527 & 414,029 & 1,10 \\
\hline 111 & 19.603 & 4,000 & 19.773 & 436,833 & 0,86 \\
\hline 112 & 21.292 & 4,000 & 21.462 & 454,162 & 0,79 \\
\hline 113 & 25.006 & 5,000 & 25.198 & 444,865 & 0,76 \\
\hline 114 & 22.318 & 3,000 & 22.516 & 442,929 & 0,88 \\
\hline 115 & 20.472 & 4,000 & 20.774 & 425,178 & 1,45 \\
\hline 116 & 16.656 & 4,000 & 16.910 & 452,587 & 1,50 \\
\hline 117 & 21.944 & 4,000 & 22.164 & 497,250 & 0,99 \\
\hline 118 & 20.639 & 3,000 & 20.876 & 457,517 & 1,14 \\
\hline 119 & 27.295 & 5,000 & 27.520 & 428,086 & 0,82 \\
\hline 120 & 20.005 & 4,000 & 20.180 & 426,216 & 0,87 \\
\hline 121 & 19.029 & 3,000 & 19.257 & 421,378 & 1,18 \\
\hline 122 & 14.864 & 3,000 & 15.041 & 424,944 & 1,18 \\
\hline 123 & 21.302 & 4,000 & 21.478 & 485,839 & 0,82 \\
\hline 124 & 16.005 & 4,000 & 16.222 & 443,111 & 1,34 \\
\hline 125 & 21.452 & 3,000 & 21.713 & 464,147 & 1,20 \\
\hline
\end{tabular}

